\title{
Review
}

Fei Cao, Xiaobao Xu*, Dejian Yu and Haibo Zeng*

\section{Lead-free halide perovskite photodetectors spanning from near-infrared to $X$-ray range: a review}

https://doi.org/10.1515/nanoph-2020-0632

Received November 29, 2020; accepted January 25, 2021;

published online February 17, 2021

\begin{abstract}
Photodetectors based on semiconducting materials are vital building blocks for modern systems containing optoelectronic modules. Although commercial semiconductors have established good performances, they are plagued by complex processing procedures and stalled performances. Recently, lead halide perovskites with superior semiconducting attributes have achieved stunning progress in optoelectronics including photodetectors. However, the toxicity of lead and the ill stability significantly handicap their practical use. Great efforts thus have been devoted to developing lead-free alternatives with improved stability and uncompromised traits. In this review, we thoroughly summarize recent progress in photodetectors based on lead-free halide perovskite variants. The substitution of lead with new elements usually induces a change in structure and ensuingly optoelectronic particularities, which afford unique suitability for a collection of functionality-specified photodetectors. Especially, the family of lead-free variants witnesses a range of bandgaps that construct a broadband photon detection spanning from near-infrared (NIR) to visible regimes. Besides, stress is laid on the X-ray detection capability based on especially bismuth-type lead-free perovskites, of which the strong $\mathrm{X}$-ray absorption, large bulk resistance, suppressed ion migration, and efficient charge collection enable superior
\end{abstract}

*Corresponding authors: Xiaobao Xu and Haibo Zeng, Institute of Optoelectronics \& Nanomaterials, MIIT Key Laboratory of Advanced Display Materials and Devices, College of Materials Science and Engineering, Nanjing University of Science and Technology, Nanjing 210094, China, E-mail: xiaobaoxu@njust.edu.cn (X. Xu), zeng.haibo@njust.edu.cn (H. Zeng). https://orcid.org/0000-00015378-5604 (X. Xu)

Fei Cao and Dejian Yu, Institute of Optoelectronics \& Nanomaterials, MIIT Key Laboratory of Advanced Display Materials and Devices, College of Materials Science and Engineering, Nanjing University of Science and Technology, Nanjing 210094, China
$\mathrm{X}$-ray sensitivities and ultralow detection limits. Finally, the challenges and visions are discussed.

Keywords: lead-free perovskite; near-infraxred detection; photodetector; X-ray detection; ultraviolet detection; visible light detection.

\section{Introduction}

High-performance photodetectors are fundamental components that receive light signals and convert them into analyzable electrical output, nowadays they are playing an indispensable role in numerous optoelectronic applications in both civil and military fields, such as biomedical imaging [1], optical communications [2], nondestructive inspection [3], automation control [4], and so forth. Fundamentally, central to the photodetectors are semiconducting materials, of which the photoelectric effect lays a base for the light-to-electricity conversion. Commercial photodetectors majorly rely on inorganic materials including $\mathrm{Si}, \mathrm{Ge}, \mathrm{CdX}(\mathrm{X}=\mathrm{S}, \mathrm{Se}, \mathrm{Te}), \mathrm{PbX}(\mathrm{X}=\mathrm{S}, \mathrm{Se}), \mathrm{SiC}$, $\mathrm{GaN}$, AlGaN, etc. The strong covalent bonding in these inorganic materials necessitates energy-consuming and concomitantly complicated fabrication processes. While techniques have been well established, it also dialectically means a significant bottleneck for further breakthroughs in terms of both figure-of-merits in the devices and cost. For decades, worldwide researchers have been devoted to developing innovative semiconductors towards a fundamental revolution [5, 6]. On the other hand, the ever-increasing demand is urging for various functionality-specified photodetectors, e.g., photons of energy spanning from the X-ray range to the nearinfrared range see vastly different attributes, hence calling for carefully-designed semiconductors that can actively respond to the photons. In this regard, the photon energy ranges detectable determined by the semiconductor bandgaps should be carefully inspected when developing a new material family with light sensitivity. 
Emerging innovative material types have been well documented in literature, among them lead halide perovskites distinguish themselves with stunning semiconducting individualities, including large light absorption coefficient [7], balanced ambipolar charge mobility [8], long charge carrier diffusion length [9, 10], and facile bandgap tunability [11-13]. In addition, the superior particularities can be easily obtained by lowtemperature solution-phase methods thanks to the defect-benign nature [14-16]. Such advantages have been well demonstrated by the astounding development of corresponding photovoltaic devices, which witness rocketing power conversion efficiency in the past decade (https://www.nrel.gov/pv/cell-efficiency.html). In parallel, great progress has been arrived at in their application of photodetectors [17], desirable performances of high detectivity, fast response speed, and low detection limit can be readily obtained, stressed is the broadband detection ranging from near-infrared (NIR) to deep ultraviolet (DUV) lights [18-22]. Promisingly, proof-ofconcept applications for practical use were presented with effectiveness, the scientific research is experiencing a booming period.

However, the real commercialization of halide perovskite stalls due to the notorious instability and the toxicity of water-soluble $\mathrm{Pb}$ compounds (i.e., lead halides) [23, 24]. In light of such predicament, the concept of "lead-free perovskite" was put forward in pursuit of alternatives that hopefully contain no toxic elements, afford enhanced stability, but retain likewise exceptional semiconducting properties [25]. A wealth of variants of lead halide perovskites have been proposed thus, but existing outcomes indicate that these materials are usually inferior to lead halide perovskites, and require delicate modulation to achieve decent device performances. But still, great progress has been realized with continuing efforts, exemplarily, solar cells based on lead-free perovskite variants achieved a highest PV efficiency of $11.4 \%$ hitherto [26], with the full potential to be unlocked. For the photodetection application, the lead-free variants exhibit unique material features from one to another. Especially, each of them fits a unique detection range, for example, Sn-based 3D halide perovskite possessing a narrower bandgap has a large potential for the near-infrared (NIR) detection [27, 28], while the $\mathrm{Cu}$ based OD perovskite with a larger bandgap is highly suitable for ultraviolet (UV) detectors. Indeed, proper lead-free variants can be found for photodetection all cross the UV-visible-NIR range. Intriguingly, some types of lead-free perovskites were recently even confirmed as efficient $\mathrm{X}$-ray sensitive materials in the form of either indirect scintillators or direct detectors [29-31]. In particular, those based on bismuth (Bi), the element with the highest $Z$ value among the stable ones, enjoy the merits of high density, large average $Z$ value, efficient charge transport, suppressed ion migration, etc., thus allowing not only strong X-ray absorption but also efficient charge collection.

In this review, we intend to systematically summarize the recent progress in the field of lead-free halide perovskite-based photodetectors. Classified according to the detection range are the photodetectors, which are cataloged into four types for discussion, i.e., NIR photodetectors, visible photodetectors, UV photodetectors, and $\mathrm{X}$-ray detectors. Concomitantly, the substitution of lead also yields a structure change and ensuingly a variation in optoelectronic properties, the content is also introduced for each type with an emphasis on the structure-function relationship. Especially, the utilization of lead-free perovskite variants, mainly $\mathrm{Bi}$-based types, in X-ray detection is stressed, the high-Z merit for X-ray absorption, large bulk resistance for low noise currents, suppressed ion migrations under large bias, and enhanced stability collectively advocate them as promising candidates for X-ray detection. Finally, a vision and challenges of the lead-free perovskite variants-based photodetectors are provided.

\section{Lead-free perovskite materials and photodetectors}

It should be noted that perovskite materials respect an $\mathrm{ABX}_{3}$ composition that defines a specific structure, where the $\mathrm{BX}_{6}$ octahedron corner-share to each other and the $\mathrm{A}^{+}$ intercalates the voids of the framework [32]. However, halide perovskite was gradually found to own highly rich derivatives with an abundance of non-perovskite conformations. Although they do not follow a standard perovskite lattice motif, their semiconducting properties were usually compared with parental halide perovskites, thus, they are still called "perovskite" for simplicity oftentimes. These non-standard perovskites have opened an extensive playground for fundamental researches, and have also revealed numerous intriguing applications with a large part in photodetectors. In view of this, these subclasses will be included in this review.

Ideal $\mathrm{Pb}$-free candidates serving as the photodetector active layer are expected to combine desirable semiconducting merits of low toxicity, strong light absorption, large carrier charge mobilities, and long charge carrier lifetimes. The outstanding properties of lead-based perovskites are partially attributed to the strong $\mathrm{Pb} 6 s-\mathrm{I} 5 p$ 
anti-bonding coupling [7], referring to this criterion, alternative elements that endow $\mathrm{ns}^{2}$ lone pairs, namely $\mathrm{Sn}^{2+}$ and $\mathrm{Ge}^{2+}$, have been heavily investigated [33-36]. However, the device performances of $\mathrm{Sn}^{2+}$ or $\mathrm{Ge}^{2+}$ based perovskite devices were found to be poor in early attempts [37, 38], and they are also plagued by ready oxidation that significantly enfeebles the performances and even causes degradations. Thus, researchers moved forward to other elements with similar electrical structure and ionic radius, and $\mathrm{Bi}^{3+}, \mathrm{Sb}^{3+}$, $\mathrm{Ag}^{+}$, and $\mathrm{In}^{+} / \mathrm{In}^{3+}$ came into notice, which were unraveled to build up various lattice conformations described by $\mathrm{A}_{2} \mathrm{~B}(\mathrm{I}) \mathrm{B}(\mathrm{III}) \mathrm{X}_{6}, \mathrm{~A}_{3} \mathrm{~B}(\mathrm{III}) \mathrm{X}_{9}$, and $\mathrm{A}_{2} \mathrm{~B}(\mathrm{IV}) \mathrm{X}_{6}$. Also, explore were more elements, those corresponding perovskite variants have been successfully prepared experimentally are highlighted in the periodic table (Figure 1a) [39-57]. The various conformations endow different semiconducting properties, especially a collection of bandgaps. The bandgap of the semiconductor in photodetectors decisively influences the detection range of the photon energy, and it is intriguing to find that the extensive leadfree perovskite family composes a broadband photodetection ranging from NIR to ultraviolet lights, and even $\mathrm{X}$-ray photons as schematically illustrated in Figure $1 \mathrm{~b}$. In the following the photodetectors will be cataloged by the detection range and discussed separately, the emphasis will be laid on the detailed material properties and the device performances.

\subsection{NIR photodetectors}

Benefitting from the merits including low photodamage to biological samples, deep tissue penetration, and minimum interference from background autofluorescence in living biosystems, NIR light has been regarded as a powerful tool for medical diagnosis, surgery, and therapy [59-61]. Hence, NIR photodetectors have attracted much attention in the past decades. Though narrow-bandgap materials like gallium arsenide, silicon, lead selenide, and indium gallium arsenide have achieved appreciable success in the NIR photodetection [62-65], the fabrication processes including alloying, doping, etching, epitaxy, and so on in these inorganic narrow-bandgap materials are complicated and costly. The halide perovskite devices with convenient and low-cost solution preparation method see great advantages, but the wide bandgap of $\mathrm{Pb}$-based perovskite limits the photodetection range. Even $\mathrm{FAPbI}_{3}$ with the narrowest bandgap in the lead halide perovskite family cuts off the absorption at $850 \mathrm{~nm}$ that barely overlaps with the NIR band [66].

Among all of the lead-free alternative elements for $\mathrm{Pb}^{2+}, \mathrm{Sn}^{2+}$ is considered as the most potential candidate, because it possesses similar valency and comparable ionic radius to $\mathrm{Pb}^{2+}\left(\mathrm{Sn}^{2+} 1.35 \AA\right.$ and $\left.\mathrm{Pb}^{2+} 1.49 \AA ̊\right)$ [67]. The $\mathrm{Pb}^{2+}$-to$\mathrm{Sn}^{2+}$ substitution retains the perovskite structure (corresponding crystal structure can be found in Figure 1b, the (a)

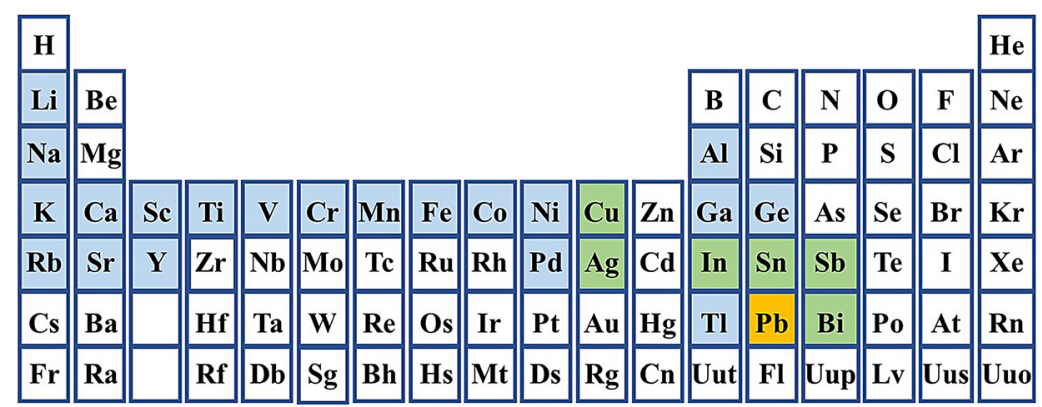

(b)

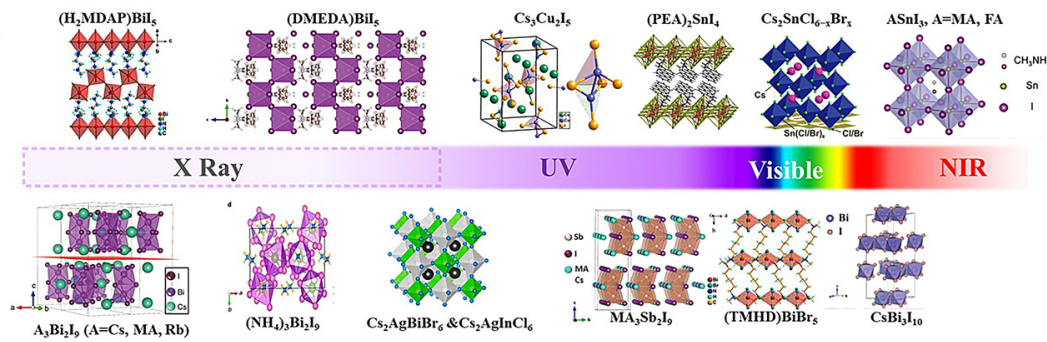

Figure 1: Elements for substituting lead, corresponding material structure and the photodetection range.

(a) Orange: Lead; Blue: elements that corresponding perovskite variants have been successfully prepared experimentally; Green: Elements that the corresponding perovskite variants have been successfully applied in photodetectors. (b) Summary of various lead-free perovskite variants, and corresponding detection ranges of the photodetectors based on them. 
NIR part), but results in a narrower bandgap along with lower exciton binding energies and longer carrier diffusion lengths [68]. Consequently, Sn-based perovskites are able to extend the detection band to the NIR regime. However, pure Sn-based perovskite photodetectors were scarcely reported, which is mainly owing to the notorious stability. In detail, the $\mathrm{Sn}^{2+}$ cation easily undergoes oxidation due to the high-lying $5 s$ orbitals, rendering the corresponding perovskite extremely unstable in the ambient atmosphere. According to the charge conservation rationale, the oxidization will cause a large density of oxygen vacancy, which curtails the charge transport or even causes material degradation [69]. For photodetectors, the oxygen vacancy will also short-circuit the devices, hence abrogating the device function. Various strategies have been proposed to meliorate the oxidation issue, including composition engineering [70], precursor engineering [71], additive engineering $[27,72]$, and so on. The use of additives like tin fluoride $\left(\mathrm{SnF}_{2}\right)$ during the crystallization process to relieve the oxidation rate was confirmed effective [27, 72]. Yan's group demonstrated photodetectors based on a single layer of lead-free $\mathrm{FASnI}_{3}$ perovskite (Figure 2a), whose responsive range covers $300-1000 \mathrm{~nm}$, as shown in Figure 2b [27]. The authors introduced a hydroxybenzene sulfonic acid additive and excessive $\mathrm{SnCl}_{2}$ to blunt perovskite grains of the $\mathrm{FASnI}_{3}$ film, the resulted photodetector delivered a maximum responsivity of $1.1 \times 10^{5} \mathrm{~A} \mathrm{~W}^{-1}$ under a driving bias voltage of $0.5 \mathrm{~V}$, a decent detectivity of $1.9 \times 10^{12}$ Jones was also obtained.

Alternatively, encapsulation is another widely accepted physical strategy for almost all electronic and optoelectronic devices, the isolation against moisture and oxygen can fundamentally reduce the oxidation of $\mathrm{Sn}^{2+}$. In a work of Fan's group [58], the authors firstly reported a NIR photodetector based on three-dimensional $\mathrm{CH}_{3} \mathrm{NH}_{3} \mathrm{SnI}_{3}$ perovskite nanowire arrays, which was templated and embedded inside the nanopores of the PAT (Figure 2c). They put forward that, unlike the heavily-studied polycrystalline films, in which the inevitable pinholes and grain boundaries provide passageways for the entry and diffusion of oxygen (Figure 2d), whereas the $\mathrm{CH}_{3} \mathrm{NH}_{3} \mathrm{SnI}_{3}$ nanowires are tightly embedded within the nanopores of the PAT, the sidewalls of PAT may block inward diffusion of water and oxygen molecules, thus retarding the degradation [58]. Quantificationally, the decay indicated by the PL weakening points out a significantly slowed decay in the $\mathrm{CH}_{3} \mathrm{NH}_{3} \mathrm{SnI}_{3}$ nanowires by 840 times as compared to a planar thin film, i.e., while the PL of a planar thin film disappeared within $30 \mathrm{~min}$ of exposure, the PL intensity of the $\mathrm{CH}_{3} \mathrm{NH}_{3} \mathrm{SnI}_{3}$ nanowires was able to maintain $65 \%$ of the initial value after eight days. In parallel, the device stability assessment was carried out referring to the photocurrent, the authors exposed the film device and nanowires device to the air of $70 \%$ humidity, while the photocurrent of the (a)
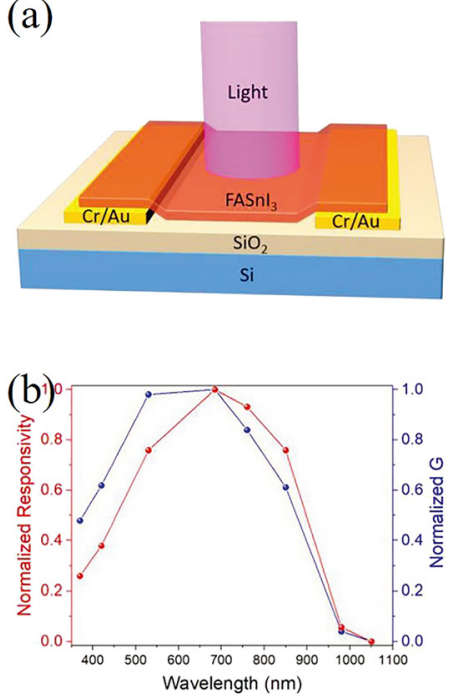

(c)

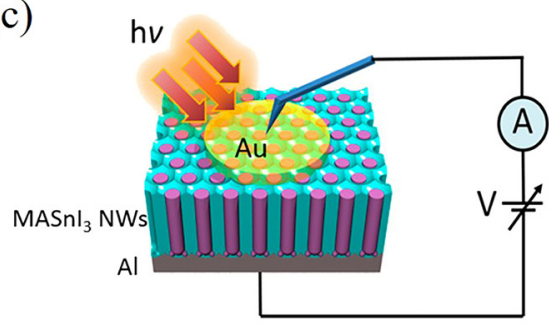

(d)

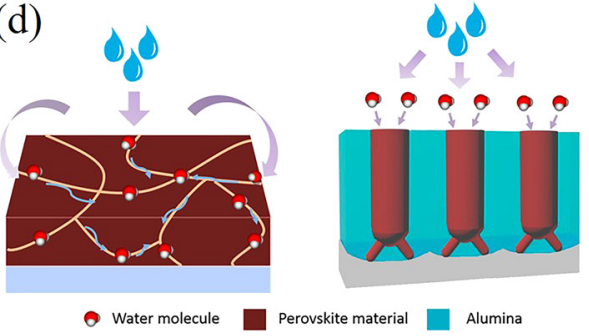

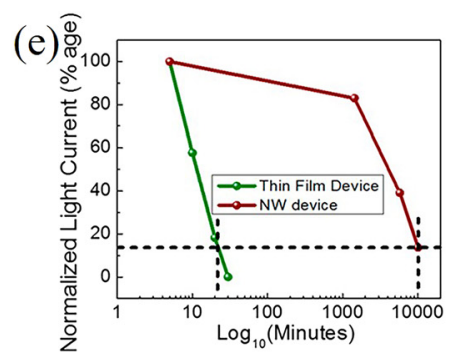

(f)

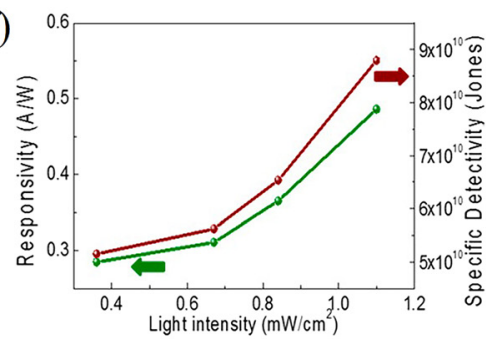

Figure 2: NIR photodetectors based on $\mathrm{FASnl}_{3}$.

(a) Schematic view of the $\mathrm{FASnl}_{3}$ photodetector structure. (b) Normalized wavelength-dependent responsivity and optical gain of the FASnl 3 photodetector. Reproduced with permission. Copyright 2019, Wiley-VCH Verlag [27]. (c) Schematic view of the FASnl ${ }_{3}$ perovskite nanowires inside PAT. (d) Schematic illustration of stability improving mechanism. (e) Light current decays of the packaged and nonpackaged photodetectors. (f) Specific detectivity and Responsivity of the $\mathrm{FASnl}_{3}$ perovskite nanowires photodetector upon different light intensities. Reproduced with permission. Copyright 2017, American Chemical Society [58]. 
film device degraded instantaneously to zero, the nanowires device in contrast showed a much more robust performance, the photocurrent declined to 2.7 from $19.8 \mu \mathrm{A}$ after as long as seven days, as shown in Figure 2e. In addition to the enhanced stability, the NIR detector presented a reliable detection performance with a responsivity of $0.47 \mathrm{~A} \mathrm{~W}^{-1}$ and a specific detectivity of $8.8 \times 10^{10}$ Jones under the illumination of $1.1 \mathrm{~mW} / \mathrm{cm}^{2}$ (Figure 2f). The response rate of the photodetector features a rise time of $1500 \mathrm{~ms}$ and a decay time of $400 \mathrm{~ms}$, which are believed to be further improved by reducing the length of nanowires. Other methods to obtain stable pure Sn perovskite-based detectors include tetravalent $\mathrm{Sn}^{4+}$ substitution and dimension reduction. However, both methods change the lattice structure, which results in shifted bandgaps that no longer overlap with the NIR band, thus a detailed introduction of these materials and corresponding photodetectors will not be offered here but in the following.

\subsection{Visible light photodetectors}

Visible light detectors are mostly used in daily life. In principle, the NIR photodetectors discussed above can also be used as visible light photodetectors, in this part, we will talk about the photodetectors that respond within the visible light range. As mentioned above, replacing divalent $\mathrm{Pb}^{2+}$ with tetravalent $\mathrm{Sn}^{4+}$ yields a stable variant with a change in dimension, as a result, the response band blueshifts to the visible range. In detail, the $\mathrm{Pb}^{2+}$-to- $\mathrm{Sn}^{4+}$ substitution forces voids of half $\mathrm{B}$ sites in the $\mathrm{ABX}_{3}$ perovskite structure to maintain charge conservation, the resulted product thus respects a formula of $\mathrm{A}_{2} \mathrm{Sn} \square \mathrm{X}_{6}$ ( $\square$ represents the vacancy, $\mathrm{X}=\mathrm{Cl}, \mathrm{Br}$, I, simplified as $\mathrm{A}_{2} \mathrm{SnX}_{6}$ hereafter), thus the $\mathrm{A}_{2} \mathrm{SnX}_{6}$ series is also regarded as "defect" perovskite. Figure $3 \mathrm{a}$ shows the crystal structure of $\mathrm{Cs}_{2} \mathrm{SnCl}_{6-x} \mathrm{Br}_{x}$, although it still pertains to a 3D crystal structure, the $\left[\mathrm{SnX}_{6}\right]^{2-}$ octahedra are isolated spatially from each other [75], thus, thus the "defect" perovskites $\mathrm{Cs}_{2} \mathrm{SnCl}_{6-x} \mathrm{Br}_{x}$ is also seen as zero-dimensional (OD) perovskite in view of the connection manner.

Xia's group fabricated narrowband photodetectors with the $0 D$ perovskites $\mathrm{Cs}_{2} \mathrm{SnCl}_{6-x} \mathrm{Br}_{x}$ [73]. A mechanism of charge collection narrowing (CCN) must be firstly mentioned, i.e., short-wavelength photons penetrate only a shallow depth, and the photogenerated charges can easily be trapped or recombine during the diffusion towards the counter electrode, so that only the longwavelength photons close to the absorption onset can be harvested with efficacy, hence causing a narrowband light response [76]. By delicately regulating the $\mathrm{Br} / \mathrm{Cl}$ ratio, the response spectra of the $\mathrm{Cs}_{2} \mathrm{SnCl}_{6-\chi} \mathrm{Br}_{x}$ series cover the entire visible spectrum according to the UV-vis diffuse reflectance spectra (Figure 3b). As shown in Figure 3c, the asfabricated detectors characterize a narrow full-width at half-maximum (FWHM) of $45 \mathrm{~nm}$, and the detectivity was calculated to be $2.71 \times 10^{10}$ Jones. Notably, benefiting from the unique structural conformation where the $\mathrm{Cl}^{-}\left(\mathrm{Br}^{-}\right)$ions are connected to an $\mathrm{Sn}^{4+}$ cation, the $\mathrm{Cs}_{2} \mathrm{SnCl}_{6-x} \mathrm{Br}_{x}$ presents better stability and higher ion diffusion barriers compared to typical lead halide perovskites, the lowest diffusion barriers of $\mathrm{Cl} / \mathrm{Br}$ ions were found to be $0.33 / 0.23 \mathrm{eV}$, larger than that of $\mathrm{MAPbBr}_{3}(\approx 0.2 \mathrm{eV})$ [77]. Thus, the $\mathrm{Cs}_{2} \mathrm{SnBr}_{6}$ based detector showed higher working stability than $\mathrm{MAPbBr}_{3}$ under a high bias (Figure 3d).

On the other hand, 2D layered perovskites, in which the small A-site cation $\left(\mathrm{ABX}_{3}\right)$ is replaced with bulky organic cations like butylammonium $\left(\mathrm{BA}^{+}\right)$and phenylethylammonium $\left(\mathrm{PEA}^{+}\right)$, usually show higher stability than 3D counterparts [78, 79]. Qian et al. reported a flexible visible light photodetector based on lead-free 2D perovskite (PEA) $\mathrm{SnI}_{4}$, the crystal structure is shown in Figure 3e. The resulted device showed a wide response to visible light (Figure 3f), and delivered a responsivity of $16 \mathrm{~A} \mathrm{~W}^{-1}$ at a

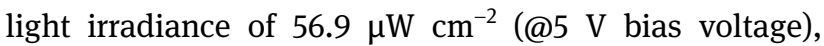
correspondingly, the specific detectivity was calculated to be $1.92 \times 10^{11}$ Jones.

Except for the tin-based perovskite, other elements like $\mathrm{Sb}^{3+}$ and $\mathrm{Bi}^{3+}$ also give rise to perovskite variants in replacement of lead, these perovskite variants have been successfully used in visible light detection [83, 84], and usually show higher stability compared with lead-based counterparts. Yang et al. developed a photodetector based on $\mathrm{MA}_{3} \mathrm{Sb}_{2} \mathrm{I}_{9}$ microcrystals (Figure 4b, inset) [80]. Figure 4a illustrates the crystal lattice of $\mathrm{MA}_{3} \mathrm{Sb}_{2} \mathrm{I}_{9}$, which pertains to the so-called dimer polymorph consisting of isolated face-shared $\left[\mathrm{Sb}_{2} \mathrm{X}_{9}\right]$ bioctahedra, and exhibits a hexagonal $\mathrm{PG}_{3} / \mathrm{mmc}$ symmetry. Due to the isolation of $\left[\mathrm{Sb}_{2} \mathrm{I}_{9}\right]$ bioctahedra, $\mathrm{MA}_{3} \mathrm{Sb}_{2} \mathrm{I}_{9}$ is regarded as $0 \mathrm{D}$ material. It owns a moderate bandgap of $1.92 \mathrm{eV}$, which is larger than the 3D lead-type counterpart (the bandgap of $\mathrm{MAPbI}_{3}$ is $1.5-1.6 \mathrm{eV}$ ) [9]. Thus, the light response of the fabricated $\mathrm{MA}_{3} \mathrm{Sb}_{2} \mathrm{I}_{9}$ falls within the visible light regime. Figure $4 \mathrm{~b}$ shows the powerdependent photocurrent and responsivity of $\mathrm{MA}_{3} \mathrm{Sb}_{2} \mathrm{I}_{9}$ based photodetector under a bias of $5 \mathrm{~V}$, the linear dynamic range (LDR) reaches $84 \mathrm{~dB}$ and the responsivity is about $40 \mathrm{~A} \mathrm{~W}^{-1}$ at an incident light power $200 \mathrm{nW} / \mathrm{cm}^{2}$, it also delivers a commendable detectivity of $10^{12}$ Jones (Figure 4c). In fact, the lead-free perovskite with the formula of $\mathrm{A}_{3} \mathrm{~B}_{2} \mathrm{X}_{9}$ also allows another crystal structure in a layered form, the layered crystal structure is derived from the hypothetical perovskite compound $\mathrm{ABX}_{3}$ by removing 
(a)

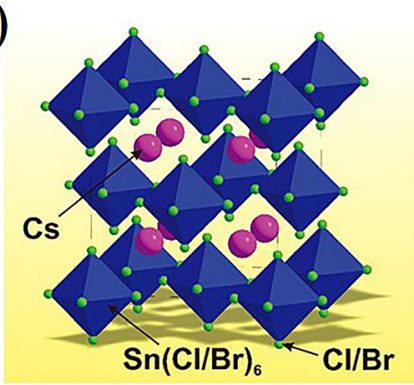

(c)

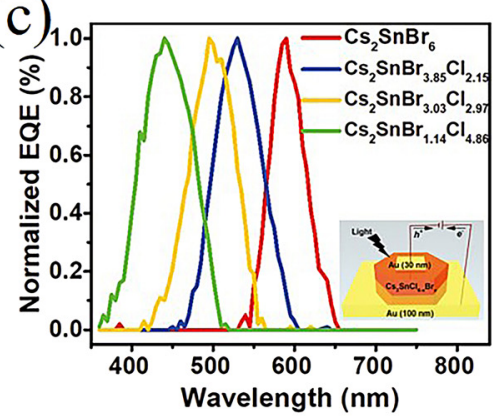

(e)

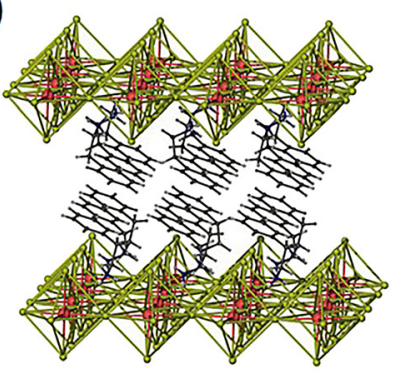

(b)

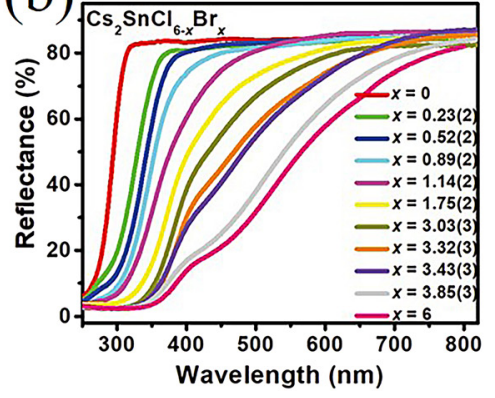

(d)

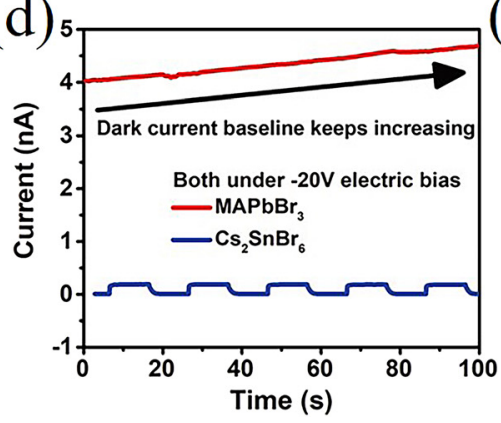

$(\mathrm{f})$

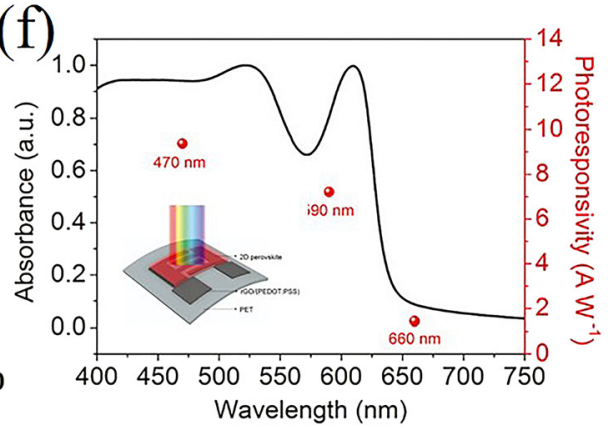

Figure 3: Tin perovskite variants-based visible photodetectors.

(a) Schematic view of the $\mathrm{Cs}_{2} \mathrm{SnCl}_{6-x} \mathrm{Br}_{x}$ crystal structure by discrete $\left[\mathrm{Sn}(\mathrm{Cl}, \mathrm{Br})_{6}\right]^{2-}$ octahedra, which are caused by the missing of $\mathrm{Sn}$ atoms. (b) Composition-dependent UV-vis. diffuse reflectance spectra of $\mathrm{Cs}_{2} \mathrm{SnCl}_{6-x} \mathrm{Br}_{x}(x=0-6)$. (c) Normalized EQE spectra of $\mathrm{Cs}{ }_{2} \mathrm{Sn}\left(\mathrm{Br}_{2} \mathrm{Cl}\right)_{6}$ single crystal-based photodetectors measured under a $-20 \mathrm{~V}$ bias. Inset: schematic diagram of the device configuration. (d) Dark current drift test of a $\mathrm{Cs}_{2} \mathrm{SnBr}_{6}$ (1.3 mm in thickness) crystal in comparison to a $\mathrm{MAPbBr}_{3}$ crystal (1.4 mm in thickness) measured under a constant $-20 \mathrm{~V}$ electric bias. Reproduced with permission. Copyright 2019, Wiley-VCH Verlag [73]. (e) Schematic diagram of the 2D layered (PEA) $2 \mathrm{SnI}_{4} \mathrm{Crystal}$ structure (orange balls for tin atoms; yellow balls for iodine atoms; blue balls for nitrogen atoms; dark grey balls for carbon atoms; light grey balls for hydrogen atoms). (f) Absorption spectrum of the perovskite film (with $30 \mathrm{~mol}_{\mathrm{O}} \mathrm{SnF}_{2}$ ) and the wavelength-dependent photoresponsivity at 470 , 590 and $660 \mathrm{~nm}\left(130 \mu \mathrm{W} \mathrm{cm}{ }^{-2}\right.$ irradiance, $5 \mathrm{~V}$ bias). Inset: Schematic view of the (PEA) ${ }_{2}$ Snl 4 -based flexible photodetector. Reproduced with permission. Copyright 2018, Royal Society of Chemistry [74].

every third B layer along the $\langle 111\rangle$ direction to keep the charge balance, this conformation is commonly observed in Bi-based perovskite variants, which will be discussed later in detail.

Tong et al. developed a red light photodetector based on $\mathrm{CsBi}_{3} \mathrm{I}_{10}$ perovskite thin film [81]. Both the device and the crystal structure are schematically illustrated in Figure 4d, the crystal structure can be described as a 2D layered structure [85]. As shown in the absorption spectrum and wavelength-dependent responsivity (Figure 4e), the absorption range extends to $700 \mathrm{~nm}$ and the responsivity reaches up to $21.8 \mathrm{~A} \mathrm{~W}^{-1}$, also, obtained was a high detectivity of $1.93 \times 10^{13}$ Jones. In addition, the device affords response times of $0.33 / 0.38 \mathrm{~ms}$ for the rise and fall processes, respectively (as shown in Figure 4f). Ji et al. also reported a visible photodetector based on a new lead-free perovskite derivative (TMHD) $\mathrm{BiBr}_{5}(\mathrm{TMHD}=\mathrm{N}, \mathrm{N}, \mathrm{N}, \mathrm{N}$ tetramethyl-1,6-hexanediammonium) [82]. As shown is Figure 4g, the (TMHD) $\mathrm{BiBr}_{5}$ has a $1 \mathrm{D}$ zigzag-chainlike perovskite structure with a space group of $P 2_{1} / n$, where the octahedra are corner-shared to each other [86]. An inchsized (TMHD) $\mathrm{BiBr}_{5}$ single crystal was grown, the photograph is showed in Figure $4 \mathrm{~h}$ inset, based on the singlecrystalline (TMHD)BiBr ${ }_{5}$ photodetectors were fabricated with a wide response spectrum of 365-700 nm (Figure 4h). However, the device performance seems to be less efficient, the responsivity is limited to $100 \mathrm{~mA} \mathrm{~W}^{-1}$ under a high bias of $10 \mathrm{~V}$ and an incident light $0.8 \mathrm{~mW} \mathrm{~cm}^{-2}$, and the response rate featuring rise and fall times of 8.9 and $10.2 \mathrm{~ms}$ were obtained (Figure 4i).

The trivalent bismuth, in combination with a monovalent cation, can also construct a double halide perovskite by replacing two bivalent $\mathrm{Pb}^{2+}$ in a halide perovskite structure. Among them, the $\mathrm{Bi}^{3+}-\mathrm{Ag}^{+}$system has been one of the most heavily investigated double halide perovskites [88]. The bandgaps of 1.72-2.19 eV although preclude them against solar light harvest, but render them suitable for visible light photodetection $[89,90]$. Yang et al. reported a photodiode based on optimized $\mathrm{Cs}_{2} \mathrm{AgBiBr}_{6}$ double perovskite film [87]. The device architecture is shown in 
(a)

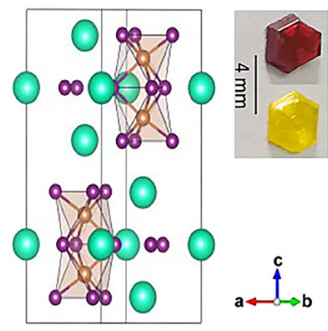

(d)

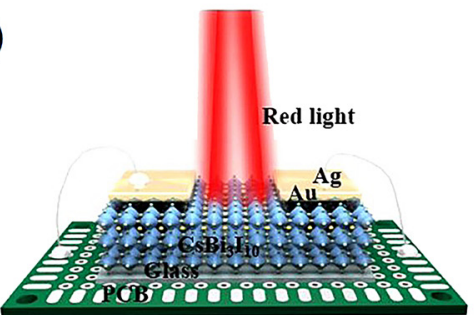

(g)

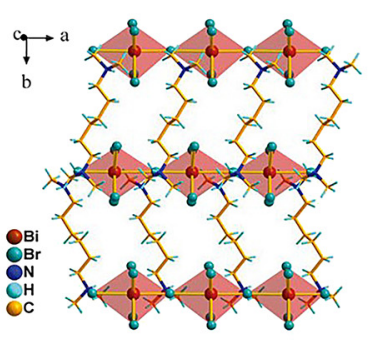

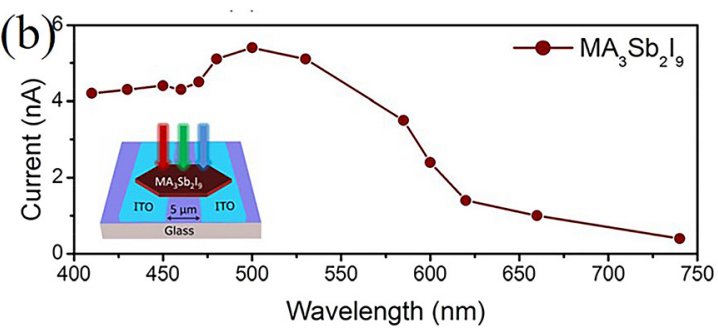
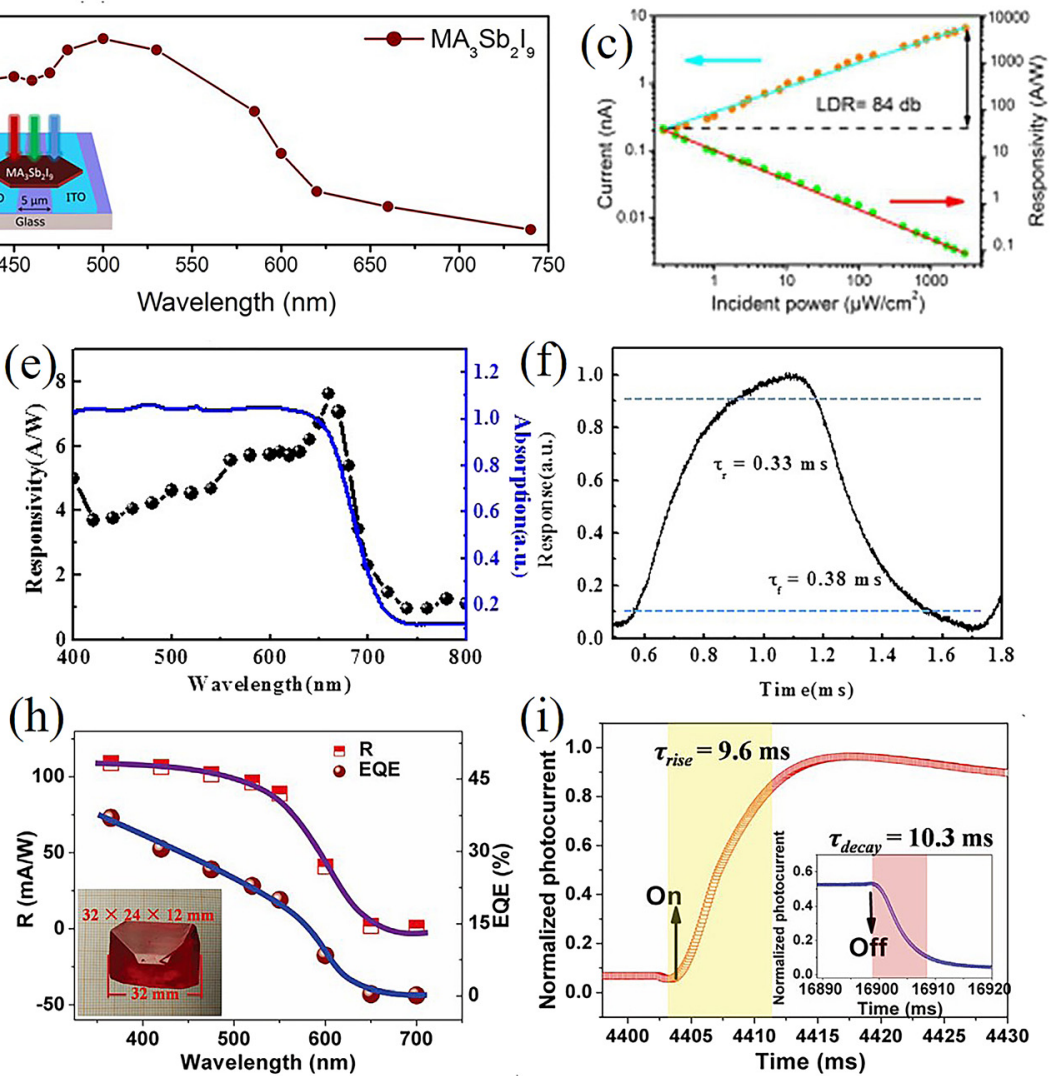

(i)

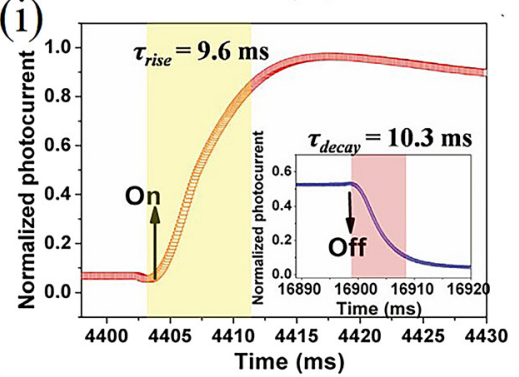

Figure 4: $\mathrm{Sb}^{3+}$-based and $\mathrm{Bi}^{3+}$-based perovskite variants for visible light photodetection.

(a) crystal structure of $\mathrm{MA}_{3} \mathrm{Sb}_{2} \mathrm{l}_{9}$ perovskite single crystals, upper left: Photograph of as-prepared $\mathrm{MA}_{3} \mathrm{Sb}_{2} \mathrm{I}_{9}$ (dark red) and $\mathrm{MA}_{3} \mathrm{Sb}_{2} \mathrm{Br}_{9}$ (light yellow) single crystals. (b) Wavelength-dependent photocurrent of $\mathrm{MA}_{3} \mathrm{Sb}_{2} \mathrm{l}_{9}$ microcrystal $\left(5 \mathrm{~V}\right.$ bias, $\left.1 \mathrm{~mW} / \mathrm{cm}^{2}\right)$ photodetector, inset: schematic of the $\mathrm{MA}_{3} \mathrm{Sb}_{2} \mathrm{I}_{9}$ microcrystal photodetector. (c) Power-dependent photocurrent and responsivity with $5 \mathrm{~V}$ bias (460 nm). Reproduced with permission. Copyright 2018, American Chemical Society [80]. (d) schematic illustration of the crystal structure and device structure of the $\mathrm{CSBi}_{3} \mathrm{I}_{10}$ perovskite film; the purple, green, and yellow spheres represent $\mathrm{Bi}$, I, and $\mathrm{Cs}$ atoms, respectively. (e) Comparative presentation of the absorption spectrum of the $\mathrm{CsBi}_{3} \mathrm{I}_{10}$ film and the responsivity of the corresponding photodetectors. (f) the estimating rise time and fall time of $\mathrm{CsBi}_{3} \mathrm{l}_{10}$ detectors. Reproduced with permission. Copyright 2017, American Chemical Society [81]. (g) crystal structure of the (TMHD) $\mathrm{BiBr}_{5}$ single crystal. (h) wavelength dependence of photoresponsivity $R$ and EQE of the (TMHD)BiBr$r_{5}$ single-crystal device. (i) Temporal photocurrent response, highlighting a rise time of $9.6 \mathrm{~ms}$ and a decay time of $10.3 \mathrm{~ms}$. Reproduced with permission. Copyright 2018, Wiley-VCH Verlag [82].

Figure $5 \mathrm{a}$, the $\mathrm{Cs}_{2} \mathrm{AgBiBr}_{6}$ films were processed to own enlarged grain sizes and reduced trap density to combine with optimized electron and hole transport interlayers, the resulted photodetector showed favorable performances. The spectral responsivity and detectivity at $0 \mathrm{~V}$ bias of the $\mathrm{Cs}_{2} \mathrm{AgBiBr}_{6}$ photodetectors are shown in Figure 5b, it reveals prominent responses in the visible range of $<500 \mathrm{~nm}$. The responsivity and detectivity were measured to be $0.14 \mathrm{~A} \mathrm{~W}^{-1}$ and $3.29 \times 10^{12}$ Jones at $445 \mathrm{~nm}$, respectively. Moreover, the high-quality film engenders a low noise current that contributes to an ultralow detection limit down to a $\sim \mathrm{pW} \mathrm{cm} \mathrm{cm}^{-2}$ level. The LDR was measured to be as high as 193.4 dB (Figure 5c), which indicates reliable signal output within a large illumination intensity range. In addition, an ultrafast response rate featuring a characteristic time of $\approx 17$ ns was also obtained according to the transient photocurrent measurement (Figure 5d).

\subsection{Ultraviolet (UV) detectors}

Being widely used in civil and military applications, including flame detection, missile warning systems, secure space-to-space communication, and biological analysis, ultraviolet (UV) photodetectors are a useful tool [92-94]. Traditional UV detectors based on oxides, such as zinc oxide $(\mathrm{ZnO})$ and tin oxide $\left(\mathrm{SnO}_{2}\right)$, usually suffer from a slow response time due to the formation of massive oxygen vacancies [95, 96]. A UV detector possessing large responsivity, fast response, good stability, low processing 
(a)
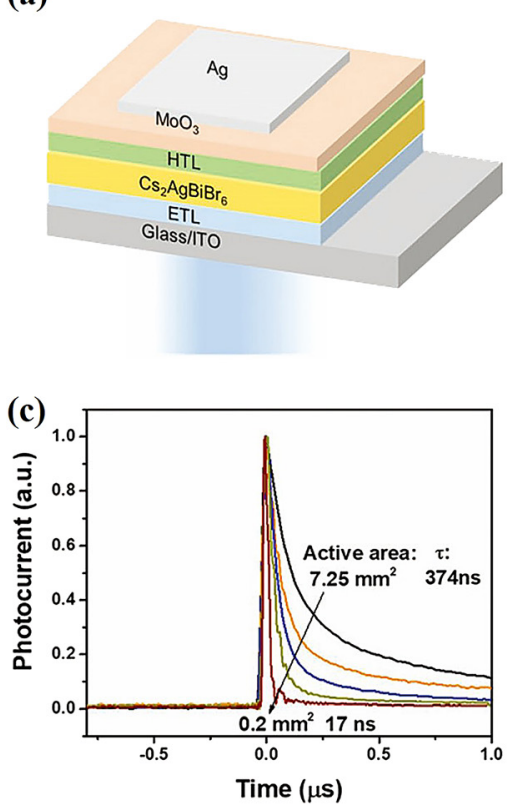
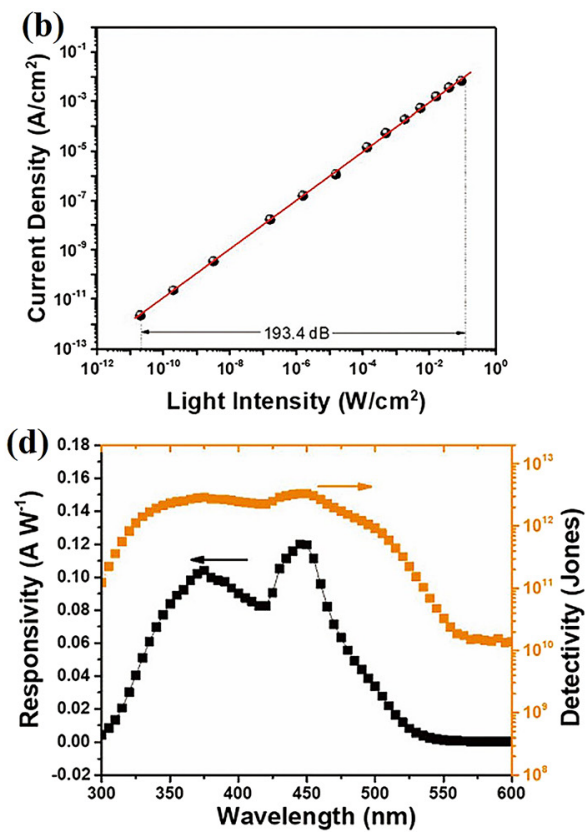

Figure 5: $\mathrm{Cs}_{2} \mathrm{AgBiBr}_{6}$ double halide perovskite for visible light photodetection. (a) Schematic structure of the $\mathrm{Cs}_{2} \mathrm{AgBiBr}_{6}$ based photodetector. (b) Spectral responsivity and detectivity of the $\mathrm{Cs}_{2} \mathrm{AgBiBr}_{6}$ photodetector operated at $0 \mathrm{~V}$. (c) LDR of the $\mathrm{Cs}_{2} \mathrm{AgBiBr}_{6}$ photodetectors upon a $450 \mathrm{~nm}$ light illumination. (d) Transient photocurrent of the $\mathrm{Cs}_{2} \mathrm{AgBiBr}_{6}$ photodetector with a range of active areas from 7.25 to $0.2 \mathrm{~mm}^{2}$ (at $0 \mathrm{~V}$ bias). Reproduced with permission. Copyright 2019, Wiley-VCH Verlag [87]. cost, and environmental safety is urgently needed. The bandgap of lead halide perovskites can be tailored, usually using $\mathrm{Cl}^{-}$as the anion, to obtain UV response [97]. However, the poor solubility of $\mathrm{Cl}$ reagents easily compromises the film quality and thus limits the device application. The appearance of lead-free perovskites created new possibilities for ultraviolet photodetectors, lots of them adopt dimension-reduced crystal structures and entirely different semiconducting properties, which render them suitable for the application in ultraviolet detectors. Cu-based perovskite is a typical example, with a formula of $\mathrm{Cs}_{3} \mathrm{Cu}_{2} \mathrm{I}_{5}$, the schematic view of the crystal structure thereof is shown in Figure 6a. The crystallographic phase fingerprinted by XRD measurement indicates an orthorhombic phase of $\mathrm{Cs}_{3} \mathrm{Cu}_{2} \mathrm{I}_{5}$ (Figure 6b) [98, 99], where there are two types of $\mathrm{Cu}^{+}$sites, namely a tetrahedral site and a trigonal site (the pink (a)

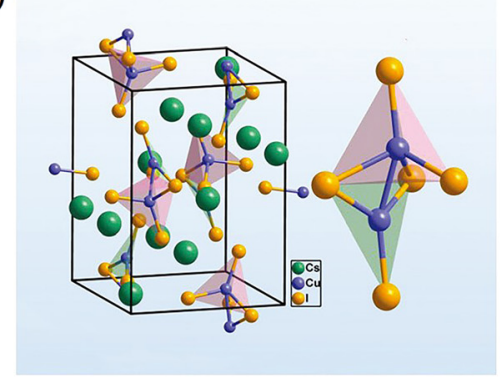

(c)

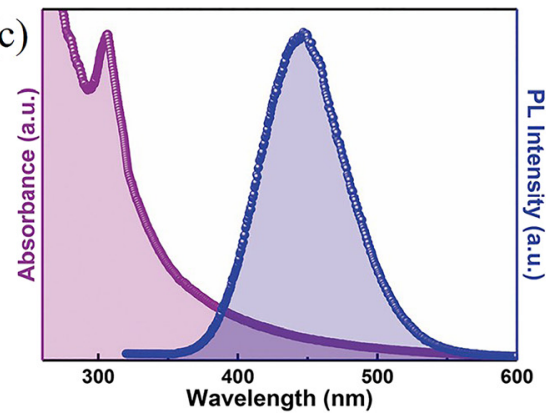

(b)
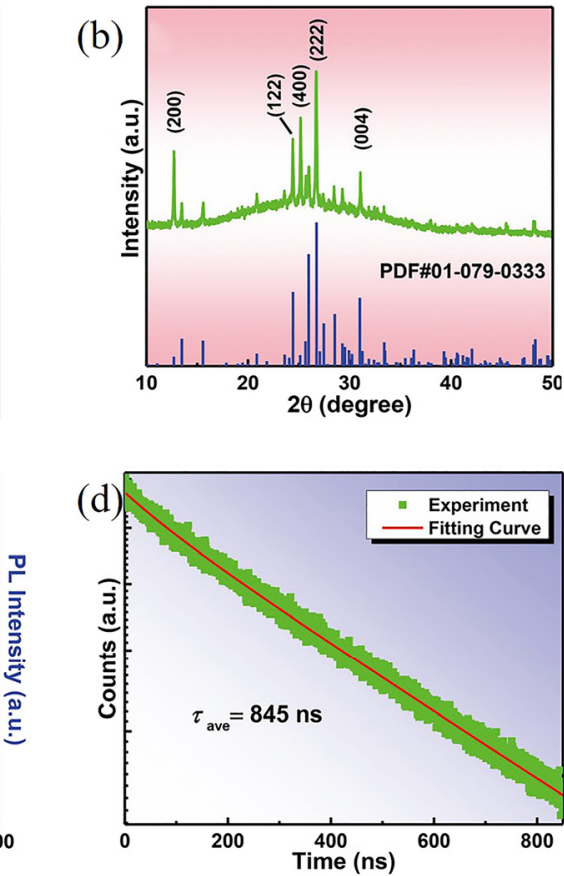

Figure 6: Characterization of the crystallographic phase and optical properties of $\mathrm{Cs}_{3} \mathrm{Cu}_{2} \mathrm{I}_{5}$.

(a) Perspective of the crystal structure of orthorhombic $\mathrm{Cs}_{3} \mathrm{Cu}_{2} \mathrm{I}_{5}$. (b) XRD pattern of the $\mathrm{Cs}_{3} \mathrm{Cu}_{2} \mathrm{I}_{5}$ thin film. (c) PL and absorption spectra of the $\mathrm{Cs}_{3} \mathrm{Cu}_{2} \mathrm{I}_{5}$ thin film measured at room temperature. (d) Time-resolved PL decay and the fitting curve of the $\mathrm{Cs}_{3} \mathrm{Cu}_{2} \mathrm{I}_{5}$ thin film. Reproduced with permission. Copyright 2020, American Chemical Society [91]. 
tetrahedral surface and the green trigonal, respectively) in each $\left[\mathrm{Cu}_{2} \mathrm{I}_{5}\right]^{3-}$ unit. The $\left[\mathrm{Cu}_{2} \mathrm{I}_{5}\right]^{3-}$ units are isolated by the $\mathrm{Cs}^{+}$ ions [91], thus, the $\mathrm{Cs}_{3} \mathrm{Cu}_{2} \mathrm{I}_{5}$ can be regarded as a $\mathrm{OD}$ perovskite variant [99]. DFT calculation pointed out that the $\mathrm{Cs}_{3} \mathrm{Cu}_{2} \mathrm{I}_{5}$ has a wide direct bandgap of $3.8 \mathrm{eV}$, as was also confirmed by experimental results [99]. The absorption spectrum lays the onset at $326 \mathrm{~nm}$ (Figure 6c) in the UV range, indicating a selective response to UV photons. The time-resolved PL measurement in Figure $6 \mathrm{~d}$ further reveals that $\mathrm{Cs}_{3} \mathrm{Cu}_{2} \mathrm{I}_{5}$ is endowed with a long charge lifetime of about 845 ns, which is much longer than those of leadhalide perovskite materials (typically a few to tens of nanoseconds) [100]. These properties unambiguously unveil the great potential of $\mathrm{Cu}$-based perovskites in UV detection.

Zhang et al. took a modified antisolvent vaporassisted crystallization process to directly grow the $\mathrm{Cs}_{3} \mathrm{Cu}_{2} \mathrm{I}_{5}$ crystalline film on an ITO glass substrate to construct a UV detector, as shown in Figure 7a [101]. The responsivity of the resulted UV detector is presented in Figure $7 \mathrm{~b}$, benefitting from the wide bandgap of lead-free perovskite $\mathrm{Cs}_{3} \mathrm{Cu}_{2} \mathrm{I}_{5}$, the detector shows conspicuous sensitivity to the irradiation within the UV band but is nearly blind to visible photons, the rejection ratio was calculated to be 17.8. However, the overall device performances are not satisfactory, the light current is merely $140 \mathrm{pA}$ under the illumination of $2.74 \mathrm{~mW} / \mathrm{cm}^{-2}$, and the corresponding on/off ratio is limited to 142 . As plotted in Figure 7c, the highest values of EQE, responsivity and detectivity under $265 \mathrm{~nm}$ DUV irradiation of $111 \mu \mathrm{W} \mathrm{cm}{ }^{-2}$ are $0.05 \%, 0.11 \mathrm{~mA} \mathrm{~W}^{-1}$, and $1.1 \times 10^{9}$ Jones, respectively, the values are all less satisfactory. The rise time and fall time are 49.9 and $26.19 \mathrm{~ms}$, respectively (Figure 7d). The inferior performances may be attributed to, along with the poor film quality (Figure 7a: inset, presenting lots of pinholes and grain boundaries), the intrinsically ill electrical properties, that is, $\mathrm{Cs}_{3} \mathrm{Cu}_{2} \mathrm{I}_{5}$ pertain to a OD lattice, thus weak is the orbital overlap between adjacent $\left[\mathrm{Cu}_{2} \mathrm{I}_{5}\right]^{3-}$ units, which results in a low carrier mobility. In the work of Zhang et al., they explored the charge transport characteristics of $\mathrm{Cs}_{3} \mathrm{Cu}_{2} \mathrm{I}_{5}$ single crystals by using the space charge limited current (SCLC) approach, the simulated hole mobility and electron mobility are $0.036 \mathrm{~cm}^{2} /(\mathrm{V} \mathrm{s})$ and $0.828 \mathrm{~cm}^{2} /(\mathrm{V} \mathrm{s})$, respectively, which are much lower than $3 \mathrm{D}$ lead perovskites (the hole and electron mobility of $\mathrm{CH}_{3} \mathrm{NH}_{3} \mathrm{PbBr}_{3}$ are $164 \mathrm{~cm}^{2} /(\mathrm{V} \mathrm{s})$ and $24.8 \mathrm{~cm}^{2} /(\mathrm{V} \mathrm{s})$, respectively) [9]. Better performance can be obtained by improving the film quality, in this regard, Liang et al. prepared the $\mathrm{Cs}_{3} \mathrm{Cu}_{2} \mathrm{I}_{5}$ thin film by employing a solution spin-coating process, the resulted film showed a denser and smoother morphology [91]. As a result, a better performance was achieved characterizing a large photoresponsivity of $\sim 17.8 \mathrm{~A} \mathrm{~W}^{-1}$, a high specific detectivity of $1.12 \times 10^{12}$ Jones, and a fast response speed of $465 /$ $897 \mu \mathrm{s}$ at a lower light intensity of $7.0 \mu \mathrm{W} \mathrm{cm}^{-2}$.
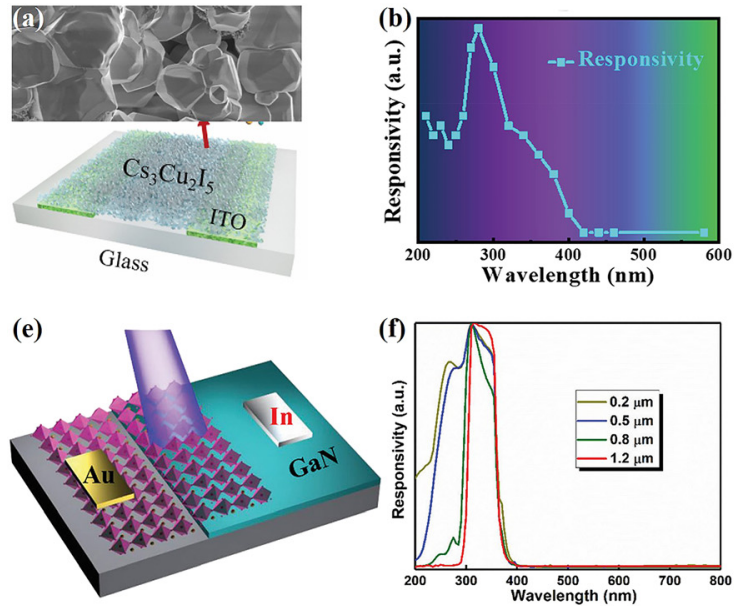
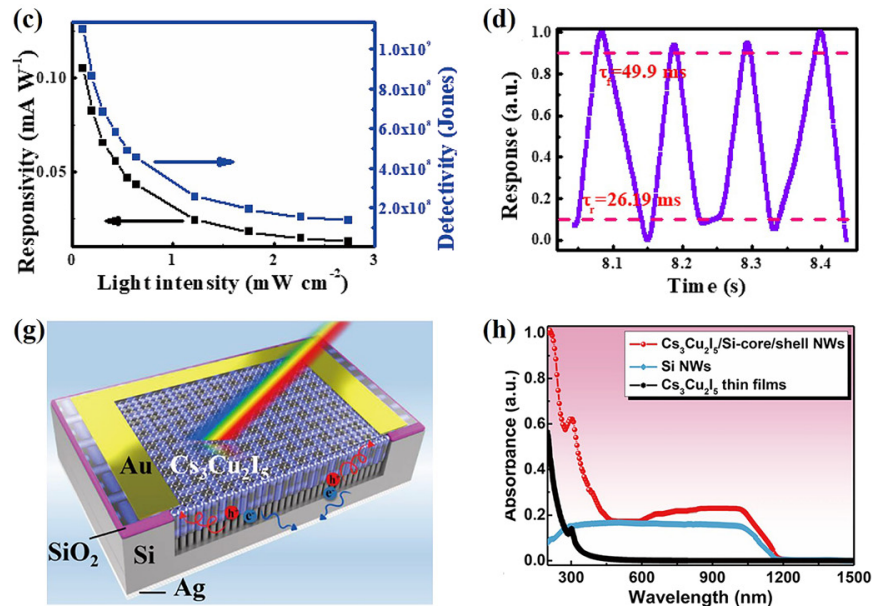

Figure 7: $\mathrm{Cs}_{3} \mathrm{Cu}_{2} \mathrm{I}_{5}$ for UV photodetection.

(a) Schematic view of the DUV device (below) and the FESEM image of the $\mathrm{Cs}_{3} \mathrm{Cu}_{2} \mathrm{I}_{5}$ film (above). (b) Spectral responsivity of the $\mathrm{Cs}_{3} \mathrm{Cu}_{2} \mathrm{I}_{5}$-based photodetector. (c) Responsivity and detectivity of the $\mathrm{Cs}_{3} \mathrm{Cu}_{2} \mathrm{I}_{5}$-based photodetector upon various light intensities. (d) Response curve of the $\mathrm{Cs}_{3} \mathrm{Cu}_{2} \mathrm{I}_{5}$-based photodetector under a pulsed $265 \mathrm{~nm}$ irradiation of $20 \mathrm{~Hz}$ frequency. Reproduced with permission. Copyright 2019, American Chemical Society [101]. (e) Schematic illustration of the $\mathrm{Cs}_{3} \mathrm{Cu}_{2} \mathrm{I}_{5} / \mathrm{GaN}$ heterojunction device. (f) Spectral responsivity of the photodetector with a collection of layer thicknesses. Copyright 2019, Royal Society of Chemistry [28]. (g) Schematic device structure of the $\mathrm{Cs}_{3} \mathrm{Cu}_{2} \mathrm{I}_{5} / \mathrm{Si}_{-} \mathrm{Core}_{\mathrm{s}} / \mathrm{shell}$ nanowires heterojunction photodetector. (h) Absorption spectra of Si nanowires, $\mathrm{Cs}_{3} \mathrm{Cu}_{2} \mathrm{I}_{5}$, and the hybrid system. Copyright 2020, American Chemical Society [102]. 
Li et al. demonstrated a narrowband UV photodetector based on lead-free $\mathrm{Cs}_{3} \mathrm{Cu}_{2} \mathrm{I}_{5}$ film with high stability [28]. As shown in Figure 7e, the $\mathrm{Cs}_{3} \mathrm{Cu}_{2} \mathrm{I}_{5}$ precursor was cast on the commercially available $\mathrm{n}-\mathrm{GaN} / \mathrm{Al}_{2} \mathrm{O}_{3}$ substrates, then an In electrode and an $\mathrm{Au}$ electrode were evaporated onto the $\mathrm{GaN}$ and $\mathrm{Cs}_{3} \mathrm{Cu}_{2} \mathrm{I}_{5}$ films on the two sides to establish a heterojunction narrowband detector. By using the CCN concept, a narrow spectral response window of 300$370 \mathrm{~nm}$ was realized, and the FWHM of the response spectrum could be tailored by controlling the perovskite film thickness and the applied bias voltage. Figure $7 \mathrm{f}$ shows the narrowband response of the photodetectors with a range of absorber thicknesses. The representative UV narrowband detector demonstrates a high responsivity of $0.28 \mathrm{~A} \mathrm{~W}^{-1}$, a specific detectivity of $1.4 \times 10^{12}$ Jones under $1 \mathrm{~mW} \mathrm{~cm}{ }^{-2}$ light illumination at zero bias. And an on/off ratio of $1.2 \times 10^{5}$, short response times of $95 / 130 \mathrm{~ms}(800 \mathrm{~Hz})$ can also be extracted under UV light excitation $(320 \mathrm{~nm})$. With the laudable UV detection capability, the Cu-based perovskites can compensate for the UV photodetection of other photodetectors by integration. Recently, Liang et al. combined the $\mathrm{Cs}_{3} \mathrm{Cu}_{2} \mathrm{I}_{5}$ with $\mathrm{Si}$ nanowires to achieve a UV-visible-NIR broadband photodetector (Figure 7g) [102]. The as-fabricated $\mathrm{Cs}_{3} \mathrm{Cu}_{2} \mathrm{I}_{5} / \mathrm{Si}$ nanowire photodetector demonstrated a multi-band photodetection spanning from deep the UV to NIR region (Figure $7 \mathrm{~h}$ ), the responsivity and detectivity were calculated to be $130 \mathrm{~mA} \mathrm{~W}^{-1}$ and $3.1 \times 10^{10}$ Jones, respectively, at zero bias under $265 \mathrm{~nm}$ light illumination, the results are nearly 600 times better than solely using silicon detector at this wavelength.

It is noteworthy that the abovementioned $\mathrm{Cu}$-based perovskite photodetectors all present much higher water and oxygen stability than the $\mathrm{Pb}$-based counterpart. Liang et al. demonstrated that their unsealed $\mathrm{Cs}_{3} \mathrm{Cu}_{2} \mathrm{I}_{5}$ thin-film photodetectors own good operation stability to endure $11 \mathrm{~h}$ of continuous running in the open air, and the photodetection capability could be maintained even after 80 days' storage in the ambient air [91]. Li showed that their UV detector could handle a high operating temperature of $373 \mathrm{~K}$ for $12 \mathrm{~h}$ of continuous working, and retain its photodetection capability after air exposure of one month [28]. All these results show great potential for the use of copper perovskite in UV detectors.

In addition to $\mathrm{Cu}$-based perovskite, lead-free double perovskites that were demonstrated to own selective UV absorptions, as well as ultralong carrier lifetimes and low trap densities, in the form of single crystal, also own great promise for UV detection [103]. In the work of Luo et al., they reported high-quality $\mathrm{Cs}_{2} \mathrm{AgInCl}_{6}$ single crystals with an average size of $2.88 \times 2.81 \times 1.95 \mathrm{~mm}$ with $\mathrm{UV}$ absorption. After optimization, the as-grown $\mathrm{Cs}_{2} \mathrm{AgInCl}_{6}$ presents an extremely low trap density of $(8.6 \pm 1.9) \times 10^{8} \mathrm{~cm}^{-3}$, which is even lower than that of lead perovskite single crystals $[104,105]$, and the carrier mobility was measured to be as high as $3.31 \mathrm{~cm}^{2} \mathrm{~V}^{-1} \mathrm{~s}^{-1}[103]$. Further, the authors fabricated two-terminal planar UV detectors based on the $\mathrm{Cs}_{2} \mathrm{AgInCl}_{6}$ single crystals (Figure 8a, inset), the photodetector presents effective response to UV photons (Figure 8a and b). Delivered were moderate device performances of $1035 \mathrm{~Hz}$ $\mathrm{f}_{-3 \mathrm{~dB}}$ bandwidth (Figure 8c), 0.8/1 ms response times, $0.013 \mathrm{~A} \mathrm{~W}^{-1}$ peak responsivity, $9.60 \times 10^{11}$ Jones detectivity (Figure 8d), and $1.55 \times 10^{-15} \mathrm{~A} / \mathrm{Hz}^{1 / 2}$ noise current [103].

The summarized device performances of these UV photodetectors are presented in Table 1, it can be found that all these photodetectors are present in the form of a planar configuration, and usually deliver slow response rates (featuring a time constant in the sub-millisecond level) and poor detection limit $\left(\approx \mu \mathrm{W} \mathrm{cm}{ }^{-2}\right)$, which fall far behind those of lead perovskite counterparts $[19,106,107]$. The slow response time is largely influenced by the device structure, and in the planar type photodetector configuration there is usually a large channel width between the electrodes, as a result, the charge needs a long traverse time to arrive at the electrodes. It is also observed that copper perovskite variants usually suffer from poor quality when processed into films by solution methods, the pinholes and grain boundary thereof further jeopardize the carrier transport. In light of these two regards, innovative methods for fabricating high-quality films, based on which vertical type photodetectors can be constructed, are central to improving the device performance, as has been shown in $\mathrm{Cs}_{2} \mathrm{AgBiBr}_{6}$ visible photodetectors [87].

\subsection{X-ray detection}

X-ray detection is of great significance for applications covering military, medical, engineering, civil, and scientific use [108-110]. There are two manners of detecting $\mathrm{X}$-ray [111,112], one is an indirect way that uses scintillators to firstly convert the $\mathrm{X}$-ray photons into low-energy UV-visible photons, which are then detected by commercially mature photodetectors in a matching range. The other uses no intermediate scintillators but rather directly converts the X-ray photons into electrical signals with semiconductor detectors. While the former is more widely adopted due to low cost and facile integration, the latter usually offers better spatial resolution and a simpler device configuration [113]. Albeit the continuous efforts devoted to traditional semiconductors and the respectable progress achieved, these materials are still plagued by disbenefits of operational difficulty, high energy consumption in 

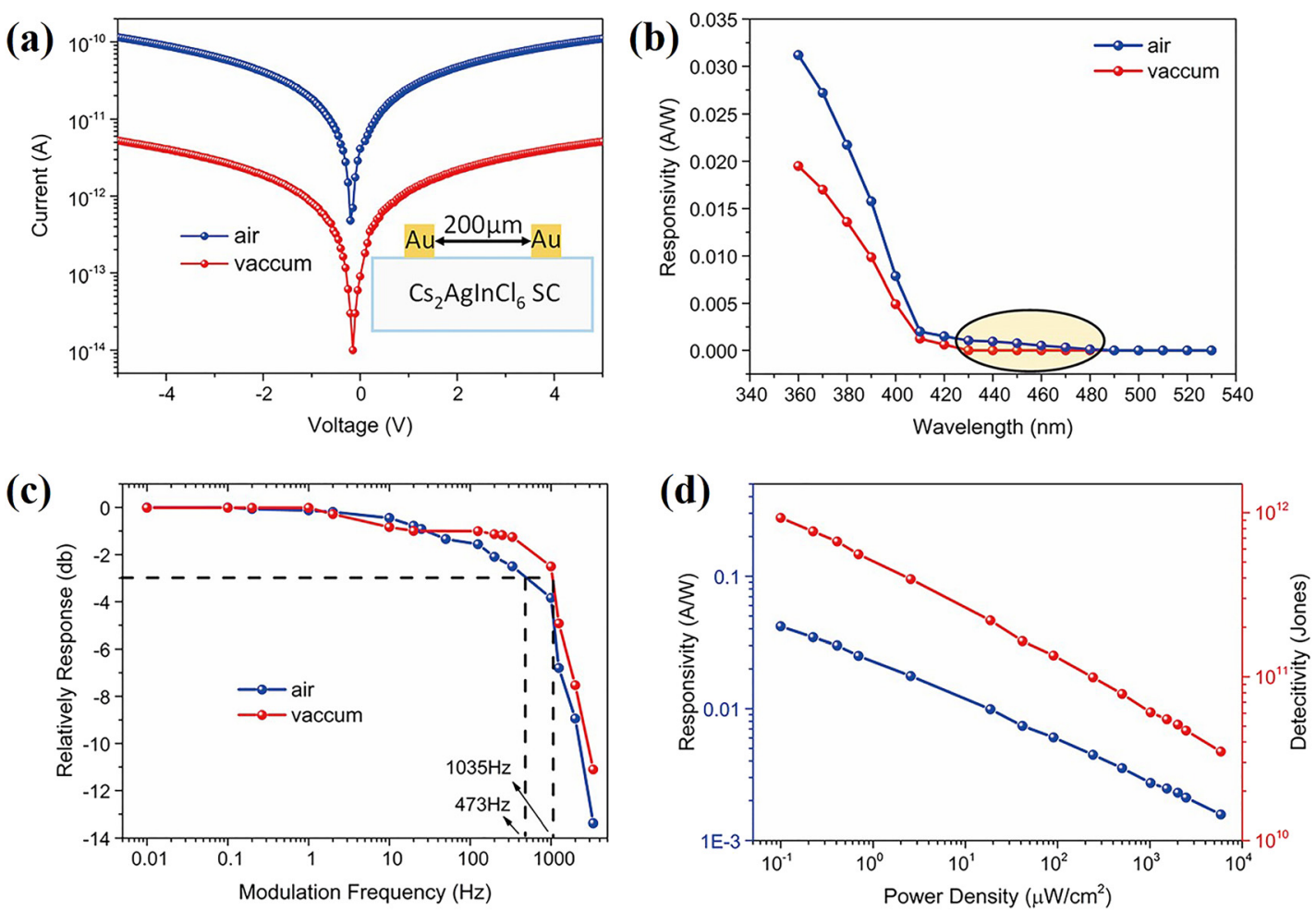

Figure 8: (a) The current-voltage characteristic of the detector in dark condition. Inset: the device configuration for photoconductive planar detector. (b) Normalized response of the detector vs. the input signal frequency (light intensity of $1.27 \mathrm{~mW} \mathrm{~cm}^{-2}$ ) at a bias voltage of $5 \mathrm{~V}$. The $-3 \mathrm{~dB}$ point is marked with the dashed line. (c) Wavelength-dependent responsivity under $5 \mathrm{~V}$ bias. The light source is the bromine tungsten lamp modulated by optical grating to generate monochromatic light with a minimum step of $10 \mathrm{~nm}$. (d) Light intensity-dependent responsivity and normalized detectivity under the bias of $5 \mathrm{~V}$ in vacuum. Reproduced with permission. Copyright 2017, American Chemical Society [103].

Table 1: Summary of the key device parameters of some reported lead-free perovskite UV photodetectors.

\begin{tabular}{|c|c|c|c|c|c|}
\hline Photodetectors & Detectivi (Jones) & Responsivity & Response time & Detection limit & Ref. \\
\hline $\mathrm{ITO} / \mathrm{Cs}_{3} \mathrm{Cu}_{2} \mathrm{I}_{5} / \mathrm{ITO}$ & $1.10 \times 10^{9}$ & $0.11 \mathrm{~mA} \mathrm{~W}^{-1}$ & - & $111 \mu \mathrm{W} \mathrm{cm}-2$ & [101] \\
\hline $\mathrm{Au} / \mathrm{Cs}_{3} \mathrm{Cu}_{2} \mathrm{I}_{5} / \mathrm{Au}$ & $1.12 \times 10^{12}$ & $17.8 \mathrm{~A} \mathrm{~W}^{-1}$ & $465 / 897 \mu \mathrm{s}$ & $0.07 \mathrm{~mW} \mathrm{~cm}^{-2}$ & [91] \\
\hline $\mathrm{Au} / \mathrm{Cs}_{3} \mathrm{Cu}_{2} \mathrm{I}_{5} / \mathrm{GaN} / \mathrm{In}$ & $1.40 \times 10^{12}$ & $0.28 \mathrm{~A} \mathrm{~W}^{-1}$ & $95 / 130 \mathrm{~ms}$ & $1 \mu \mathrm{W} \mathrm{cm}{ }^{-2}$ & [28] \\
\hline $\mathrm{Cs}_{3} \mathrm{Cu}_{2} \mathrm{I}_{5} / \mathrm{Si}$-core/shell nanowires & $3.10 \times 10^{12}$ & $130 \mathrm{~mA} \mathrm{~W}^{-1}$ & $92.5 / 189.2 \mu \mathrm{s}$ & $12 \mu \mathrm{W} \mathrm{cm}-2$ & [102] \\
\hline $\mathrm{Cs}_{2} \mathrm{AgInCl}_{6} \mathrm{SCs}$ & $10^{12}$ & $0.013 \mathrm{~A} \mathrm{~W}^{-1}$ & $1 \mathrm{~ms}$ & $0.1 \mu \mathrm{W} \mathrm{cm}-2$ & [103] \\
\hline
\end{tabular}

fabrication, and difficulty of growing high-quality single crystals $[114,115]$. In recent years, lead halide perovskites, in both forms of scintillator and direct detector, have been revealed to be potential candidates for $\mathrm{X}$-ray detection [30, 116-127]. Subsequent research focus turned to lead-free alternatives that afford nontoxicity and environmental friendship but retain the exceptional semiconducting attributes. It has been prevailingly revealed that lead-free halide perovskites are usually less effective in fluorescence, which questions their potential as scintillators [128]. Nevertheless, several types, mainly $\mathrm{Bi}$ types, were demonstrated to own laudable direct X-ray sensing capability. The superiorities of Bi-based types are based on two considerations: (i) The absorption coefficient of X-ray is proportional to $Z^{4}$, and $\mathrm{Bi}$ is the heaviest among stable elements, which maximizes the X-ray absorption. (ii) Bibased halide perovskites are often indirect semiconductors, in which the recombination of electrons and holes are intrinsically slow to enhance the harvest of photogenerated electrons and holes. The Bi-based halide perovskites can be classified into two types in terms of the lead substitution, i.e., double halide perovskite and pure Bi type. In the following, a review of their progress in direct $\mathrm{X}$-ray detection is reviewed. 


\subsubsection{X-ray detection based on Bi-based double halide perovskite}

The $\mathrm{Bi}^{3+}-\mathrm{Ag}^{+}$system is one of the most intriguing members of the double halide perovskite family $[129,130]$, as is mentioned in Section 2.2 Visible light photodetectors. The attributes of containing heavy elements, indirect bandgap, long charge lifetime [88], and decent stability [90], collectively justify the great potential for X-ray detection. The X-ray detection is highly penetrating and necessitates a large thickness, in addition to a large absorption coefficient, to ensure sufficient absorption. In addition, low noise and high sensitivity in the active material are of necessity, thus required is a low density of structural imperfections that undesirably engender a large noise current and compromise the harvest of photogenerated charges. Therefore, bulk single crystal is an ideal form for X-ray detection. To obtain enhanced detection performances, especially a high sensitivity towards feeble $\mathrm{X}$-rays, the quality of the $\mathrm{Cs}_{2} \mathrm{AgBiBr}_{6}$ single crystal should be carefully engineered. Particular attention should be paid to the ready disordering of the $\left[\mathrm{AgBr}_{6}\right]$ and $\left[\mathrm{BiBr}_{6}\right]$ octahedra within, which varies local electronic structure $[89,131,132]$. Xiao et al. revealed that shallow states (e.g., $\mathrm{Ag}^{+}$-vacancy) and deep states (e.g., Bi vacancies and $\mathrm{Ag}_{\mathrm{Bi}}$ antisites) can easily form to curtail $\mathrm{Cs}_{2} \mathrm{AgBiBr}_{6}$ [133], Steele et al. suggested the importance of optimizing the parasitic recombination pathways, probably by cooling, in enhancing the performance of $\mathrm{Cs}_{2} \mathrm{AgBiBr}_{6} \mathrm{X}$-ray detector [134]. It has also been prevailingly unraveled that this type of material is subject to the easy formation of polarons caused by lattice distortion, as is confirmed by the broadband photoluminescence stemming from consequent selftrapped excitons (STEs) [73, 135].

Tang's group firstly reported the use of $\mathrm{Cs}_{2} \mathrm{AgBiBr}_{6} \mathrm{SCs}$ in X-ray detection, via proper treatment with thermal annealing and surface treatment, a low detection limit of $59.7 \mathrm{nGy}_{\text {air }} \mathrm{s}^{-1}$ was realized [136]. Simulated X-ray absorption coefficients versus photon energy could be calculated with the average atomic number, the coefficient of $\mathrm{Cs}_{2} \mathrm{AgBiBr}_{6}$ was compared with those of $\mathrm{Si}$, CdTe, and $\mathrm{MAPbBr}_{3}\left(\mathrm{MA}^{+}=\mathrm{CH}_{3} \mathrm{NH}_{3}{ }^{+}\right)$in Figure 9a, it shows that $\mathrm{Cs}_{2} \mathrm{AgBiBr}_{6}$ outcompetes the other semiconductors in a wide photon energy range spanning from soft X-ray to gamma radiation. Towards $\mathrm{X}$-ray photons of $50 \mathrm{keV}$, the dependences of attenuation efficiency on sample thickness in these materials are further compared (Figure 9b). Fundamentally, a larger absorption coefficient enables an enhanced capturing capability of X-ray photons, the result shows that $\mathrm{Cs}_{2} \mathrm{AgBiBr}_{6}$ is able to consume $99 \% \mathrm{X}$-ray photons with a $1.18 \mathrm{~mm}$ thickness, whereas in $\mathrm{MAPbBr}_{3}$ the value increases to $2.28 \mathrm{~mm}$. Endurance to thermal stress is also an important figure-of-merit to assess the stability for practical application, the widely studied $\mathrm{MAPbX}_{3}(\mathrm{X}=\mathrm{Cl}$, $\mathrm{Br}, \mathrm{I})$ halide perovskite suffers from easy thermal decomposition owing to the ready release of organic $\mathrm{MA}^{+}$[137], in this regard, $\mathrm{Cs}_{2} \mathrm{AgBiBr}_{6}$ incorporates $\mathrm{Cs}^{+}$rather than $\mathrm{MA}^{+}$to constitute a fully-inorganic composition [138], therefore enjoying a highly improved thermoresistance. Indeed, the thermogravimetric analysis presented in Figure 9c characterizes superior stability below $430{ }^{\circ} \mathrm{C}$. These gorgeous attributes were then interpreted into sensitive X-ray detection. The as-grown $\mathrm{Cs}_{2} \mathrm{AgBiBr}_{6}$ SCs, howbeit with high quality, were found to be further optimized via thermal annealing and surface treatment, in this way a large $\mu \tau$ product of $6.0 \times 10^{-3} \mathrm{~cm}^{2} \mathrm{~V}^{-1}$ and a low surface recombination rate of $36.9 \mathrm{~cm} \mathrm{~s}^{-1}$ were obtained. The large $\mu \tau$ product ensures an efficient collection of X-ray-generated charges, the sensitivity versus voltage is plotted in Figure 9d, a laudable value of $8 \mu \mathrm{C} \mathrm{Gy}_{\text {air }}{ }^{-1} \mathrm{~cm}^{-2}\left(0.5 \mathrm{~V} \mathrm{~mm}^{-1}\right)$ ( $E_{\text {eff. }}=30 \mathrm{keV}$ X-ray photons) was realized, the sensitivity further climbed to $105 \mu \mathrm{C} \mathrm{Gyair}^{-1} \mathrm{~cm}^{-2}$ upon $25 \mathrm{~V} \mathrm{~mm}^{-1}$ electric field. This value is higher than that of the commercial $\alpha$-Se detectors $\left(20 \mu \mathrm{C} \mathrm{Gy}_{\text {air }}{ }^{-1} \mathrm{~cm}^{-2}\right)$, although oper-

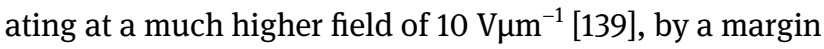
of five times. As well, the suppressed surface recombination accounts for a reduced surface leakage current, which strengthens the detection of faint X-ray signal. In consideration of both the random charge carrier dynamics and ripples in the X-ray generator, the noise current was calculated from the fluctuation of the photocurrent, and the signal-to-noise ratio versus voltage is plotted upon variant radiation dose rates. Referring to a benchmark ratio of 3 defined by the International Union of Pure and Applied Chemistry (IUPAC) [140], a detection limit of $59.7 \mathrm{nGy}_{\text {air }} \mathrm{s}^{-1}$ at $5 \mathrm{~V}$ was obtained (Figure 9e). Although the value is no better than that of $\mathrm{MAPbBr}_{3}\left(36 \mathrm{nGy}_{\text {air }} \mathrm{s}^{-1} @ 1 \mathrm{~V}\right)$ [121], it is orders of magnitude lower than the regular medical diagnostics limit $\left(5.5 \mu \mathrm{Gy}_{\text {air }} \mathrm{s}^{-1}\right)[141,142]$.

The authors further demonstrated that $\mathrm{Cs}_{2} \mathrm{AgBiBr}_{6}$ is more resistant against ion migration, which can be triggered under higher biases to cause a larger noise current [143]. To assess the activation energy of ion migration, an electrical fitting method suggested by Li et al. was adopted [144], the activation energy of $\mathrm{Cs}_{2} \mathrm{AgBiBr}_{6}$ was then calculated to $348 \mathrm{meV}$ (Figure 9f), which is almost two times larger than that of $\mathrm{MAPbBr}_{3}(127 \mathrm{meV})$. The suppressed ion migration allows reliable operation under higher bias voltages without significantly exacerbated noise currents.

The single crystal form endows the best material quality for X-ray detection, but current growth methods do not support a large-area application of single crystals. 

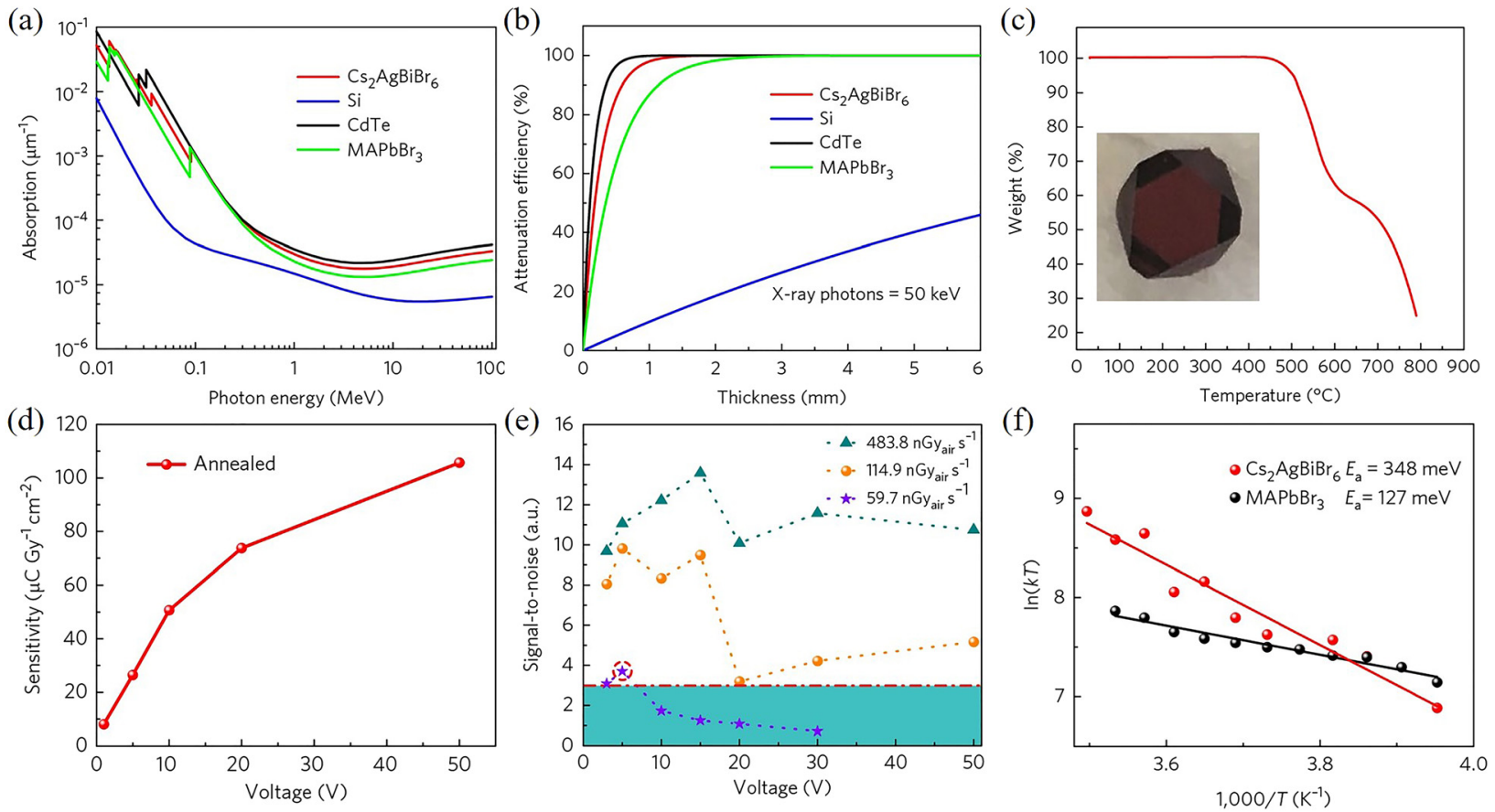

Figure 9: Characterizations of $\mathrm{Cs}_{2} \mathrm{AgBiBr}_{6} \mathrm{SC}$ for $\mathrm{X}$-ray detection.

(a) Simulated dependence of the absorption coefficients of $\mathrm{CS}_{2} \mathrm{AgBiBr}_{6}, \mathrm{MAPbBr}_{3}, \mathrm{CdTe}$, and $\mathrm{Si}$ on photon energy in a wide range spanning from $X$-rays to gamma radiation. (b) Thickness-dependent $X$-ray attenuation efficiency in several representative semiconductors, the selected $X$-ray photon energy is $50 \mathrm{keV}$. (c) Thermogravimetric analysis curve of $\mathrm{Cs}_{2} \mathrm{AgBiBr}_{6}$. Inset: photograph of the $\mathrm{Cs}_{2} \mathrm{AgBiBr}_{6} \mathrm{SC}$. (d) $\mathrm{Sensitivity}$ of the $\mathrm{Cs}_{2} \mathrm{AgBiBr}_{6}$ single crystal-based $\mathrm{X}$-ray detector versus bias. (e) Signal-to-noise ratio of the device versus bias, the ratio is derived by calculating the standard deviation of the photocurrent upon X-ray irradiation. (f) Arrhenius plots of the kT-1000/T relationship to calculate the activation energy of ion migration. Reproduced with permission. Copyright 2017, Springer Nature [136].

Towards this issue, the same group further advocated heteroepitaxially-passivated polycrystalline $\mathrm{Cs}_{2} \mathrm{AgBiBr}_{6}$ for X-ray detection [145]. Firstly, the authors adopted an isostatic-pressing to assemble $\mathrm{Cs}_{2} \mathrm{AgBiBr}_{6}$ powders into a wafer, and an annealing process at $350{ }^{\circ} \mathrm{C}$ was applied during the pressing process to induce grain regrowth. An overdose of $\mathrm{BiBr}_{3}$ was incorporated in the precursor, the $\mathrm{BiBr}_{3}$ will react with the moisture in the air to produce $\mathrm{BiOBr}$. BiOBr adopts a layered structure with $\left[\mathrm{Bi}_{2} \mathrm{O}_{2}\right]$ slabs being sandwiched by $\mathrm{Br}$ slabs, the $\mathrm{Br}^{-}$arrangement along the (001) plane is in the same manner as that in the $\mathrm{Cs}_{2} \mathrm{AgBiBr}_{6}$ (001) plane, a small lattice mismatch of $1.6 \%$ can be estimated according to the lattice parameters. Therefore, the $\mathrm{BiOBr}$ is believed to afford a heteroepitaxial growth interfacing the grain boundaries of $\mathrm{Cs}_{2} \mathrm{AgBiBr}_{6}$ grains as illustrated in Figure 10a.

Such a heteroepitaxial growth brings in two benefits: on the one hand, while pristine $\mathrm{Cs}_{2} \mathrm{AgBiBr}_{6}$ is subject to $\mathrm{Br}^{-}$migration under bias, the $\mathrm{BiOBr}$ on the grain boundary deactivates the ion migration paths. For confirmation, the authors measured the resistivity of the pristine $\mathrm{Cs}_{2} \mathrm{AgBiBr}_{6}$ wafer and the $\mathrm{Cs}_{2} \mathrm{AgBiBr}_{6}+\mathrm{BiOBr}$ wafer (Figure 10b). Indeed, the introduction of $\mathrm{BiOBr}$ increases the resistivity by approximately five times from $2.0 \times 10^{9}$ to $1.6 \times 10^{10} \Omega \mathrm{cm}$. Further, the activation energy of ion migration was fitted as shown in Figure 10c, the $\mathrm{Cs}_{2} \mathrm{AgBiBr}_{6}+\mathrm{BiOBr}$ wafer characterizes a high energy barrier of $360 \mathrm{meV}$, which is significantly higher than the value of $203 \mathrm{meV}$ in pristine $\mathrm{Cs}_{2} \mathrm{AgBiBr}_{6}$ wafer and even slightly higher than that of $\mathrm{Cs}_{2} \mathrm{AgBiBr}_{6}$ single crystals in their previous report [136]. On the other hand, the authors also presumed defect passivation by $\mathrm{BiOBr}$, thus enabling a better electrical structure for charge collection upon X-ray irradiation. An increase of the $\mu \tau$ product, which depicts the distance charges can transit under bias, embodies such improvement. The $\mu \tau$ product in the $\mathrm{Cs}_{2} \mathrm{AgBiBr}_{6}+\mathrm{BiOBr}$ wafer climbs to $5.51 \times 10^{-3} \mathrm{~cm}^{2} \mathrm{~V}^{-1}$ from $1.57 \times 10^{-3} \mathrm{~cm}^{2} \mathrm{~V}^{-1}$ in the pristine reference (Figure 10d). The time-resolved PL measurement renders a glimpse of the charge recombination dynamics, the charge lifetime is greatly prolonged after the introduction of BiOBr, which indicates suppression of the defectassisted charge recombination (Figure 10e). In all, the improved bulk resistivity and charge transit entitle the wafer for high-fidelity X-ray imaging. To simulate the X-ray imaging application, a planar array based on the wafer is fabricated, the X-ray signal was firstly filtrated by a "HUST" 

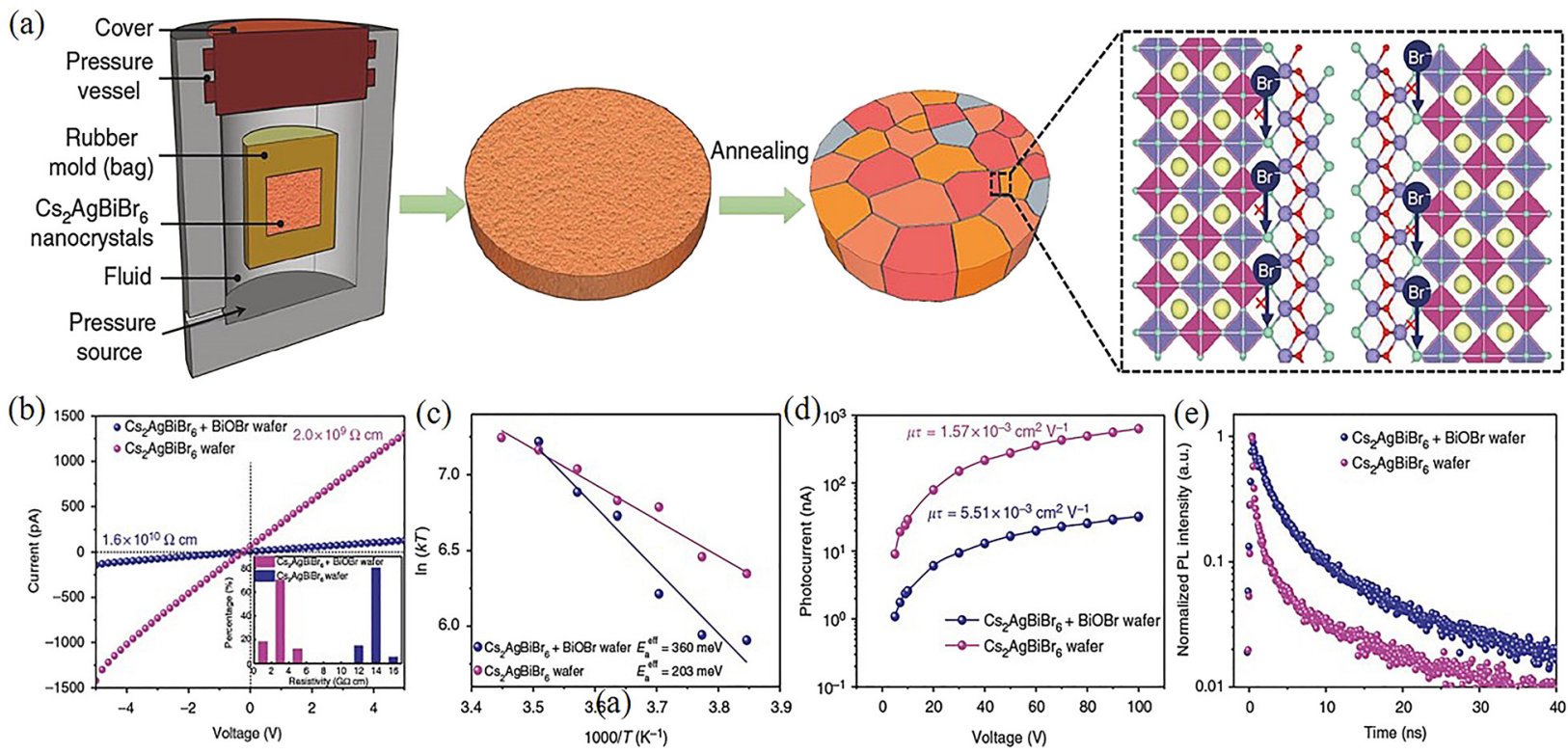

(f)
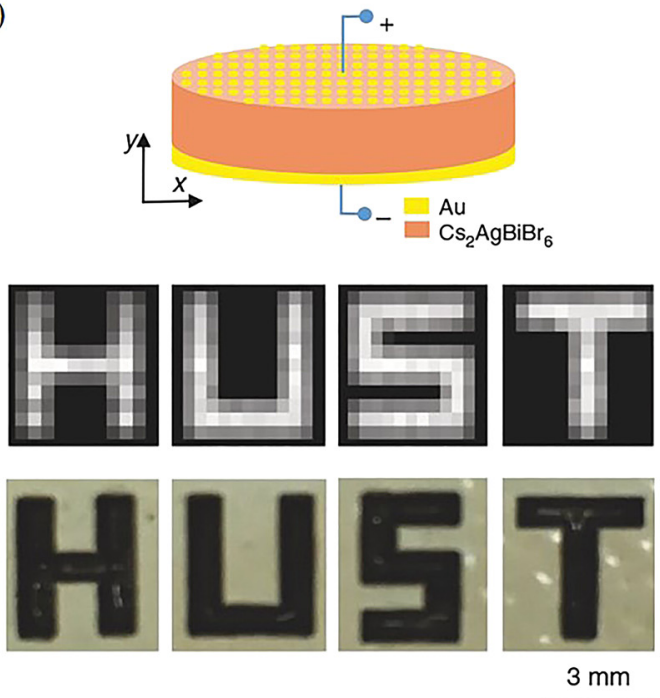

(g)
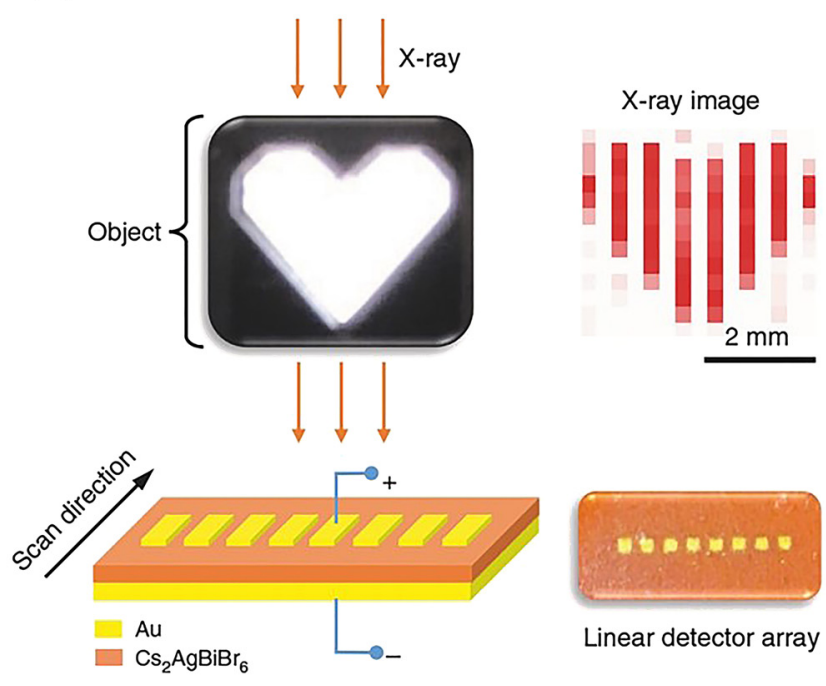

Figure 10: Polycrystalline $\mathrm{Cs}_{2} \mathrm{AgBiBr}_{6}$ wafer for $\mathrm{X}$-ray detection.

(a) Schematic diagram of the preparation method of the $\mathrm{Cs}_{2} \mathrm{AgBiBr}_{6}$ wafer. Isostatic-pressing with a $200 \mathrm{MPa}$ hydraulic press is used to press $\mathrm{Cs}_{2} \mathrm{AgBiBr}_{6}$ powder into the wafer followed by an annealing process. (b) Characterization of the resistivity via the $I-V$ curve. Inset: the statistical result of the resistivity. (c) Fitting of the activation energy of ion migration with Arrhenius plots of $k T$ versus $1000 / T$. (d) Biasdependent photoconductivity to derive the $\mu \tau$ product in the $\mathrm{Cs}_{2} \mathrm{AgBiBr}_{6}$ wafers. (e) Time-resolved photoluminescence of the $\mathrm{Cs}_{2} \mathrm{AgBiBr}_{6}$ wafers. ( $f$ ) Schematic view of the X-ray imaging with the $\mathrm{CS}_{2} \mathrm{AgBiBr}_{6}$ wafer. The X-ray image (above) is compared with the optical image (below) to show high fidelity. (g) Sketch of the linear detector array. Corresponding optical image and X-ray image. Reproduced with permission. Copyright 2019, Springer Nature [145].

logo mask and then received by the wafer, the areal current intensity was read out in every pixel, and the outcome well reproduces the "HUST" mask (Figure 10f). As well, the authors demonstrated a linear array of eight pixels $(0.8 \mathrm{~mm}$ pixel size and $0.8 \mathrm{~mm}$ pitch size) to scan the $\mathrm{X}$-ray signal in one direction to distinguish a heart-shaped logo (Figure 10g). A higher resolution can be expected by further minimizing the pixel and pitch size.
Unambiguously, Tang's work demonstrated the great potential of $\mathrm{Cs}_{2} \mathrm{AgBiBr}_{6}$ in X-ray detection, an abundance of ensuing works were then done to expedite the understanding and improve the performance of $\mathrm{Cs}_{2} \mathrm{AgBiBr}_{6}-$ based X-ray detector. For example, Yuan et al. reported the regulation of ordered-disordered phase transition with phenylethylamine bromide and improved the sensitivity up to $288.8 \mu \mathrm{C} \mathrm{Gy}_{\text {air }}{ }^{-1} \mathrm{~cm}^{-2}$ under an electric field of 
22.7 V mm [146]. Tang's group further developed a controlled cooling synthesis of $\mathrm{Cs}_{2} \mathrm{AgBiBr}_{6}$ SC with improved quality, which yields a high sensitivity of $1974 \mu \mathrm{C}$ $\mathrm{Gy}_{\text {air }}{ }^{-1} \mathrm{~cm}^{-2}$ along with a low detection limit of $45.7 \mathrm{nGy}_{\text {air }} \mathrm{s}^{-1}$ [147]. $\mathrm{Xu}$ et al. introduced the use of dimension-reduced (BA) ${ }_{2} \mathrm{CsAgBiBr}_{7}$ for X-ray detection, 2D halide perovskites has long been regarded as a more stable alternative for the 3D counterparts [78, 79, 148], the authors also reported the favorable attributes of large $\mu \tau$ product (up to $1.21 \times 10^{-3} \mathrm{~cm}^{2} \mathrm{~V}^{-1}$ ), high bulk resistance, and low density of trap states, which collectively contribute to a decent sensitivity of 4.2 (@5 $\mathrm{V} \mathrm{mm}^{-1}$ ). The lower sensitivity compared with that of the 3D counterpart is probably caused by less effective charge traverse in the out-of-plane direction in 2D halide perovskites [29]. Zhang et al. tried high-quality $\mathrm{Cs}_{2} \mathrm{AgBiBr}_{6}$ films rather than single crystals, with a large diffusion electron-hole length $(\sim 700 \mathrm{~nm})$ and a long charge carrier lifetime, the authors demonstrated an extraordinary sensitivity of $1.8 \times 10^{4} \mu \mathrm{C} \mathrm{Gy}_{\text {air }}{ }^{-1} \mathrm{~cm}^{-2}$ [149], although partly due to the high electric field applied $\left(1667 \mathrm{~V} \mathrm{~mm}^{-1}\right)$. A commendable detection limit of 145.2 $n \mathrm{~Gy}_{a i r} \mathrm{~s}^{-1}$ was also achieved [149]. A summary of the progress in the $\mathrm{Cs}_{2} \mathrm{AgBiBr}_{6}$-based $\mathrm{X}$-ray detector is listed in Table 2 in terms of key performances.

\subsubsection{Pure Bi-based perovskite variants for X-ray detection}

In addition to the combination with a monovalent cation that builds a double halide perovskite structure, pure $\mathrm{Bi}^{3+}$ can also construct perovskite derivative structures as potential X-ray sensitive materials. Intriguingly, the $\mathrm{Pb}^{2+}$-to$\mathrm{Bi}^{3+}$ heterovalent substitution in HPs engenders a different bonding manner, the resultant compound respects a wealth of different crystallographic structures. And when assessing these new materials in terms of X-ray detection, both ionic behavior and charge properties should be considered. Yang's group proposed $\left(\mathrm{NH}_{4}\right)_{3} \mathrm{Bi}_{2} \mathrm{I}_{9}$ as the X-ray sensor with anisotropy [30]. $\left(\mathrm{NH}_{4}\right)_{3} \mathrm{Bi}_{2} \mathrm{I}_{9}$ belongs to the $\mathrm{A}_{3} \mathrm{~B}_{2} \mathrm{X}_{9}$ family [151], which possesses two types of lattice structures when varying the A-site cation, e.g., $\mathrm{Cs}_{3} \mathrm{Bi}_{2} \mathrm{I}_{9}$ follows a $0 \mathrm{D}$ structure where the $\left[\mathrm{PbI}_{6}\right]$ octahedra are disconnected, while $\left(\mathrm{NH}_{4}\right)_{3} \mathrm{Bi}_{2} \mathrm{I}_{9}$ follows a 2D layered structure as schematically illustrated in Figure 11a. Although the discontinued connection fashion largely limits the optoelectronic properties of the OD members [152], the authors demonstrated that the 2D layered structure in $\left(\mathrm{NH}_{4}\right)_{3} \mathrm{Bi}_{2} \mathrm{I}_{9}$ enables anisotropic electronic properties and ensuingly an anisotropic X-ray detection performance.

Firstly, the simulated X-ray absorption coefficients of $\left(\mathrm{NH}_{4}\right)_{3} \mathrm{Bi}_{2} \mathrm{I}_{9}$ is compared with those of typical semiconductors, including $\mathrm{Cs}_{2} \mathrm{AgBiBr}_{6}, \mathrm{MAPbBr}_{3}$, CdTe, and $\mathrm{Si}$, as shown in Figure 11b. The high $\mathrm{Z}$ value of $\mathrm{Bi}$ contributes to a large X-ray absorption coefficient in $\left(\mathrm{NH}_{4}\right)_{3} \mathrm{Bi}_{2} \mathrm{I}_{9}$, which outpaces $\mathrm{Si}$ and halide perovskite counterparts of $\mathrm{Cs}_{2} \mathrm{Ag}$ $\mathrm{BiBr}_{6}, \mathrm{MAPbBr}_{3}$, and is closely comparable to CdTe. It is estimated that a $0.99 \mathrm{~mm}$-thick $\left(\mathrm{NH}_{4}\right)_{3} \mathrm{Bi}_{2} \mathrm{I}_{9}$ is able to attenuate $99 \%$ of the X-ray photons of $50 \mathrm{keV}$ energy, while $\mathrm{MAPbBr}_{3}$ needs $2.28 \mathrm{~mm}$. The large absorption coefficient ensures an efficient harvest of X-ray photons that subsequently evoke charge carriers. Interestingly, the layered structure of $\left(\mathrm{NH}_{4}\right)_{3} \mathrm{Bi}_{2} \mathrm{I}_{9}$, with the stacking layers being connected by hydrogen bonds and van der Waals forces, endows vastly different charge transport behaviors in the in-plane and out-of-plane directions. The authors firstly developed a low-temperature solution method to prepare large-sized SC as shown in Figure 11c, the largest size reaches $21 \times 20 \times 7 \mathrm{~mm}^{3}$. The $2 \mathrm{D}$ layered crystal structure favors a lateral growth with the low-energy (001) plane being exposed. Then the $\mu \tau$ products in both directions

Table 2: Summary of figure-of-merits of the $\mathrm{Bi}-\mathrm{Ag}$ double halide perovskite $\mathrm{X}$-ray detector in literature.

\begin{tabular}{|c|c|c|c|c|}
\hline Material & X-ray energy (eV) & Sensitivity $\left(\mu \mathrm{C} \mathrm{Gy}{ }_{\text {air }}{ }^{-1} \mathrm{~cm}^{-2}\right)$ & Detection limit ( $\mathrm{nGy}_{\mathrm{air}} \mathrm{s}^{-1}$ ) & Ref. \\
\hline $\mathrm{Cs}_{2} \mathrm{AgBiBr}_{6} \mathrm{SC}$ & $\leq 50 \mathrm{k}, E_{\text {peak }}=30 \mathrm{k}$ & $\begin{array}{r}105\left(25 \mathrm{~V} \mathrm{~mm}^{-1}\right) \\
8\left(0.5 \mathrm{~V} \mathrm{~mm}^{-1}\right)\end{array}$ & $59.7\left(2.5 \mathrm{~V} \mathrm{~mm}^{-1}\right)$ & [136] \\
\hline $\mathrm{Cs}_{2} \mathrm{AgBiBr}_{6} \mathrm{SC}$ & $18-100 \mathrm{k}, E_{\mathrm{eff}}=39 \mathrm{k}$ & $\begin{array}{l}316\left(6 \mathrm{~V} \mathrm{~mm}^{-1}\right) \\
54.7\left(1 \mathrm{~V} \mathrm{~mm}^{-1}\right)\end{array}$ & - & [150] \\
\hline $\mathrm{Cs}_{2} \mathrm{AgBiBr}_{6} \mathrm{SC}$ & $50 \mathrm{k}$ & $\begin{array}{l}288.8\left(22.7 \mathrm{~V} \mathrm{~mm}^{-1}\right) \\
18.1\left(0.454 \mathrm{~V} \mathrm{~mm}^{-1}\right)\end{array}$ & - & [146] \\
\hline $\mathrm{CS}_{2} \mathrm{AgBiBr}_{6}$ wafer & $\leq 50 \mathrm{k}, E_{\text {peak }}=30 \mathrm{k}$ & $250\left(1000 \mathrm{~V} \mathrm{~mm}^{-1}\right)$ & $95.3\left(5-10 \mathrm{~V} \mathrm{~mm}^{-1}\right)$ & [145] \\
\hline $\mathrm{Cs}_{2} \mathrm{AgBiBr}_{6} \mathrm{SC}$ & $\leq 50 \mathrm{k}, E_{\text {peak }}=30 \mathrm{k}$ & $\begin{array}{r}1974\left(50 \mathrm{~V} \mathrm{~mm}^{-1}\right) \\
24.23\left(2.5 \mathrm{~V} \mathrm{~mm}^{-1}\right)\end{array}$ & $45.7\left(2.5 \mathrm{~V} \mathrm{~mm}^{-1}\right)$ & [147] \\
\hline$(\mathrm{BA})_{2} \mathrm{CsAgBiBr}_{7} \mathrm{SC}$ & $70 \mathrm{k}$ & $4.2\left(5 \mathrm{~V} \mathrm{~mm}^{-1}\right)$ & - & [29] \\
\hline $\mathrm{Cs}_{2} \mathrm{AgBiBr}_{6}$ film & $E_{\text {peak }}=83 \mathrm{k}$ & $1.8 \times 10^{4}\left(1667 \mathrm{~V} \mathrm{~mm}^{-1}\right)$ & $145.2\left(667 \mathrm{~V} \mathrm{~mm}^{-1}\right)$ & [149] \\
\hline$\alpha$-Se & $20 \mathrm{k}$ & $20\left(10000 \mathrm{~V} \mathrm{~mm}^{-1}\right)$ & - & [139] \\
\hline
\end{tabular}




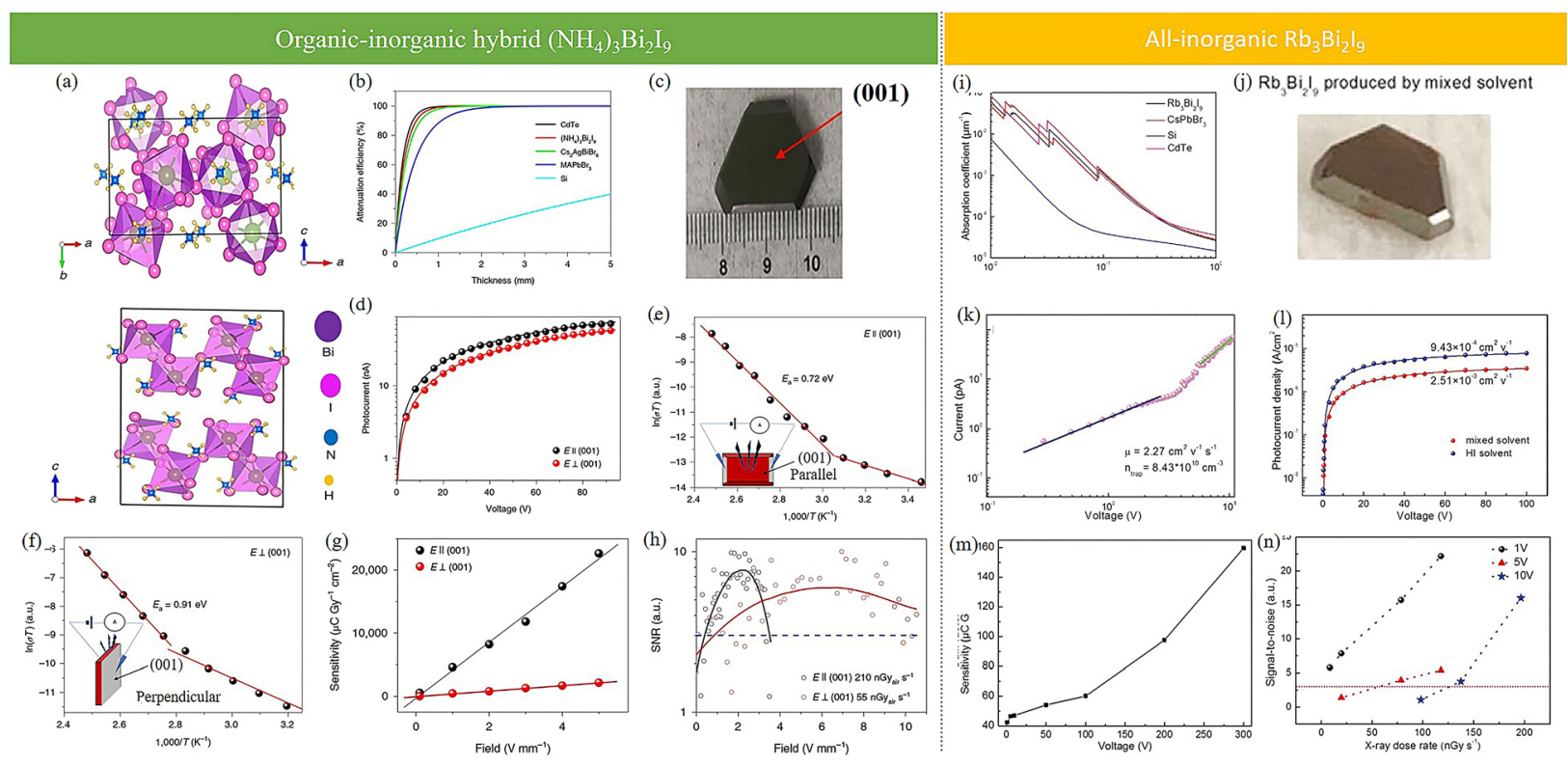

Figure 11: 2D Bi-based perovskite variants for $\mathrm{X}$-ray direction.

(a)-(h) characterize the anisotropic X-ray detection of $\left(\mathrm{NH}_{4}\right)_{3} \mathrm{Bi}_{2} \mathrm{l}_{9}$. (i)-(n) characterize the X-ray detection of $\mathrm{Rb}_{3} \mathrm{Bi} \mathrm{I}_{2} \mathrm{l}_{9}$. (a) Schematic illustration of the $\left(\mathrm{NH}_{4}\right)_{3} \mathrm{Bi}_{2} \mathrm{l}_{9}$ crystal structure along the $c$ and $b$ axes. (b) Comparison of the thickness-dependent attenuation efficiencies of $\left(\mathrm{NH}_{4}\right)_{3} B i_{2} l_{9}$, $\mathrm{Cs}_{2} \mathrm{AgBiBr}_{6}, \mathrm{MAPbBr}_{3}, \mathrm{CdTe}$, and Si towards $50 \mathrm{keV}$ X-ray photons. (c) Photograph of $\left(\mathrm{NH}_{4}\right)_{3} \mathrm{Bi}_{2} \mathrm{l}_{9}$ single crystal. (d) Bias voltage-dependent photoconductivity of $\left(\mathrm{NH}_{4}\right)_{3} \mathrm{Bi}_{2} \mathrm{l}_{9}$ along the directions parallel and perpendicular to the (001) plane. (e)-(f) Temperature-dependent conductivity of $\left(\mathrm{NH}_{4}\right)_{3} \mathrm{Bi}_{2} \mathrm{l}_{9}$ along the derections parallel (e) and perpendicular $(\mathrm{f})$ to the (001) surface for fitting the activation energy of ion migration. (g) X-ray sensitivities and (h) signal-to-noise ratio (SNR) of the $\mathrm{Ag} /\left(\mathrm{NH}_{4}\right)_{3} \mathrm{Bi}_{2} \mathrm{l}_{9} / \mathrm{Ag}$ device in the directions parallel and perpendicular to the (001) surface. The blue dotted line denotes a benchmark SNR of 3. The detection limits are $210 \mathrm{nG}_{\text {air }} \mathrm{s}^{-1}$ for parallel and $55 \mathrm{nG}$ air $\mathrm{s}^{-1}$ for perpendicular devices, respectively. Reproduced with permission. Copyright 2019, Springer Nature [30]. (i) The photon energy-dependent absorption coefficient of $\mathrm{Rb}_{3} \mathrm{Bi}_{2} \mathrm{l}_{9}$ in comparison with a few representative semiconductors. (j) Photograph of the solution-grown $\mathrm{Rb}_{3} B \mathrm{~B}_{2} \mathrm{l}_{9}$ single crystal. (k) $I-V$ curve fitted by the space charge-limited current (SCLC) model. (l) Photoconductivity of the $\mathrm{Rb}_{3} \mathrm{Bi}_{2} \mathrm{l}_{9}$ single crystal to calculate the $\mu \tau$ product. $(\mathrm{m})$ The dependence of X-ray sensitivity on the bias voltage. (n) Signal-to-noise ratio of the device upon different bias voltages. The dashed line represents the baseline ratio of 3 according to the IUPAC definition. Adapted with permission. Copyright 2020, Wiley-VCH Verlag [153].

parallel and perpendicular to the (001) surface were measured, the dependences of the photocurrent on the bias voltage are plotted in Figure 11d. A fitting with modified Hecht equation is adopted to calculate the $\mu \tau$ products, and vastly different values of $1.1 \times 10^{-2} \mathrm{~cm}^{2} \mathrm{~V}^{-1}$ and $4.0 \times 10^{-3} \mathrm{~cm}^{2} \mathrm{~V}^{-1}$ are obtained for the parallel direction and the perpendicular direction, respectively, which confirms the anisotropy and a better charge transport in the in-plane direction. It should be noted that the $\mu \tau$ products are commensurate with those of $\mathrm{MAPbBr}_{3}$ and CdZnTe SCs $[117,154]$. The ion migration behavior was further evaluated by the energy barrier, which can be calculated according to the temperature-dependent conductivity. As shown in Figure 11e and $\mathrm{f}$, in the low-temperature range the charge carriers dominate the conductivity, while in the high-temperature range the ion migration is activated to take over the dominant role. Energy barriers of 720 and $910 \mathrm{meV}$ are obtained for the in-plane and out-of-plane directions, respectively, the values are significantly larger than that of the widely-studied $\mathrm{MAPbI}_{3}(290 \mathrm{meV})$ and suggest a greatly suppressed ion migration behavior [155].

Indeed, the large $\mu \tau$ product gives rise to efficient charge collection and thereby a high sensitivity towards $\mathrm{X}$-ray. The $\left(\mathrm{NH}_{4}\right)_{3} \mathrm{Bi}_{2} \mathrm{I}_{9}$ device in a planar configuration of $\mathrm{Ag} /\left(\mathrm{NH}_{4}\right)_{3} \mathrm{Bi}_{2} \mathrm{I}_{9} / \mathrm{Ag}$ achieves a commendable sensitivity of $0.8 \times 10^{4} \mu \mathrm{C} \mathrm{Gy}{ }_{\text {air }}{ }^{-1} \mathrm{~cm}^{-2}$ under only a $2 \mathrm{~V} \mathrm{~mm}^{-1}$ electric field (Figure 11g), this sensitivity is almost two orders of magnitude larger than that of $\mathrm{Cs}_{2} \mathrm{AgBiBr}_{6}$ single crystal detectors and three orders of magnitude higher than traditional $\alpha$-Se detectors $[136,139]$. The perpendicular direction also reveals a decent sensitivity of $803 \mu \mathrm{C} \mathrm{Gy} \mathrm{air}^{-1} \mathrm{~cm}^{-2}$, howbeit much smaller than that of the in-plane direction, it still represents a high X-ray sensitivity. In fact, the sensitivity can be further improved by increasing the bias voltage, as long as the $\left(\mathrm{NH}_{4}\right)_{3} \mathrm{Bi}_{2} \mathrm{I}_{9}$ can endure higher electrical stresses, that is where the suppressed ion migration plays a positive role. Fundamentally, the low trap state concentration in single crystals accounts for a 
suppressed 1/f noise current, and the large bulk resistance yields a small shot noise current and thermal noise current, hence a low detection limit can be realized [156]. The dependence of signal-to-noise ratio (SNR) on bias voltage along the parallel and perpendicular directions are shown in Figure 11h, following an IUPAC standard baseline of SNR $>3$ [140], minimum dose rates of $210 \mathrm{nGy}_{\text {air }} \mathrm{s}^{-1}$ for the in-plane direction and $55 \mathrm{nGy} \mathrm{yir}^{-1}$ for the out-of-plane direction are obtained. Consistently, the less effective charge transport in the out-of-plane direction, although being less good in terms of sensitivity, enables a lower detection limit, the value is on par with that of $\mathrm{Cs}_{2} \mathrm{AgBiBr}_{6}$ (59.7 $\mathrm{nGy}_{\text {air }} \mathrm{s}^{-1}$ ) [136]. Therefore, the anisotropy in X-ray detection equips the $\left(\mathrm{NH}_{4}\right)_{3} \mathrm{Bi}_{2} \mathrm{I}_{9}$ with the capability to be utilized in different conditions, e.g., the perpendicular device favors medical inspection because the low direction limit reduces X-ray exposure to the human body, while the highly sensitive parallel device is in support of detecting radiation leakage, baggage checks and so forth.

Tang's group further introduced fully-inorganic $\mathrm{Rb}_{3} \mathrm{Bi}_{2} \mathrm{I}_{9}$, which owns the same $2 \mathrm{D}$ layered crystal structure as $\left(\mathrm{NH}_{4}\right)_{3} \mathrm{Bi}_{2} \mathrm{I}_{9}$, for $\mathrm{X}$-ray detection. The authors compared the absorption coefficients of $\mathrm{Rb}_{3} \mathrm{Bi}_{2} \mathrm{I}_{9}, \mathrm{CsPbBr}_{3}$, $\mathrm{Si}$, and $\mathrm{CdTe}$ in the range of $10^{-2}-10^{0} \mathrm{MeV}$ photon energy (Figure 11i). It shows that $\mathrm{Rb}_{3} \mathrm{Bi}_{2} \mathrm{I}_{9}$ outcompetes $\mathrm{CsPbBr}_{3}$ and $\mathrm{Si}$ across the entire energy range, regardless of the resonant absorption at the $K, L$, and $M$ edges. $\mathrm{Rb}_{3} \mathrm{Bi}_{2} \mathrm{I}_{9}$ single crystals were then grown with an optimized approach (in Figure 11j), and the SCLC method was carried out to learn its semiconducting quality (Figure 11k). A low trap density of $8.43 \times 10^{10} \mathrm{~cm}^{-3}$ was attained that shows less lattice imperfections, acquired was a moderate charge mobility of $2.27 \mathrm{~cm}^{2} \mathrm{~V}^{-1} \mathrm{~s}^{-1}$ as well, which reveals the fast charge transport in the $\mathrm{Rb}_{3} \mathrm{Bi}_{2} \mathrm{I}_{9}$ single crystal. The $\mu \tau$ product was further simulated to be $2.51 \times 10^{-3} \mathrm{~cm}^{2} \mathrm{~V}^{-1}$ (Figure 111), it points out a combination of fast charge transport and a long charge lifetime that favor the charge collection. As a consequence, the $\mathrm{Rb}_{3} \mathrm{Bi}_{2} \mathrm{I}_{9} \mathrm{SC}$ detector achieved adorable sensitivities. A sensitivity of 42.5 $\mu \mathrm{C} \mathrm{Gy}_{\text {air }}{ }^{-1} \mathrm{~cm}^{-2}$ could be realized under a low electric field of $1 \mathrm{~V} \mathrm{~mm}^{-1}$, the value further ascends to 159.7 $\mu \mathrm{C} \mathrm{Gy}_{\text {air }}{ }^{-1} \mathrm{~cm}^{-2}$ when increasing the bias to $300 \mathrm{~V} \mathrm{~mm}^{-1}$, the bias voltage-dependent sensitivity is shown in Figure 11m. Further, it was found that a higher bias voltage exacerbates the noise current, and a low detection limit of $<8.32 \mathrm{nGy}_{\text {air }} \mathrm{s}^{-1}(\mathrm{SNR}=5.8$, Figure 11n) was acquired under a low bias of $1 \mathrm{~V}$ (1 $\mathrm{V} \mathrm{mm}^{-1}$ electric field).

By engineering the composition of Bi-based perovskite variants, the conformation can be further changed. Tao et al. reported a bismuth-iodide hybrid of $\left(\mathrm{H}_{2} \mathrm{MDAP}\right) \mathrm{Bi}_{5}$
$\left(\mathrm{H}_{2} \mathrm{MDAP}=\right.$ Nmethyl-1,3-diaminopropanium, $\mathrm{CH}_{3} \mathrm{NHCH}_{2}$ $\mathrm{CH}_{2} \mathrm{CH}_{2} \mathrm{NH}_{2}^{2+}$ ) with an intrinsic 1D structure, where the $\mathrm{BiI}_{6}$ octahedra are connected in a zigzag fashion [157]. It belongs to the orthorhombic crystal system with a polar space group of $P n a 2_{1}(200 \mathrm{~K})$, corresponding perspectives of the crystal structure are shown in Figure 12a and b. Density functional theory (DFT) simulation was carried out to understand the electrical structure, the result indicates an indirect bandgap of $2.035 \mathrm{eV}$, the value is a bit larger than the experimental result of $\sim 1.83 \mathrm{eV}$. Besides, it is found that the topmost valence bands mainly consist of I $5 p$ orbitals with a small contribution from $\mathrm{Bi} 6 \mathrm{~s}$ orbitals, while the lowest conduction bands primarily result from the combination of the I $5 p$ and $\mathrm{Bi} 6 p$ orbitals, thus confirming $\left[\mathrm{BiI}_{6}\right]$ octahedra as the functional units akin to lead-halogen octahedron in lead halide perovskites [159]. To characterize the semiconducting properties as well as the capability for $\mathrm{X}$-ray sensing, high-quality bulk single crystals were grown. Intriguingly, via a facile solution method, a largesized single crystal of $9 \times 7 \times 4 \mathrm{~mm}^{3}$ could be obtained as shown in Figure 12c. The SCLC method was used to fathom the semiconducting attributes of the $\left(\mathrm{H}_{2} \mathrm{MDAP}\right) \mathrm{BiI}_{5}$ single crystal, the current as a function of the bias voltage is presented in Figure 12d. The evolution of current goes through the ohmic regime, trap-filled limited regime, and finally to the Child's regime as the electric field gradually increases. The trap state density can thereby be estimated to be $\sim 3.6 \times 10^{11} \mathrm{~cm}^{-3}$ according to the equation: $n_{\text {trap }}=2 \varepsilon_{0} \varepsilon V_{\mathrm{TFL}} / q L^{2}$, where $\varepsilon_{0}$ denotes the vacuum dielectric constant, $\varepsilon$ denotes the relative dielectric constant of $\left(\mathrm{H}_{2} \mathrm{MDAP}\right) \mathrm{BiI}_{5}, q$ is the elemental charge, and $L$ is the channel length. Indeed, the low trap density confirms the high quality of the single crystal. Further, the current respects a quadratic dependence on the bias, as described by the relationship: $J_{D}=9 \varepsilon_{0} \varepsilon \mu V^{2} / 8 L^{3}$, where $J_{D}$ is dark current density, and $\mathrm{V}$ is the applied voltage. The charge mobility $\mu$ of $\left(\mathrm{H}_{2} \mathrm{MDAP}\right) \mathrm{BiI}_{5}$, although electron or hole is not stated, is thus calculated to be $\sim 1.42 \mathrm{~cm}^{2} \mathrm{~V}^{-1} \mathrm{~s}^{-1}$, which is on the same magnitude of $\mathrm{CsPbBr}_{3}\left(1.04 \mathrm{~cm}^{2} \mathrm{~V}^{-1} \mathrm{~S}^{-1}\right)$ [160], $\mathrm{Cs}_{2} \mathrm{AgBiBr}_{6}$ $\left(\sim 3.17 \mathrm{~cm}^{2} \mathrm{~V}^{-1} \mathrm{~S}^{-1}\right)$ [136], and FAPbI $3\left(\sim 4.4 \mathrm{~cm}^{2} \mathrm{~V}^{-1} \mathrm{~S}^{-1}\right)$ [161]. The X-ray absorption coefficient of $\left(\mathrm{H}_{2} \mathrm{MDAP}\right) \mathrm{Bi}_{5}$ was then calculated to compare with those of Si and CdTe in a wide range of photon energy range, the result shows that $\left(\mathrm{H}_{2} \mathrm{MDAP}\right) \mathrm{BiI}_{5}$ outperforms these two references (Figure 12e). The efficient X-ray absorption and charge transport allow X-ray sensing with $\left(\mathrm{H}_{2} \mathrm{MDAP}\right) \mathrm{BiI}_{5}$. As shown in Figure 12f, a sensitivity of $1.1 \mu \mathrm{C} \mathrm{Gy}{ }_{\text {air }}{ }^{-1} \mathrm{~cm}^{-2}$ (2.5 $\mathrm{V} \mathrm{mm}^{-1}$, @70 keV photon energy) can be derived with the linear dependence of photocurrent upon the dose rate, this value is inferior to those of the abovementioned counterparts, which can be ascribed partly to the lower 
(a)

(d)

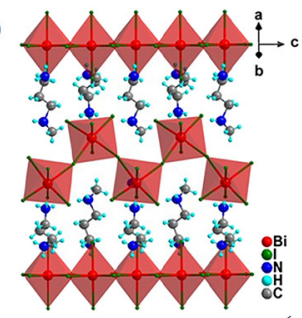

(b)

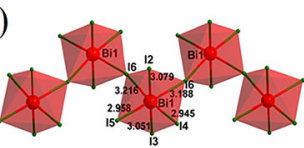

(c)

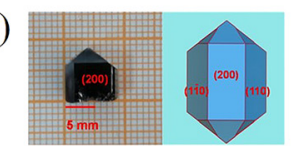

$(\mathrm{e})$

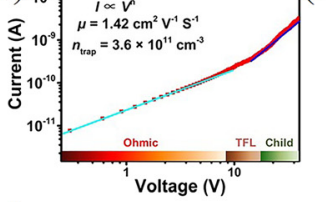

(g)

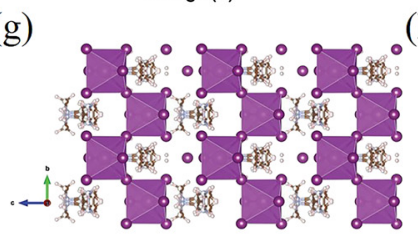

(h)

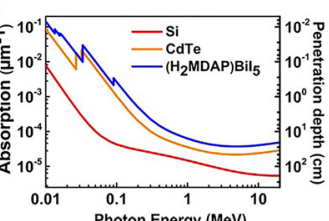

Photon Energy (MeV)
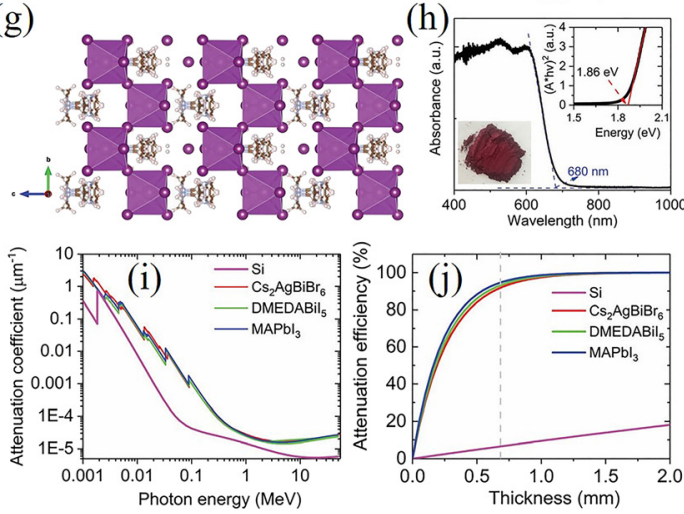
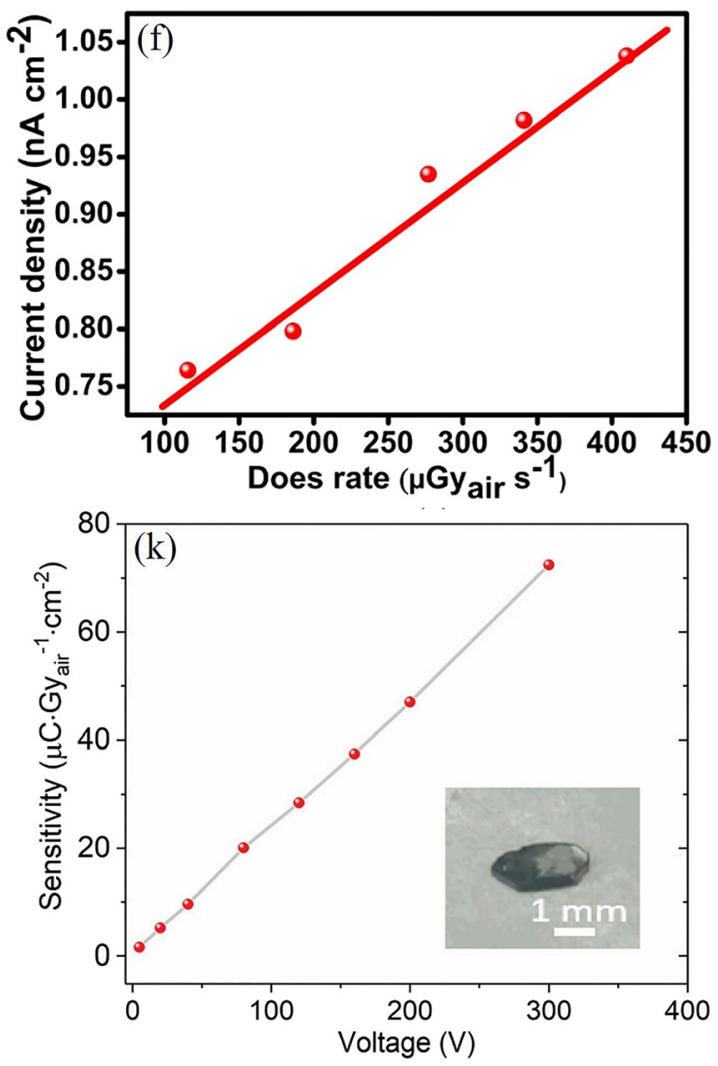

Figure 12: 1D Bi-based perovskite variants for $\mathrm{X}$-ray detection.

(a) Schematic view of the crystal structure of $\left(\mathrm{H}_{2} \mathrm{MDAP} \mathrm{Bil}_{5}\right.$ at $200 \mathrm{~K}$. (b) Schematic illustration of the inorganic Bil 6 octahedra connected in a zigzag manner. (c) bulk crystal of $\left(\mathrm{H}_{2} \mathrm{MDAP} \mathrm{Bi}_{5}\right.$ (left) and the simulated crystal shape (right). (d) Logarithmic $I-V$ curve of ( $\left.\mathrm{H}_{2} \mathrm{MDAP}\right) \mathrm{Bi}{ }_{5}$ for simulating the trap state density and the charge mobility according to the SCLC method. (e) Comparison of photon energy-dependent absorption coefficients of $\left(\mathrm{H}_{2} \mathrm{MDAP} \mathrm{Bi}_{5}\right.$, Si, and $\mathrm{CdTe}$. (f) The X-ray dose rate-dependent photocurrents. Reproduced with permission.

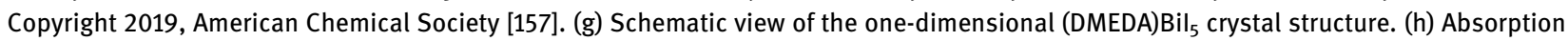
spectrum of (DMEDA)Bil ${ }_{5}$ in the form of powder. Left inset: The photograph of the powder. Right inset: The Tauc plot to simulate the bandgap. (i) Comparison of the simulated attenuation coefficients of (DMEDA)Bil ${ }_{5}, \mathrm{Cs}_{2} \mathrm{AgBiBr}_{6}, \mathrm{MAPbl}_{3}$, and Si versus photon energy. (j) Thicknessdependent attenuation efficiency of (DMEDA)Bil ${ }_{5}, \mathrm{Cs}_{2} \mathrm{AgBiBr}_{6}, \mathrm{MAPbl}_{3}$, and Si towards X-ray of $50 \mathrm{keV}$ photon energy. The dotted line denotes a thickness of $690 \mathrm{~mm}$. (k) Photocurrent as a function of X-ray dose rate. Inset: the photograph of the (DMEDA)Bil ${ }_{5}$ single crystal. Reproduced with permission. Copyright 2020, the Royal Society of Chemistry [158].

electric filed and the higher photon energy for measurement and, more importantly, a less efficient charge collection associated with the intrinsic electronic structure of $\left(\mathrm{H}_{2} \mathrm{MDAP}^{\mathrm{M}} \mathrm{BiI}_{5}\right.$.

Likewise, Tang's group also introduced a class of Bibased perovskite variant- (DMEDA)BiI ${ }_{5}\left(\mathrm{DMEDA}^{2+}\right.$ : $\mathrm{CH}_{3} \mathrm{NH}_{3} \mathrm{CH}_{2} \mathrm{CH}_{2} \mathrm{NH}_{3} \mathrm{CH}_{3}{ }^{2+}$ ) with a one-dimensional conformation [158]. Similar to the $\left(\mathrm{H}_{2} \mathrm{MDAP}\right) \mathrm{BiI}_{5}$ above, it also pertains to the orthorhombic system but a Pnma space group (Figure $12 \mathrm{~g}$ ). The $\left[\mathrm{BiI}_{6}\right]$ octahedra are cornerconnected to form a chain, the adjacent chains are separated by the DMEDA molecules. The sample in the form of ground powders was used to measure the bandgap via Tauc plot. Observing a sharp rise in absorption above the onset, the authors assumed a direct bandgap and fitted the value to be $\sim 1.86 \mathrm{eV}$ (Figure 12h). The photon energydependent X-ray absorption coefficient and the thicknessdependent attenuation efficiency (for $50 \mathrm{keV}$ photons) were calculated as shown in Figure 12i and $\mathrm{j}$, thanks to the high $Z$ of $\mathrm{Bi}$, the X-ray absorption of (DMEDA)Bil ${ }_{5}$ is closely commensurate with $\mathrm{MAPbI}_{3}$ and $\mathrm{Cs}_{2} \mathrm{AgBiBr}_{6}$ counterparts and is much better than Si. A 690 mm-thick (DMEDA)BiI is able to consume $93.2 \%$ X-ray photons of $50 \mathrm{keV}$ energy. A device in a basis of the single crystal was then fabricated, and the X-ray sensitivities of $1.6 \mu \mathrm{C} \mathrm{Gy} \mathrm{air}^{-1} \mathrm{~cm}^{-2}$ at a $7.24 \mathrm{~V} \mathrm{~mm}^{-1}$ electric field and $72.5 \mu \mathrm{C} \mathrm{Gy} \mathrm{yair}^{-1} \mathrm{~cm}^{-2}$ at a $494 \mathrm{~V} \mathrm{~mm}^{-1}$ electric field were obtained (Figure 12k). Overall, the one-dimensional conformation does not afford as good X-ray sensitivity as parental lead-based halide perovskites. 
The Bi-based perovskite variants also include a OD motif, $\mathrm{Cs}_{3} \mathrm{Bi}_{2} \mathrm{I}_{9}, \mathrm{MA}_{3} \mathrm{Bi}_{2} \mathrm{I}_{9}$, and $\mathrm{AgBi}_{2} \mathrm{I}_{7}$ for example, the crystal structure of the representative $0 \mathrm{D} \mathrm{Cs}_{3} \mathrm{Bi}_{2} \mathrm{I}_{9}$ is shown in Figure 13a. The Bi-I units are isolated from each other, which indicates a weak electronic interaction and blunt charge transport. Therefore, the OD variants have been unfavorable for optoelectronic/electronic applications. However, recent papers showed that the $0 \mathrm{D} \mathrm{Cs}_{3} \mathrm{Bi}_{2} \mathrm{I}_{9}$ can construct sensitive $\mathrm{X}$-ray detectors when prepared into high-quality single crystals. To obtain such high-quality $\mathrm{Cs}_{3} \mathrm{Bi}_{2} \mathrm{I}_{9}$ single crystals, Liu's group develop a nucleation-controlled solution method, a typical large-sized $\mathrm{Cs}_{3} \mathrm{Bi}_{2} \mathrm{I}_{9}$ single crystal is shown in Figure 13b inset. The Tauc plot method was carried out to estimate the bandgap (Figure 13b), and a value of $1.96 \mathrm{eV}$ was obtained. The boundary-free single crystal offers a benign electronic structure for charge transport, estimation of the $\mu \tau$ product by the bias-dependent X-ray induced photocurrent was carried to confirm this. A decent $\mu \tau$ product of $7.97 \times 10^{-4} \mathrm{~cm}^{-2} \mathrm{~V}^{-1}$ was obtained using a modified Hecht equation, the result indicates an advantageous harvest of photogenerated charges. Further, the capability of absorbing $\mathrm{X}$-ray photons is quantified and compared with that of several representative semiconductors, the photon energydependent X-ray absorption coefficient is shown in Figure 13c. It can be observed that the absorption coefficient of $\mathrm{Cs}_{3} \mathrm{Bi}_{2} \mathrm{I}_{9}$ is a bit higher than CsI and CdTe, and is much higher than

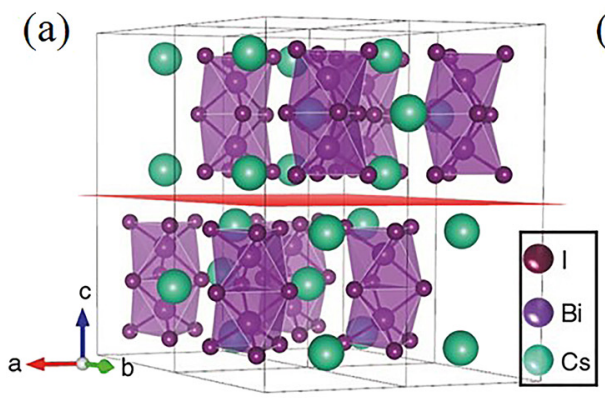

(d)
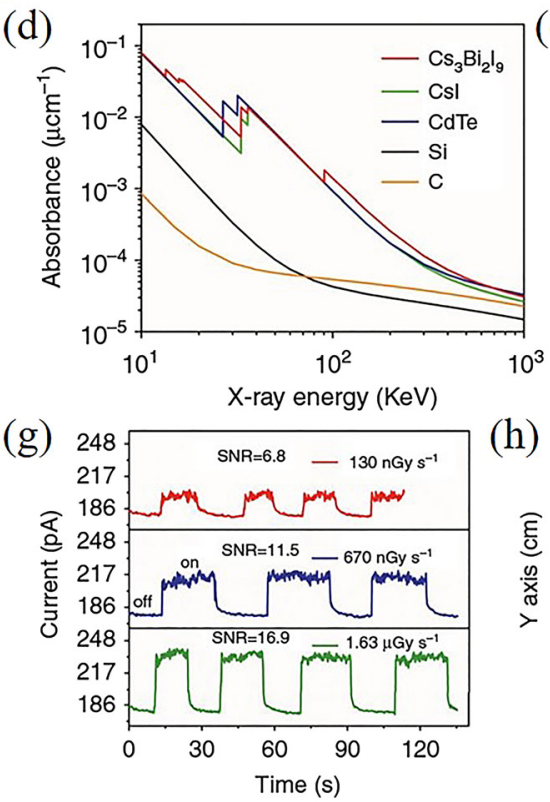

(h) (b)

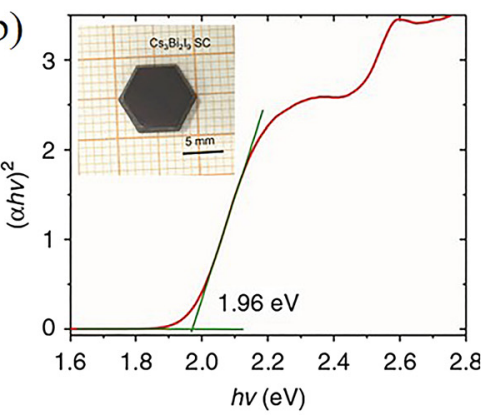

(e)
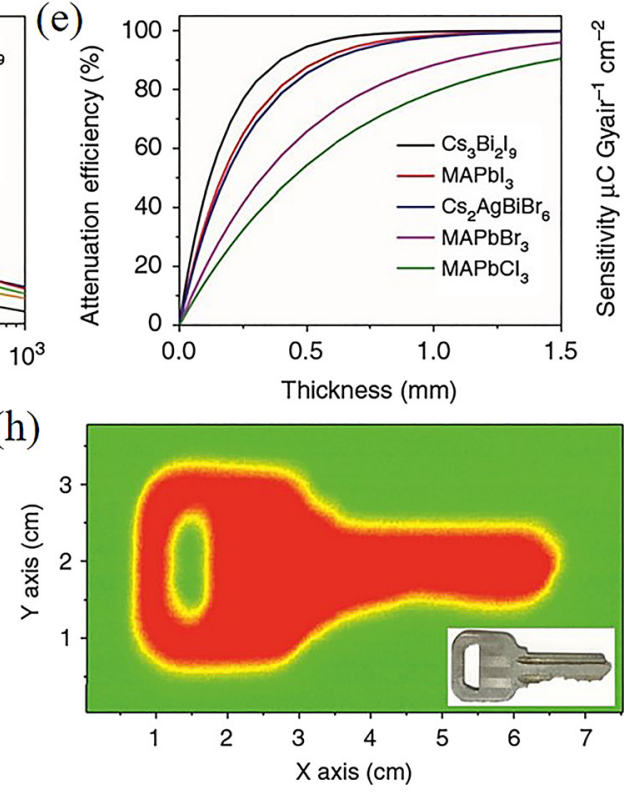
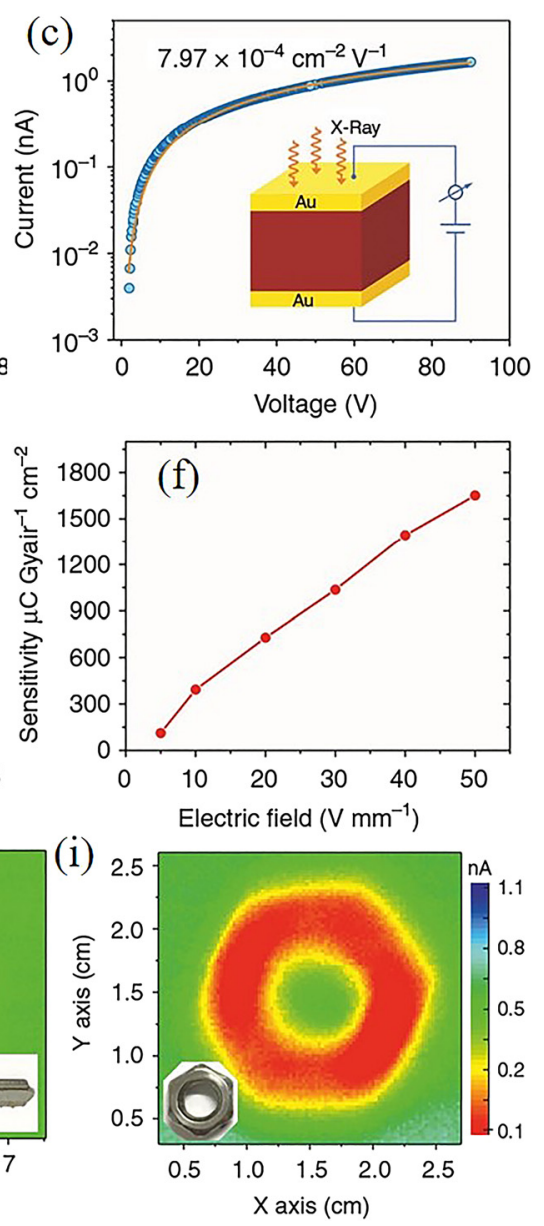

Figure 13: $0 \mathrm{D}$ Bi-based perovskite variants $\left(\mathrm{Cs}_{3} \mathrm{Bi}_{2} \mathrm{I}_{9}\right)$ for $\mathrm{X}$-ray detection.

(a) Schematic view of the $0 \mathrm{D}$ Bi-based perovskite variant. $\mathrm{Cs}_{3} \mathrm{Bi}_{2} \mathrm{I}_{9}$ and $\mathrm{MA}_{3} \mathrm{Bi}_{2} \mathrm{I}_{9}$ respect the same crystal structure. (b) Estimation of the bandgap of $\mathrm{Cs}_{3} \mathrm{Bi}_{2} \mathrm{I}_{9}$ with Tauc plot from the absorption spectrum. Inset: Photograph of a representative $\mathrm{Cs}_{3} \mathrm{Bi}_{2} \mathrm{l}_{9}$ single crystal. (c) Estimation of the $\mu \tau$ product of the $\mathrm{Cs}_{3} \mathrm{Bi}_{2} \mathrm{I}_{9}$ single crystal by photoconductivity measurement. Inset: Schematic view of the device structure. (d) Photon energy-dependent X-ray absorption coefficients of $\mathrm{Cs}_{3} \mathrm{Bi}_{2} \mathrm{I}_{9}, \mathrm{Csl}, \mathrm{CdTe}$, Si, and carbon. (e) Comparison of the thickness-dependent attenuation efficiency of $\mathrm{Cs}_{3} \mathrm{Bi}_{2} \mathrm{I}_{9}, \mathrm{MAPbl}_{3}, \mathrm{Cs}_{2} \mathrm{AgBiBr}_{6}, \mathrm{MAPbBr}_{3}, \mathrm{MAPbCl}_{3}$, Si, and carbon towards X-ray photons of $40 \mathrm{keV}$ energy. (f) Sensitivity of the $\mathrm{Cs}_{3} \mathrm{Bi}_{2} \mathrm{I}_{9}$ single crystal detector under various electric fields. (g) Photocurrent response of the $\mathrm{Cs}_{3} \mathrm{Bi}_{2} \mathrm{I}_{9}$ single crystal device upon different $\mathrm{X}$-ray

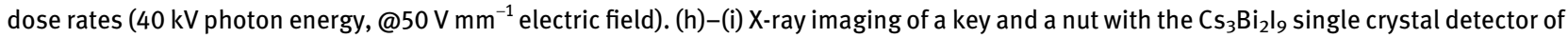
$1 \times 1 \mathrm{~mm}^{2}$ (50 V mm $\mathrm{m}^{-1}$ electric field, $36.2 \mu \mathrm{Gy}_{\text {air }} \mathrm{s}^{-1} \mathrm{X}$-ray dose rate). Adapted with permission. Copyright 2020, Springer Nature [102]. 
commercial carbon and Si. A thickness-dependent X-ray attenuation efficiency (Figure 13d) further reveals the superiority of $\mathrm{Cs}_{3} \mathrm{Bi}_{2} \mathrm{I}_{9}$, it shows a stronger energy consumption than the other perovskite references at the same thickness. Quantificationally, a $\mathrm{Cs}_{3} \mathrm{Bi}_{2} \mathrm{I}_{9}$ single crystal of $0.5 \mathrm{~mm}$ thick is able to attenuate $94.7 \%$ of the incident X-ray photons, comparing to $87.7 \%$ in $\mathrm{MAPbI}_{3}, 85.7 \%$ in $\mathrm{Cs}_{2} \mathrm{AgBiBr}_{6}, 65.9 \%$ in $\mathrm{MAPbBr}_{3}$, and $54.2 \%$ in $\mathrm{MAPbCl}_{3}$ (Figure 13e). The dependence of sensitivity on the electric field is shown in Figure $13 f$. At $50 \mathrm{~V} \mathrm{~mm}^{-1}$, the sensitivity reaches up to $1652.3 \mu \mathrm{C} \mathrm{Gy} \mathrm{air}^{-1} \mathrm{~cm}^{-2}$, which is higher than that of $\alpha$-Se detectors ( $\left.440 \mu \mathrm{C} \mathrm{Gy}_{\text {air }}{ }^{-1} \mathrm{~cm}^{-2}\right)$, measured under a significantly higher electric field of $15000 \mathrm{~V} \mathrm{~mm}^{-1}$ [162], by a margin of 3.7 times. Figure $13 \mathrm{~g}$ presents the I-t response of the $\mathrm{Cs}_{3} \mathrm{Bi}_{2} \mathrm{I}_{9}$ single crystal upon alterative turning-on and turn-off of the $\mathrm{X}$-ray radiation, the electric field was fixed at $50 \mathrm{~V} \mathrm{~mm}^{-1}$. The SNR was calculated accordingly to be 6.8 when the $\mathrm{Cs}_{3} \mathrm{Bi}_{2} \mathrm{I}_{9}$ single crystal detector was exposed to a dose rate of $130 \mathrm{nGy}_{\text {air }} \mathrm{s}^{-1}$. A lower SNR of 3 defines the detection limit, which is reasonably deduced to be lower than the dose rate of $130 \mathrm{nGyair} \mathrm{s}^{-1}$. The value is approximately 42 times lower than the requirement for regular medical diagnostics $\left(5.5 \mu \mathrm{Gy}_{\text {air }} \mathrm{s}^{-1}\right)$ [142]. The low detection limit provides the base for the X-ray imaging capability for the $\mathrm{Cs}_{3} \mathrm{Bi}_{2} \mathrm{I}_{9}$ single crystal. As shown in Figure $13 \mathrm{~h}$ and i, the obtained images of a metallic key and a nut were faithfully reproduced with distinct color contrast. A higher spatial resolution can be expected with reduced test distance and pixel size [163]. Liu's group further unraveled that the $0 \mathrm{D}$ motif renders a feeble ion migration, which allows a high operating bias voltage for improving the sensitivity towards X-ray [149].

Instead of the single crystal that necessitates careful control over the synthesis, Tie et al. adopted a powder form $\mathrm{MA}_{3} \mathrm{Bi}_{2} \mathrm{I}_{9}\left(\mathrm{MA}^{+}=\mathrm{CH}_{3} \mathrm{NH}_{2}^{+}\right)$that can be facilely prepared [164]. The $\mathrm{MA}_{3} \mathrm{Bi}_{2} \mathrm{I}_{9}$ powders were further compressed into a polycrystalline wafer by cold isostatic pressure equipment, as shown in Figure 14a inset. A bandgap of $2.08 \mathrm{eV}$ can be obtained by Tauc plot (Figure 14a), and a moderate $\mu \tau$ product of $4.6 \times 10^{-5} \mathrm{~cm}^{2} \mathrm{~V}^{-1}$ was estimated according to the photocurrent-bias relationship with a fitting with the Hecht equation (Figure 14b). This value is two order of magnitude lower than that of the $\mathrm{MA}_{3} \mathrm{Bi}_{2} \mathrm{I}_{9}$ single crystal $\left(2.8 \times 10^{-3}\right.$ and $1.2 \times 10^{-3} \mathrm{~cm}^{2} \mathrm{~V}^{-1}$ for the in-plane and out-ofplane directions) by the same group [31], which implies a tradeoff between the fabrication convenience and the charge transport capability. Advantageously, $\mathrm{MA}_{3} \mathrm{Bi}_{2} \mathrm{I}_{9}$ endows a strong $\mathrm{X}$-ray absorption capability, the photon energy-dependent absorption coefficient, and the thickness-related attenuation efficiency towards $35.5 \mathrm{keV}$ photons are shown in Figure $14 \mathrm{C}$ and $\mathrm{d}$ in comparison with $\alpha$-Se, $\mathrm{Cd}_{0.9} \mathrm{Zn}_{0.1} \mathrm{Te}$ (CZT), $\mathrm{MAPbBr}_{3}$, and $\mathrm{CsPbBr}_{3}$. The strong X-ray absorption contributes to a sensitive response to $\mathrm{X}$-ray, the $I-t$ measurement upon X-ray irradiation of the $\mathrm{MA}_{3} \mathrm{Bi}_{2} \mathrm{I}_{9}$ wafer is shown in Figure 14e. The signal current density $\left(J_{s}\right)$ was calculated as $J_{s}=J_{p}-J_{d}\left(J_{p}\right.$ and $J_{d}$ are the average photocurrent density and the average dark current density, respectively), and the noise current was defined as $J_{n}=\sqrt{\frac{1}{N} \sum_{i}^{N}\left(J_{i}-J_{p}\right)^{2}}\left(U_{i}\right.$ is the instant photocurrent, $N$ is the number of data points used). Therefore, the SNR could be calculated as SNR $=J_{s} / J_{n}$, the SNR values $\left(@ 70 \mathrm{~V} \mathrm{~mm}^{-1}\right.$ electric field) upon different X-ray dose rates are presented in Figure 14f. Intercepted by a baseline of $S N R=3$, a favorable detection limit of $9.3 \mathrm{nGy}_{\text {air }} \mathrm{s}^{-1}$ can be obtained. Further, the X-ray sensitivity $(S)$ was calculated according to $S=q / D$ ( $q$ is the charge density, $D$ is the dose of X-ray), a value of $563 \mu \mathrm{C} \mathrm{Gy}{ }_{\text {air }}{ }^{-1} \mathrm{~cm}^{-2}$ was obtained under an electric field of $210 \mathrm{~V} \mathrm{~mm}^{-1}$, the sensitivity is much higher than the commercial $\alpha$-Se $\left(20 \mu \mathrm{C} \mathrm{Gyair}^{-1} \mathrm{~cm}^{-2}\right.$, @100, $\left.000 \mathrm{~V} \mathrm{~cm}^{-1}\right)$ [139].

In addition, the same group also reported the $\mathrm{AgBi}_{2} \mathrm{I}_{7}$ type 0D perovskite and explored its application in X-ray detection [165]. The crystal structure of $\mathrm{AgBi}_{2} \mathrm{I}_{7}$ is shown in Figure $14 \mathrm{~g}$ inset, each $\mathrm{Ag}^{+}$is coordinated with six $I^{-}$to form an octahedron, while each $\mathrm{Bi}^{3+}$ coordinates with eight $\mathrm{I}^{-}$to form a hexahedron. The thickness-related attenuation efficiency to $100 \mathrm{keV}$ photon is shown in Figure $14 \mathrm{~h}$, it infers that $\sim 97 \%$ of the incident X-rays can be absorbed by a $0.5 \mathrm{~mm}$ thick $\mathrm{AgBi}_{2} \mathrm{I}_{7}$. To verify the X-ray detection performance of the $\mathrm{AgBi}_{2} \mathrm{I}_{7}$ single crystals, the detectors with a device structure of $\mathrm{Au} / \mathrm{AgBi}_{2} \mathrm{I}_{7}$ single crystal/Au were fabricated. A detection limit of $72 \mathrm{nGy}_{\text {air }} \mathrm{s}^{-1}$ (Figure 14h) and a sensitivity up to $282.5 \mu \mathrm{C}$ Gyair ${ }^{-1} \mathrm{~cm}^{-2}$ (Figure 14i) were obtained, these results entitle $\mathrm{AgBi}_{2} \mathrm{I}_{7}$ to be another promising candidate for X-ray detection. In all, the X-ray detector parameters of Bi-based perovskite variants are comparatively listed in Table 3.

\section{Summary and outlook}

While lead-based halide perovskites are manifesting continuous breakthroughs in optoelectronic and photovoltaic applications, including the photodetector application centered here, the toxicity is a hidden danger that the market will finally confront. Lead-free perovskite alternatives are the vision of the field, and great efforts have been devoted to expanding the lead-free perovskite family. The substitution of lead easily engenders new lattice structures, oftentimes non-perovskite structures, and the semiconducting particularities vary as well. Respectable signs of progress have been achieved in utilizing these perovskite variants for the photodetection application. 

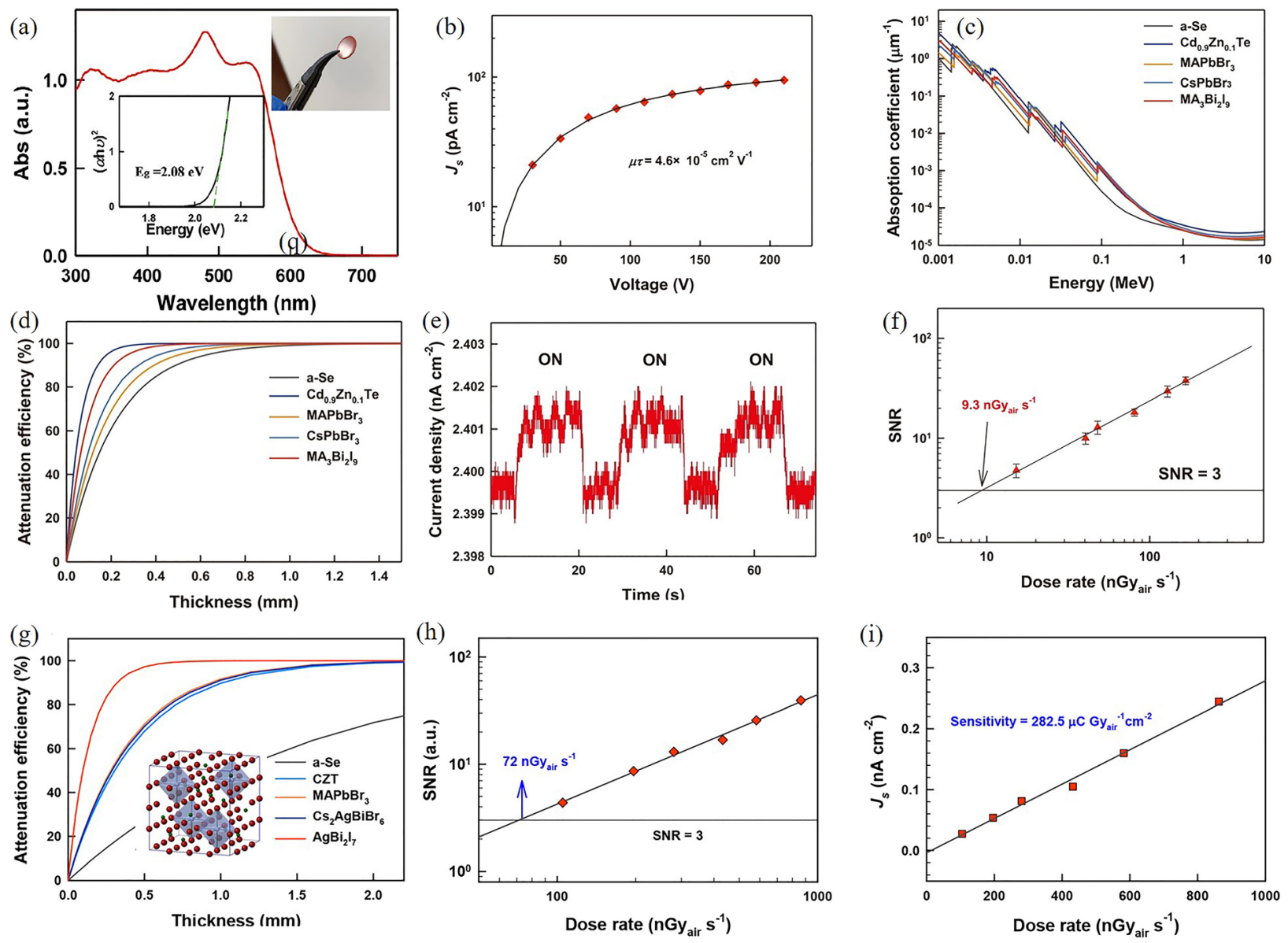

Figure 14: $0 \mathrm{D}$ Bi-based perovskite variants $\left(\mathrm{MA}_{3} \mathrm{Bi}_{2} \mathrm{I}_{9}\right.$ and $\left.A g B \mathrm{i}_{2} \mathrm{I}_{7}\right)$ for $\mathrm{X}$-ray detection.

(a) Absorption spectrum of polycrystalline $\mathrm{MA}_{3} \mathrm{Bi}_{2} \mathrm{l}_{9}$ wafer. Inset: Tauc plot to estimate the bandgap assuming a direct bandgap. (b) Estimation of the $\mu \tau$ product of the polycrystalline $\mathrm{MA}_{3} \mathrm{Bi}_{2} \mathrm{l}_{9}$ wafer by photoconductivity measurement. (c) Photon energy-dependent $\mathrm{X}$-ray absorption coefficients of a-Se, $\mathrm{Cd}_{0.9} \mathrm{Zn}_{0.1} \mathrm{Te}(\mathrm{CZT}), \mathrm{MAPbBr}_{3}, \mathrm{CsPbBr}_{3}$, and $\mathrm{MA}_{3} \mathrm{Bi}_{2} \mathrm{I}_{9}$. (d) Comparison of the thickness-dependent attenuation efficiencies of a-Se, CZT, $M A \mathrm{PbBr}_{3}, \mathrm{CsPbBr}_{3}$, and $\mathrm{MA}_{3} \mathrm{Bi}_{2} \mathrm{I}_{9}$ semiconductors towards X-ray photons of $35.5 \mathrm{keV}$ energy. (e) $l-t$ measurement of the $M A_{3} \mathrm{Bi}_{2} \mathrm{I}_{9}$ polycrystalline wafer under an electric field of $700 \mathrm{~V} \mathrm{~cm}^{-1}$ and an X-ray dose rate of $15.2 \mathrm{nGy}_{\text {air }} \mathrm{S}^{-1}$. (f) SNR versus dose rate of the device under $700 \mathrm{~V} \mathrm{~cm}^{-1}$ electric field. The error bars represent standard deviations. A detection limit of $9.3 \mathrm{nGy} \mathrm{s} \mathrm{can}^{-1}$ be derived from the fitting line at an SNR benchmark of 3. Adapted with permission. Copyright 2020, Wiley-VCH Verlag [164]. (g) Attenuation efficiency of a-Se, CZT, MAPbl ${ }_{3}$, $\mathrm{Cs}_{2} \mathrm{AgBiBr}_{6}$, and $\mathrm{AgBi}_{2} \mathrm{I}_{7}$ semiconductors to $100 \mathrm{keV} \mathrm{X}$-ray photons versus thickness, inset: crystal structure of $A g B i_{2} \mathrm{l}_{7}$. (h) $\mathrm{X}$-ray dose ratedependent signal-to-noise ratio (SNR) of the device. The detection limit of $72 \mathrm{nGy} \mathrm{s}^{-1}$ is derived from the slope of the fitting line with a signal-tonoise ratio of 3. (i) X-ray dose rate-dependent signal current density $\left(U_{s}\right)$ of the device. The X-ray sensitivity of the device is derived from the slope of the fitting line. Copyright 2020, the Royal Society of Chemistry.

Especially, the variants construct broadband photodetections ranging from NIR to UV light and even X-rays, so that numerous practical uses can be potentially realized with these variants.

However, the existing outcomes suggest usually inferior overall device performances compared to those based on lead halide perovskites. This can be attributed to the less good semiconducting properties in these perovskite variants, namely light absorption, charge mobility and lifetime, and especially resilience to structural imperfections. Innovative methodologies, probably vastly different from those developed for lead halide perovskites, are urgently needed to improve the material quality. In particular, it is can be easily noticed that many variants do not share the facile film fabrication as lead halide perovskites (e.g., Cu-based type [101]), howbeit some do (e.g., $\mathrm{Cs}_{2} \mathrm{AgBiBr}_{6}$ [87]), systematic strategies towards pure phase, high crystallinity, and sufficient passivation have not been established. Alternatively, single crystal is another form for photodetector 
Table 3: Summary of the X-ray detector parameters of Bi-based perovskite variants.

\begin{tabular}{|c|c|c|c|c|}
\hline Material & X-ray energy (eV) & Sensitivity $\left(\mu \mathrm{C} \mathrm{Gy} \mathrm{air}^{-1} \mathrm{~cm}^{-2}\right)$ & Detection limit (nGyair $\left.\mathbf{s}^{-1}\right)$ & Ref. \\
\hline \multirow[t]{2}{*}{$\left(\mathrm{NH}_{4}\right)_{3} \mathrm{Bi}_{2} \mathrm{I}_{9} \mathrm{SC}$} & $\leq 50 \mathrm{k}, E_{\text {peak }}=22 \mathrm{k}$ & $0.8 \times 10^{4}\left(\right.$ parallel, $\left.2 \mathrm{~V} \mathrm{~mm}^{-1}\right)$ & $210(-)$ & [30] \\
\hline & & 803 (vertical, $2 \mathrm{~V} \mathrm{~mm}^{-1}$ ) & $<55(-)$ & \\
\hline \multirow[t]{2}{*}{$\mathrm{Rb}_{3} \mathrm{Bi}_{2} \mathrm{l}_{9} \mathrm{SC}$} & $50 \mathrm{k}$ & $42.5\left(1 \mathrm{~V} \mathrm{~mm}^{-1}\right)$ & $<8.32\left(1 \mathrm{~V} \mathrm{~mm}^{-1}\right)$ & [153] \\
\hline & & $159.7\left(1 \mathrm{~V} \mathrm{~mm}^{-1}\right)$ & & \\
\hline$\left(\mathrm{H}_{2} \mathrm{MDAP}\right) \mathrm{Bil}_{5} \mathrm{SC}$ & $70 \mathrm{k}$ & $1.1\left(2.5 \mathrm{~V} \mathrm{~mm}^{-1}\right)$ & - & [157] \\
\hline \multirow[t]{2}{*}{ (DMEDA)Bil ${ }_{5} \mathrm{SC}$} & $50 \mathrm{k}$ & $1.6\left(7.24 \mathrm{~V} \mathrm{~mm}^{-1}\right)$ & - & [158] \\
\hline & & $72.5\left(494 \mathrm{~V} \mathrm{~mm}^{-1}\right)$ & & \\
\hline $\mathrm{Cs}_{3} \mathrm{Bi}_{2} \mathrm{l}_{9} \mathrm{SC}$ & $40 \mathrm{k}$ & $1652.3\left(50 \mathrm{~V} \mathrm{~mm}^{-1}\right)$ & $<130\left(50 \mathrm{~V} \mathrm{~mm}^{-1}\right)$ & [102] \\
\hline $\mathrm{Cs}_{3} \mathrm{Bi}_{2} \mathrm{l}_{9} \mathrm{SC}$ & $40 \mathrm{k}$ & $1947\left(60 \mathrm{~V} \mathrm{~mm}^{-1}\right)$ & $83\left(50 \mathrm{~V} \mathrm{~mm}^{-1}\right)$ & [149] \\
\hline $\mathrm{MA}_{3} \mathrm{Bi}_{2} \mathrm{I}_{9}$ wafer & $E_{\text {avg }}=35.5 \mathrm{k}$ & $563\left(210 \mathrm{~V} \mathrm{~mm}^{-1}\right)$ & $9.3\left(70 \mathrm{~V} \mathrm{~mm}^{-1}\right)$ & [164] \\
\hline $\mathrm{MA}_{3} \mathrm{Bi}_{2} \mathrm{I}_{9} \mathrm{SC}$ & - & 10,620 (out-of-plane, $48 \mathrm{~V} \mathrm{~mm}^{-1}$ ) & 0.62 & [31] \\
\hline $\mathrm{AgBi}_{2} \mathrm{I}_{7} \mathrm{SC}$ & $43 \mathrm{k}$ & $282.5\left(0.38 \mathrm{~V} \mathrm{~mm}^{-1}\right)$ & 72 & [165] \\
\hline$\alpha-S e$ & $20 \mathrm{k}$ & $20\left(10000 \mathrm{~V} \mathrm{~mm}^{-1}\right)$ & - & [139] \\
\hline
\end{tabular}

SC denotes single crystal.

applications and has been widely demonstrated in early papers, but given the largely different essence of each, insights into the crystal growth may still be in infancy currently. Finally, the photodetector is also regarded as an intermediate towards the photovoltaic device, in this regard, the lead-free alternatives, especially those with broadband photoresponse, are believed to possess great potential for solar cells as well, as have been presented by some inchoate researches [166]. The X-ray detection is of particular interest, some lead-free variants, mainly Bibased types in manifold conformations of 1D, 2D, and 3D hitherto have revealed comparable or even better figureof-merits than lead-based counterparts, as systematically introduced above.

Author contributions: F. C. organized and wrote this this manuscript, D. Y. contributed to information collection, discussion and paper writing. X. X and H. Z. supervised the review.

Research funding: This work was financially supported by the Natural Science Foundation of Jiangsu Province (BK20190443 and BK20160815), Young Elite Scientists Sponsorship Program by Jiangsu CAST (JS19TJGC132574), 2019 Overseas Students' Science and Technology Innovation Project Selection Funding of Nanjing, Fundamental Research Funds for the Central Universities (30919011298, 30919011299 and 30919012107), National Key R\&D Program of China (No. 2017YFA0305500), the National Natural Science Foundation of China (No. 61725402, 11604152, and 51672132), the National "ten thousand talents plan" leading talents (No. W03020394), the Six top talent innovation teams of Jiangsu Province (No. TD-XCL-004).

Conflict of interest statement: The authors declare no conflicts of interest regarding this article.

\section{References}

[1] M. R. Esmaeili-Rad and S. Salahuddin, "High performance molybdenum disulfide amorphous silicon heterojunction photodetector," Sci. Rep., vol. 3, p. 2345, 2013.

[2] D. Yu, F. Cao, Y. Gu, et al., "Broadband and sensitive twodimensional halide perovskite photodetector for full-spectrum underwater optical communication," Nano Res., vol. 14, pp. 1210-1217, 2020.

[3] K. Kawase, T. Shibuya, S. I. Hayashi, and K. Suizu, "THz imaging techniques for nondestructive inspections," CR Phys., vol. 11, pp. 510-518, 2010.

[4] C. Aghemo, L. Blaso, and A. Pellegrino, "Building automation and control systems: A case study to evaluate the energy and environmental performances of a lighting control system in offices," Autom. ConStruct., vol. 43, pp. 10-22, 2014.

[5] G. Konstantatos, "Current status and technological prospect of photodetectors based on two-dimensional materials," Nat. Commun., vol. 9, p. 5266, 2018.

[6] S. C. Dhanabalan, J. S. Ponraj, H. Zhang, and Q. Bao, "Present perspectives of broadband photodetectors based on nanobelts, nanoribbons, nanosheets and the emerging $2 \mathrm{D}$ materials," Nanoscale, vol. 8, pp. 6410-6434, 2016.

[7] W.-J. Yin, T. Shi, and Y. Yan, “Unique properties of halide perovskites as possible origins of the superior solar cell performance," Adv. Mater., vol. 26, pp. 4653-4658, 2014.

[8] G. Xing, N. Mathews, S. Sun, et al., “Long-range balanced electron- and hole-transport lengths in organic-inorganic $\mathrm{CH}_{3} \mathrm{NH}_{3} \mathrm{Pbl}_{3}$," Science, vol. 342, pp. 344-347, 2013.

[9] Q. Dong, Y. Fang, Y. Shao, et al., "Electron-hole diffusion lengths $>175 \mu \mathrm{m}$ in solution-grown $\mathrm{CH}_{3} \mathrm{NH}_{3} \mathrm{Pbl}_{3}$ single crystals," Science, vol. 347, pp. 967-970, 2015.

[10] Y. Bi, E. M. Hutter, Y. Fang, Q. Dong, J. Huang, and T. J. Savenije, "Charge carrier lifetimes exceeding $15 \mu \mathrm{s}$ in methylammonium lead iodide single crystals,” J. Phys. Chem. Lett., vol. 7, pp. 923-928, 2016.

[11] Q. A. Akkerman, V. D'Innocenzo, S. Accornero, et al., "Tuning the optical properties of cesium lead halide perovskite nanocrystals 
by anion exchange reactions," J. Am. Chem. Soc., vol. 137, pp. 10276-10281, 2015.

[12] G. Nedelcu, L. Protesescu, S. Yakunin, M. I. Bodnarchuk, M. J. Grotevent, and M. V. Kovalenko, "Fast anion-exchange in highly luminescent nanocrystals of cesium lead halide perovskites ( $\left.\mathrm{CsPbX}_{3}, \mathrm{X}=\mathrm{Cl}, \mathrm{Br}, \mathrm{I}\right)$," Nano Lett., vol. 15, pp. 5635-5640, 2015.

[13] D. Yu, F. Cao, Y. Gao, Y. Xiong, and H. Zeng, "Room-temperature ion-exchange-mediated self-assembly toward formamidinium perovskite nanoplates with finely tunable, ultrapure green emissions for achieving rec. 2020 displays," Adv. Funct. Mater., vol. 28, p. 1800248, 2018.

[14] W.-J. Yin, T. Shi, and Y. Yan, "Unusual defect physics in $\mathrm{CH}_{3} \mathrm{NH}_{3} \mathrm{Pbl}_{3}$ perovskite solar cell absorber," Appl. Phys. Lett., vol. 104, p. 063903, 2014.

[15] A. Walsh, D. O. Scanlon, S. Chen, X. G. Gong, and S.-H. Wei, "Self-regulation mechanism for charged point defects in hybrid halide perovskites," Angew. Chem., vol. 127, pp. 1811-1814, 2015.

[16] K. X. Steirer, P. Schulz, G. Teeter, et al., "Defect tolerance in methylammonium lead triiodide perovskite," ACS Energy Lett., vol. 1, pp. 360-366, 2016.

[17] H. Wang and D. H. Kim, "Perovskite-based photodetectors: materials and devices," Chem. Soc. Rev., vol. 46, pp. 5204-5236, 2017.

[18] F. Cao, J. Chen, D. Yu, et al., "Bionic detectors based on lowbandgap inorganic perovskite for selective NIR-I photon detection and imaging," Adv. Mater., vol. 32, p. 1905362, 2020.

[19] L. Dou, Y. Yang, J. You, et al., "Solution-processed hybrid perovskite photodetectors with high detectivity," Nat. Commun., vol. 5, p. 5404, 2014.

[20] V. Adinolfi, O. Ouellette, M. I. Saidaminov, et al., "Fast and sensitive solution-processed visible-blind perovskite UV photodetectors," Adv. Mater., vol. 28, pp. 7264-7268, 2016.

[21] D. Yu, F. Cao, Y. Shen, X. Liu, Y. Zhu, and H. Zeng, "Dimensionality and interface engineering of $2 \mathrm{D}$ homologous perovskites for boosted charge-carrier transport and photodetection performances," J. Phys. Chem. Lett., vol. 8, pp. 2565-2572, 2017.

[22] F. Cao, D. Yu, X. Li, et al., "Highly stable and flexible photodetector arrays based on low dimensional $\mathrm{CsPbBr} 3$ microcrystals and on-paper pencil-drawn electrodes," J. Mater. Chem. C, vol. 5, pp. 7441-7445, 2017.

[23] A. Babayigit, A. Ethirajan, M. Muller, and B. Conings, "Toxicity of organometal halide perovskite solar cells," Nat. Mater., vol. 15 , pp. 247-251, 2016.

[24] T. Leijtens, G. E. Eperon, N. K. Noel, S. N. Habisreutinger, A. Petrozza, and H. J. Snaith, "Stability of metal halide perovskite solar cells,” Adv. Energy Mater., vol. 5, p. 1500963, 2015.

[25] W. Ning and F. Gao, "Structural and functional diversity in leadfree halide perovskite materials," Adv. Mater., vol. 31, p. e1900326, 2019.

[26] C. Wang, F. Gu, Z. Zhao, et al., "Self-repairing tin-based perovskite solar cells with a breakthrough efficiency over $11 \%$," Adv. Mater., vol. 32, p. 1907623, 2020.

[27] C.-K. Liu, Q. Tai, N. Wang, G. Tang, H.-L. Loi, and F. Yan, “Snbased perovskite for highly sensitive photodetectors," Adv. Sci., vol. 6, p. 1900751, 2019.
[28] Y. Li, Z. Shi, W. Liang, et al., "Highly stable and spectrumselective ultraviolet photodetectors based on lead-free copperbased perovskites," Mater. Horiz., vol. 7, pp. 530-540, 2020.

[29] Z. Xu, X. Liu, Y. Li, et al., "Exploring lead-free hybrid double perovskite crystals of $(\mathrm{BA})_{2} \mathrm{CsAgBiBr}_{7}$ with large mobilitylifetime product toward X-ray detection," Angew Chem. Int. Ed. Engl., vol. 58, pp. 15757-15761, 2019.

[30] R. Zhuang, X. Wang, W. Ma, et al., "Highly sensitive X-ray detector made of layered perovskite-like $\left(\mathrm{NH}_{4}\right)_{3} \mathrm{Bi}_{2} \mathrm{I}_{9}$ single crystal with anisotropic response," Nat. Photonics, vol. 13, pp. 602-608, 2019.

[31] X. Zheng, W. Zhao, P. Wang, et al., "Ultrasensitive and stable $\mathrm{X}$-ray detection using zero-dimensional lead-free perovskites," J. Energy Chem., vol. 49, pp. 299-306, 2020.

[32] Q. A. Akkerman and L. Manna, "What defines a halide perovskite?” ACS Energy Lett., vol. 5, pp. 604-610, 2020.

[33] N. Ito, M. A. Kamarudin, D. Hirotani, et al., “Mixed Sn-Ge perovskite for enhanced perovskite solar cell performance in air," J. Phys. Chem. Lett., vol. 9, pp. 1682-1688, 2018.

[34] L. Wu, P. Lu, Y. Li, Y. Sun, J. Wong, and K. Yang, "First-principles characterization of two-dimensional $\left(\mathrm{CH}_{3}\left(\mathrm{CH}_{2}\right)_{3} \mathrm{NH}_{3}\right)_{2}\left(\mathrm{CH}_{3} \mathrm{NH}_{3}\right)_{\mathrm{n}-1} \mathrm{Ge}_{\mathrm{n}} \mathrm{I}_{3 \mathrm{n}+1}$ perovskite," J. Mater. Chem., vol. 6, pp. 24389-24396, 2018.

[35] D. Ray, C. Clark, H. Q. Pham, et al., "Computational study of structural and electronic properties of lead-free $\mathrm{CsMl}_{3}$ perovskites ( $\mathrm{M}=\mathrm{Ge}, \mathrm{Sn}, \mathrm{Pb}, \mathrm{Mg}, \mathrm{Ca}, \mathrm{Sr}$, and Ba)," J. Phys. Chem. C, vol. 122, pp. 7838-7848, 2018.

[36] S. Shao, J. Liu, G. Portale, et al., "Highly reproducible Sn-based hybrid perovskite solar cells with 9\% efficiency," Adv. Energy Mater., vol. 8, p. 1702019, 2018.

[37] T.-B. Song, T. Yokoyama, S. Aramaki, and M. G. Kanatzidis, "Performance enhancement of lead-free tin-based perovskite solar cells with reducing atmosphere-assisted dispersible additive," ACS Energy Lett., vol. 2, pp. 897-903, 2017.

[38] M. Zhang, M. Lyu, P. Chen, M. Hao, J.-H. Yun, and L. Wang, "Recent advances in low-toxic lead-free metal halide perovskite materials for solar cell application," Asia Pac. J. Chem. Eng., vol. 11, pp. 392-398, 2016.

[39] T. J. Huang, Z. X. Thiang, X. Yin, C. Tang, G. Qi, and H. Gong, " $\left(\mathrm{CH}_{3} \mathrm{NH}_{3}\right)_{2} \mathrm{PdCl}_{4}$ : A compound with two-dimensional organicinorganic layered perovskite structure," Chem. Eur J., vol. 22, pp. 2146-2152, 2016.

[40] R. Haegele, W. Verscharen, and D. Babel, "Notizen: EinkristallStrukturdaten einiger Fluoride und Cyanide $A_{2}{ }^{\prime} B^{\prime} M^{\prime \prime \prime} X_{6}$ der Elpasolithfamilie/Single Crystal Structural Data of Some Fluorides and Cyanides $A_{2}{ }^{\prime} B^{\prime} M^{\prime \prime \prime} X_{6}$ of the Elpasolite Family," Z. Naturforsch. B: J. Chem. Sci., vol. 30, pp. 462-464, 1975.

[41] L. R. Morss, M. Siegal, L. Stenger, and N. Edelstein, "Preparation of cubic chloro complex compounds of trivalent metals: $\mathrm{Cs}_{2} \mathrm{NaMCl}_{6}$," Inorg. Chem., vol. 9, pp. 1771-1775, 1970.

[42] G. Meyer and H.-C. Gaebell, "Halogen-elpasolithe, IV [1]. Über brom-elpasolithe $\mathrm{Cs}_{2} \mathrm{~B}^{\prime} \mathrm{M}^{\mathrm{III}} \mathrm{Br}_{6} \mathrm{BI}=\mathrm{Li}, \mathrm{Na}$; MIII = Sc, Y, La-Lu, in, V, $\mathrm{Cr}$ )/halo-elpasolites, IV [1]. On bromo-elpasolites $\mathrm{Cs}_{2} \mathrm{~B}^{\prime} \mathrm{M}^{\mathrm{III}} \mathrm{Br}_{6}$ $\mathrm{BI}=\mathrm{Li}, \mathrm{Na}$; MIII = Sc, Y, La-Lu, in, V, Cr)," Z. Naturforsch. B: J. Chem. Sci., vol. 33, pp. 1476-1478, 1978.

[43] B. M. Chadwick, D. W. Jones, H. J. Wilde, and J. Yerkess, "X-ray and neutron-diffraction studies of the crystal structures of the dicesium lithium hexacyanometallates of iron(III) and cobalt(III)," J. Crystallogr. Spectrosc. Res., vol. 15, pp. 133-146, 1985. 
[44] A. Tressaud, S. Khaïroun, J. P. Chaminade, and M. Couzi, "Structural phase transitions in $\mathrm{Rb}_{2} \mathrm{KMIIIF}_{6}$ elpasolites. I. Crystal Chemistry and calorimetric studies," Phys. Status Solidi, vol. 98, pp. 417-421, 1986.

[45] J. Grannec, A. Yacoubi, A. Tressaud, and L. Rabardel, "Structural and magnetic properties of ternary silver flourides with a cryolite-related structure," Solid State Commun., vol. 68, pp. 363-367, 1988.

[46] M. Chen, M.-G. Ju, A. D. Carl, et al., "Cesium titanium(IV) bromide thin films based stable lead-free perovskite solar cells," Joule, vol. 2, pp. 558-570, 2018.

[47] J. I. Uribe, D. Ramirez, J. M. Osorio-Guillén, J. Osorio, and F. Jaramillo, " $\mathrm{CH}_{3} \mathrm{NH}_{3} \mathrm{Cal}_{3}$ perovskite: synthesis, characterization, and first-principles studies," J. Phys. Chem. C, vol. 120, pp. 16393-16398, 2016.

[48] A. Tressaud, S. Khaïroun, L. Rabardel, T. Kobayashi, T. Matsuo, and $\mathrm{H}$. Suga, "Phase transitions in ammonium hexafluorometallates(III)," Phys. Status Solidi, vol. 96, pp. 407-414, 1986.

[49] M.-G. Ju, M. Chen, Y. Zhou, et al., "Earth-abundant nontoxic titanium(IV)-based vacancy-ordered double perovskite halides with tunable 1.0 to $1.8 \mathrm{eV}$ bandgaps for photovoltaic applications," ACS Energy Lett., vol. 3, pp. 297-304, 2018.

[50] F. Wei, Z. Deng, S. Sun, et al., "The synthesis, structure and electronic properties of a lead-free hybrid inorganic-organic double perovskite $(\mathrm{MA})_{2} \mathrm{KBiCl}_{6}(\mathrm{MA}=$ methylammonium)," Mater. Horiz., vol. 3, pp. 328-332, 2016.

[51] D. Cortecchia, H. A. Dewi, J. Yin, et al., "Lead-free $\mathrm{MA}_{2} \mathrm{CuCl}_{\mathrm{x}} \mathrm{Br}_{4-x}$ hybrid perovskites," Inorg. Chem., vol. 55, pp. 1044-1052, 2016.

[52] G. Meyer, "Halogen-elpasolithe, VI [1] erste iod-elpasolithe,

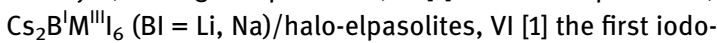
elpasolites, $\mathrm{Cs}_{2} \mathrm{~B}^{\prime} \mathrm{M}^{\mathrm{III} \mathrm{I}_{6}}(\mathrm{BI}=\mathrm{L} \mathrm{i}, \mathrm{Na})$," Z. Naturforsch. B: J. Chem. Sci., vol. 35, pp. 394-396, 1980.

[53] J. Ihringer, G. Wu, R. Hoppe, and A. W. Hewat, "Phase transitions and structures in the rare earth hexafluorides $\mathrm{Cs}_{2} \mathrm{NaHoF}_{6}$, $\mathrm{Rb}_{2} \mathrm{NaHoF}_{6}, \mathrm{Cs}_{2} \mathrm{KHoF}_{6}$ and $\mathrm{Cs}_{2} \mathrm{RbHoF}_{6}$ at $12<\mathrm{T}<300 \mathrm{~K}$," J. Phys. Chem. Solid., vol. 45, pp. 1195-1200, 1984.

[54] X. Shai, L. Zuo, P. Sun, et al., "Efficient planar perovskite solar cells using halide Sr-substituted Pb perovskite," Nanomater. Energy, vol. 36, pp. 213-222, 2017.

[55] Z. Deng, F. Wei, S. Sun, G. Kieslich, A. K. Cheetham, and P. D. Bristowe, "Exploring the properties of lead-free hybrid double perovskites using a combined computationalexperimental approach," J. Mater. Chem., vol. 4, pp. 12025-12029, 2016.

[56] A. Suzuki and T. Oku, "First-principles calculation study of electronic structures of alkali metals ( $\mathrm{Li}, \mathrm{K}, \mathrm{Na}$ and $\mathrm{Rb}$ ). incorporated formamidinium lead halide perovskite compounds," Appl. Surf. Sci., vol. 483, pp. 912-921, 2019.

[57] R. S. Lamba, P. Basera, S. Bhattacharya, and S. Sapra, "Band gap engineering in $\mathrm{Cs}_{2}\left(\mathrm{Na}_{x} \mathrm{Ag}_{1-\mathrm{x}}\right) \mathrm{BiCl}_{6}$ double perovskite nanocrystals," J. Phys. Chem. Lett., vol. 10, pp. 5173-5181, 2019.

[58] A. Waleed, M. M. Tavakoli, L. Gu, et al., "Lead-free perovskite nanowire array photodetectors with drastically improved stability in nanoengineering templates," Nano Lett., vol. 17, pp. 523-530, 2017.

[59] S. Zhu, Z. Hu, R. Tian, et al., "Repurposing cyanine NIR-I dyes accelerates clinical translation of near-infrared-II (NIR-II) bioimaging," Adv. Mater., vol. 30, p. 1802546, 2018.
[60] W. Zhu, C. Chu, S. Kuddannaya, et al., "In vivo imaging of composite hydrogel scaffold degradation using CEST MRI and two-color NIR imaging," Adv. Funct. Mater., vol. 29, p. 1903753, 2019.

[61] M. Garcia, C. Edmiston, T. York, et al., "Bio-inspired imager improves sensitivity in near-infrared fluorescence image-guided surgery," Optica, vol. 5, pp. 413-422, 2018.

[62] R. Yousefi, M. R. Mahmoudian, A. Sa'aedi, M. Cheraghizade, F. Jamali-Sheini, and M. Azarang, "Effect of annealing temperature and graphene concentrations on photovoltaic and NIR-detector applications of PbS/rGO nanocomposites," Ceram. Int., vol. 42, pp. 15209-15216, 2016.

[63] G. Wu, R. Fu, J. Chen, et al., "Perovskite/organic bulkheterojunction integrated ultrasensitive broadband photodetectors with high near-infrared external quantum efficiency over 70\%," Small, vol. 14, p. 1802349, 2018.

[64] K. H. Hendriks, W. Li, M. M. Wienk, and R. A. J. Janssen, "Smallbandgap semiconducting polymers with high near-infrared photoresponse," J. Am. Chem. Soc., vol. 136, pp. 12130-12136, 2014.

[65] Z. Zheng, L. Gan, J. Zhang, F. Zhuge, and T. Zhai, “An enhanced UV-Vis-NIR an d flexible photodetector based on electrospun $\mathrm{ZnO}$ nanowire array/PbS quantum dots film heterostructure," Adv. Sci., vol. 4, p. 1600316, 2017.

[66] C. Mu, J. Pan, S. Feng, Q. Li, and D. Xu, "Quantitative doping of chlorine in formamidinium lead trihalide $\left(\mathrm{FAPbl}_{3-x} \mathrm{Cl}_{x}\right)$ for planar heterojunction perovskite solar cells," Adv. Energy Mater., vol. 7, p. 1601297, 2017.

[67] W.-F. Yang, F. Igbari, Y.-H. Lou, Z.-K. Wang, and L.-S. Liao, "Tin halide perovskites: progress and challenges," Adv. Energy Mater., vol. 10, p. 1902584, 2020.

[68] I. Chung, J.-H. Song, J. Im, et al., "Semiconductor or metal? High electrical conductivity and strong near-infrared photoluminescence from a single material. High hole mobility and phase-transitions," J. Am. Chem. Soc., vol. 134, pp. 8579-8587, 2012.

[69] T. Leijtens, R. Prasanna, A. Gold-Parker, M. F. Toney, and M. D. McGehee, "Mechanism of tin oxidation and stabilization by lead substitution in tin halide perovskites," ACS Energy Lett., vol. 2, pp. 2159-2165, 2017.

[70] Y. Zhao, C. Li, J. Jiang, B. Wang, and L. Shen, "Sensitive and stable tin-lead hybrid perovskite photodetectors enabled by double-sided surface passivation for infrared upconversion detection," Small, vol. 16, p. 2001534, 2020.

[71] R. Lin, K. Xiao, Z. Qin, et al., "Monolithic all-perovskite tandem solar cells with $24.8 \%$ efficiency exploiting comproportionation to suppress Sn(ii) oxidation in precursor ink," Nat. Energy, vol. 4, pp. 864-873, 2019.

[72] M. H. Kumar, S. Dharani, W. L. Leong, et al., "Lead-free halide perovskite solar cells with high photocurrents realized through vacancy modulation," Adv. Mater., vol. 26, pp. 7122-7127, 2014.

[73] J. Zhou, J. Luo, X. Rong, et al., "Lead-free perovskite derivative $\mathrm{Cs}_{2} \mathrm{SnCl}_{6-\mathrm{x}} \mathrm{Br}_{\mathrm{x}}$ single crystals for narrowband photodetectors," Adv. Opt. Mater., vol. 7, p. 1900139, 2019.

[74] L. Qian, Y. Sun, M. Wu, et al., “A lead-free two-dimensional perovskite for a high-performance flexible photoconductor and a light-stimulated synaptic device," Nanoscale, vol. 10, pp. 6837-6843, 2018. 
[75] A. Kaltzoglou, M. Antoniadou, A. G. Kontos, et al., "Opticalvibrational properties of the $\mathrm{Cs}_{2} \mathrm{SnX}_{6}(\mathrm{X}=\mathrm{Cl}, \mathrm{Br}, \mathrm{I})$ defect perovskites and hole-transport efficiency in dye-sensitized solar cells," J. Phys. Chem. C, vol. 120, pp. 11777-11785, 2016.

[76] Y. Fang, Q. Dong, Y. Shao, Y. Yuan, and J. Huang, "Highly narrowband perovskite single-crystal photodetectors enabled by surface-charge recombination," Nat. Photonics, vol. 9, pp. 679-686, 2015.

[77] S. Meloni, T. Moehl, W. Tress, et al., "Ionic polarization-induced current-voltage hysteresis in $\mathrm{CH}_{3} \mathrm{NH}_{3} \mathrm{PbX}_{3}$ perovskite solar cells," Nat. Commun., vol. 7, p. 10334, 2016.

[78] H. Tsai, W. Nie, J.-C. Blancon, et al., "High-efficiency twodimensional Ruddlesden-Popper perovskite solar cells," Nature, vol. 536, pp. 312-316, 2016.

[79] I. C. Smith, E. T. Hoke, D. Solis-Ibarra, M. D. McGehee, and H. I. Karunadasa, "A layered hybrid perovskite solar-cell absorber with enhanced moisture stability," Angew. Chem., vol. 126, pp. 11414-11417, 2014.

[80] B. Yang, Y.-J. Li, Y.-X. Tang, et al., “Constructing sensitive and fast lead-free single-crystalline perovskite photodetectors," J. Phys. Chem. Lett., vol. 9, pp. 3087-3092, 2018.

[81] X.-W. Tong, W.-Y. Kong, Y.-Y. Wang, J.-M. Zhu, L.-B. Luo, and Z.-H. Wang, "High-performance red-light photodetector based on lead-free bismuth halide perovskite film," ACS Appl. Mater. Interfaces, vol. 9, pp. 18977-18985, 2017.

[82] C. Ji, P. Wang, Z. Wu, et al., "Inch-size single crystal of a lead-free organic-inorganic hybrid perovskite for high-performance photodetector," Adv. Funct. Mater., vol. 28, p. 1705467, 2018.

[83] B.-W. Park, B. Philippe, X. Zhang, H. Rensmo, G. Boschloo, and E. M. J. Johansson, "Bismuth based hybrid perovskites $A_{3} B i_{2} l_{9}(A$ : methylammonium or cesium) for solar cell application," Adv. Mater., vol. 27, pp. 6806-6813, 2015.

[84] J.-C. Hebig, I. Kühn, J. Flohre, and T. Kirchartz, “Optoelectronic properties of $\left(\mathrm{CH}_{3} \mathrm{NH}_{3}\right)_{3} \mathrm{Sb}_{2} \mathrm{l}_{9}$ thin films for photovoltaic applications,” ACS Energy Lett., vol. 1, pp. 309-314, 2016.

[85] Wu, C., Q. Zhang, G. Liu et al., "From Pb to Bi: A promising family of $\mathrm{Pb}$-free optoelectronic materials and devices," Adv. Energy Mater., vol. 10, pp. 1902496, 2020.

[86] W. Zhang, K. Tao, C. Ji, et al., " $\left.\mathrm{C}_{6} \mathrm{H}_{13} \mathrm{~N}\right)_{2} \mathrm{Bil}_{5}$ : A one-dimensional lead-free perovskite-derivative photoconductive light absorber," Inorg. Chem., vol. 57, pp. 4239-4243, 2018.

[87] J. Yang, C. Bao, W. Ning, et al., "Stable, high-sensitivity and fastresponse photodetectors based on lead-free $\mathrm{Cs}_{2} \mathrm{AgBiBr}_{6}$ double perovskite films," Adv. Opt. Mater., vol. 7, p. 1801732, 2019.

[88] A. H. Slavney, T. Hu, A. M. Lindenberg, and H. I. Karunadasa, "A bismuth-halide double perovskite with long carrier recombination lifetime for photovoltaic applications," J. Am. Chem. Soc., vol. 138, pp. 2138-2141, 2016.

[89] F. Ji, J. Klarbring, F. Wang, et al., "Lead-free halide double perovskite $\mathrm{Cs}_{2} \mathrm{AgBiBr}_{6}$ with decreased band gap," Angew Chem. Int. Ed. Engl., vol. 59, pp. 15191-15194, 2020.

[90] E. T. McClure, M. R. Ball, W. Windl, and P. M. Woodward, " $\mathrm{Cs}_{2} \mathrm{AgBiX}_{6}(\mathrm{X}=\mathrm{Br}, \mathrm{Cl})$ : new visible light absorbing, lead-free halide perovskite semiconductors," Chem. Mater., vol. 28, pp. 1348-1354, 2016.

[91] W.-Q. Liang, Y. Li, J.-L. Ma, et al., “A solution-processed ternary copper halide thin films for air-stable and deep-ultraviolet-sensitive photodetector," Nanoscale, vol. 12, pp. 17213-17221, 2020.

[92] M. Razeghi and A. Rogalski, "Semiconductor ultraviolet detectors,” J. Appl. Phys., vol. 79, pp. 7433-7473, 1996.
[93] B. Zhao, F. Wang, H. Chen, et al., "Solar-blind avalanche photodetector based on single $\mathrm{ZnO}-\mathrm{Ga}_{2} \mathrm{O}_{3}$ core-shell microwire," Nano Lett., vol. 15, pp. 3988-3993, 2015.

[94] T. Oshima, T. Okuno, N. Arai, N. Suzuki, H. Hino, and S. Fujita, "Flame detection by a $\beta$-Ga203-based sensor," Jpn. J. Appl. Phys., vol. 48, p. 011605, 2009.

[95] H. Chen, L. Hu, X. Fang, and L. Wu, "General fabrication of monolayer $\mathrm{SnO}_{2}$ nanonets for high-performance ultraviolet photodetectors," Adv. Funct. Mater., vol. 22, pp. 1229-1235, 2012.

[96] W. Y. Weng, S. J. Chang, C. L. Hsu, and T. J. Hsueh, “A ZnO-nanowire phototransistor prepared on glass substrates," ACS Appl. Mater. Interfaces, vol. 3, pp. 162-166, 2011.

[97] H. Hu, Z. Han, B. Huang, Y. Dong, and Y. Zou, “Intermediate phase-assisted solution preparation of two dimensional $\mathrm{CsPbCl}_{3}$ perovskite for efficient ultraviolet photodetection," J. Colloid Interface Sci., vol. 554, pp. 619-626, 2019.

[98] T. Jun, K. Sim, S. limura, et al., "Lead-free highly efficient blueemitting $\mathrm{Cs}_{3} \mathrm{Cu}_{2} \mathrm{I}_{5}$ with $0 \mathrm{D}$ electronic structure," Adv. Mater., vol. 30, p. 1804547, 2018.

[99] R. Lin, Q. Zhu, Q. Guo, Y. Zhu, W. Zheng, and F. Huang, “Dual self-trapped exciton emission with ultrahigh photoluminescence quantum yield in $\mathrm{CsCu}_{2} \mathrm{I}_{3}$ and $\mathrm{Cs}_{3} \mathrm{Cu}_{2} \mathrm{I}_{5}$ perovskite single crystals," J. Phys. Chem. C, vol. 124, pp. 20469-20476, 2020.

[100] Z. Shi, Y. Li, Y. Zhang, et al., "High-efficiency and air-stable perovskite quantum dots light-emitting diodes with an allinorganic heterostructure," Nano Lett., vol. 17, pp. 313-321, 2017.

[101] Z.-X. Zhang, C. Li, Y. Lu, et al., "Sensitive deep ultraviolet photodetector and image sensor composed of inorganic leadfree $\mathrm{Cs}_{3} \mathrm{Cu}_{2} \mathrm{I}_{5}$ perovskite with wide bandgap," J. Phys. Chem. Lett., vol. 10, pp. 5343-5350, 2019.

[102] W. Liang, Z. Shi, Y. Li, et al., "Strategy of all-inorganic $\mathrm{Cs}_{3} \mathrm{Cu}_{2} \mathrm{I}_{5} /$ Si-Core/Shell nanowire heterojunction for stable and ultraviolet-enhanced broadband photodetectors with imaging capability," ACS Appl. Mater. Interfaces, vol. 12, pp. 37363-37374, 2020.

[103] J. Luo, S. Li, H. Wu, et al., " $\mathrm{Cs}_{2} \mathrm{AgInCl}_{6}$ double perovskite single crystals: parity forbidden transitions and their application for sensitive and fast UV photodetectors," ACS Photonics, vol. 5, pp. 398-405, 2018.

[104] Y. Liu, Z. Yang, D. Cui, et al., "Two-inch-sized perovskite $\mathrm{CH}_{3} \mathrm{NH}_{3} \mathrm{PbX}_{3}(\mathrm{X}=\mathrm{Cl}, \mathrm{Br}, \mathrm{I})$ crystals: growth and characterization," Adv. Mater., vol. 27, pp. 5176-5183, 2015.

[105] Shi, D., V. Adinolfi, R. Comin, et al., "Low trap-state density and long carrier diffusion in organolead trihalide perovskite single crystals," Science, vol. 347, pp. 519-522, 2015.

[106] C. Bao, Z. Chen, Y. Fang, et al., “Low-noise and large-lineardynamic-range photodetectors based on hybrid-perovskite thin-single-crystals," Adv. Mater., vol. 29, p. 1703209, 2017.

[107] C. Bao, J. Yang, S. Bai, et al., "High performance and stable Allinorganic metal halide perovskite-based photodetectors for optical communication applications," Adv. Mater., vol. 30, p. 1803422, 2018.

[108] A. Sakdinawat and D. Attwood, "Nanoscale X-ray imaging," Nat. Photonics, vol. 4, pp. 840-848, 2010.

[109] M. J. Yaffe and J. A. Rowlands, "X-ray detectors for digital radiography," Phys. Med. Biol., vol. 42, pp. 1-39, 1997.

[110] S. Kasap, J. B. Frey, G. Belev, et al., "Amorphous and polycrystalline photoconductors for direct conversion flat panel X-ray image sensors," Sensors, vol. 11, pp. 5112-5157, 2011. 
[111] F. G. Zhou, Z. Z. Li, W. Lan, Q. Wang, L. M. Ding, and Z. W. Jin, "Halide perovskite, a potential scintillator for X-ray detection," Small Methods, vol. 4, p. 2000506, 2020.

[112] H. Wei and J. Huang, "Halide lead perovskites for ionizing radiation detection," Nat. Commun., vol. 10, p. 1066, 2019.

[113] W. Heiss and C. Brabec, "Perovskites target X-ray detection," Nat. Photonics, vol. 10, pp. 288-289, 2016.

[114] T. E. Schlesinger, J. E. Toney, H. Yoon, et al., "Cadmium zinc telluride and its use as a nuclear radiation detector material," Mat. Sci. Eng. R, vol. 32, pp. 103-189, 2001.

[115] A. E. Bolotnikov, S. O. Babalola, G. S. Camarda, et al., "Extended defects in CdZnTe radiation detectors," IEEE Trans. Nucl. Sci., vol. 56, pp. 1775-1783, 2009.

[116] S. Yakunin, M. Sytnyk, D. Kriegner, et al., "Detection of X-ray photons by solution-processed lead halide perovskites," Nat. Photonics, vol. 9, p. 444-+, 2015.

[117] H. Wei, Y. Fang, P. Mulligan, et al., "Sensitive X-ray detectors made of methylammonium lead tribromide perovskite single crystals," Nat. Photonics, vol. 10, p. 333, 2016.

[118] M. D. Birowosuto, D. Cortecchia, W. Drozdowski, et al., "X-ray scintillation in lead halide perovskite crystals," Sci. Rep., vol. 6, p. $37254,2016$.

[119] S. Shrestha, R. Fischer, G. J. Matt, et al., "High-performance direct conversion X-ray detectors based on sintered hybrid lead triiodide perovskite wafers," Nat. Photonics, vol. 11, pp. 436-440, 2017.

[120] Y. C. Kim, K. H. Kim, D.-Y. Son, et al., "Printable organometallic perovskite enables large-area, low-dose X-ray imaging," Nature, vol. 550, p. 87, 2017.

[121] W. Wei, Y. Zhang, Q. Xu, et al., "Monolithic integration of hybrid perovskite single crystals with heterogenous substrate for highly sensitive X-ray imaging," Nat. Photonics, vol. 11, pp. 315-321, 2017.

[122] J. H. Heo, D. H. Shin, J. K. Park, D. H. Kim, S. J. Lee, and S. H. Im, "High-performance next-generation perovskite nanocrystal scintillator for nondestructive X-ray imaging," Adv. Mater., vol. 30, p. e1801743, 2018.

[123] Q. Chen, J. Wu, X. Ou, et al., “All-inorganic perovskite nanocrystal scintillators," Nature, vol. 561, pp. 88-93, 2018.

[124] L. Basirico, S. P. Senanayak, A. Ciavatti, M. Abdi-Jalebi, B. Fraboni, and $\mathrm{H}$. Sirringhaus, "Detection of $\mathrm{X}$-rays by solutionprocessed cesium-containing mixed triple cation perovskite thin films," Adv. Funct. Mater., vol. 29, p. 1902346, 2019.

[125] J. Liu, B. Shabbir, C. Wang, et al., "Flexible, printable soft-X-ray detectors based on all-inorganic perovskite quantum dots," Adv. Mater., vol. 31, p. e1901644, 2019.

[126] V. B. Mykhaylyk, H. Kraus, and M. Saliba, "Bright and fast scintillation of organolead perovskite $\mathrm{MAPbBr}_{3}$ at low temperatures," Mater. Horiz., vol. 6, pp. 1740-1747, 2019.

[127] F. Cao, D. Yu, W. Ma, et al., "Shining emitter in a stable host: design of halide perovskite scintillators for X-ray imaging from commercial concept," ACS Nano, vol. 14, pp. 5183-5193, 2020.

[128] B. Yang and K. Han, "Charge-carrier dynamics of lead-free halide perovskite nanocrystals," Acc. Chem. Res., vol. 52, pp. 3188-3198, 2019.

[129] H. Wu, Y. Ge, G. Niu, and J. Tang, "Metal halide perovskites for X-ray detection and imaging,” Matter, vol. 4, pp. 144-163, 2021.
[130] Y. Wu, X. Li, and H. Zeng, "Lead-free halide double perovskites: structure, luminescence, and applications," Small Struct., p. 2000071, 2020, https://doi.org/10.1002/sstr.202000071.

[131] J. Yang, P. Zhang, and S.-H. Wei, "Band structure engineering of $\mathrm{Cs}_{2} \mathrm{AgBiBr}_{6}$ perovskite through order-disordered transition: $\mathrm{A}$ first-principle study," J. Phys. Chem. Lett., vol. 9, pp. 31-35, 2017.

[132] J. Kim, H. Kim, M. Chandran, S. C. Lee, S. H. Im, and K. H. Hong, "Impacts of cation ordering on bandgap dispersion of double perovskites," Apl. Mater., vol. 6, p. 084903, 2018.

[133] Z. Xiao, W. Meng, J. Wang, and Y. Yan, "Thermodynamic stability and defect Chemistry of bismuth-based lead-free double perovskites," ChemSusChem, vol. 9, pp. 2628-2633, 2016.

[134] J. A. Steele, W. Pan, C. Martin, et al., "Photophysical pathways in highly sensitive $\mathrm{Cs}_{2} \mathrm{AgBiBr}_{6}$ double-perovskite single-crystal X-ray detectors," Adv. Mater., vol. 30, p. e1804450, 2018.

[135] J. Luo, X. Wang, S. Li, et al., "Efficient and stable emission of warm-white light from lead-free halide double perovskites," Nature, vol. 563, pp. 541-545, 2018.

[136] W. Pan, H. Wu, J. Luo, et al., " $\mathrm{Cs}_{2} \mathrm{AgBiBr}_{6}$ single-crystal X-ray detectors with a low detection limit," Nat. Photonics, vol. 11, pp. 726-732, 2017.

[137] Kim, H.-S., J.-Y. Seo, and N.-G. Park, "Material and device stability in perovskite solar cells," ChemSusChem, vol. 9, pp. 2528-2540, 2016.

[138] F. Wei, Z. Deng, S. Sun, et al., "Synthesis and properties of a lead-free hybrid double perovskite: $\left(\mathrm{CH}_{3} \mathrm{NH}_{3}\right)_{2} \mathrm{AgBiBr}_{6}$," Chem. Mater., vol. 29, pp. 1089-1094, 2017.

[139] S. O. Kasap, "X-ray sensitivity of photoconductors: application to stabilized a-Se," J. Phys. D Appl. Phys., vol. 33, pp. 2853-2865, 2000.

[140] M. Thompson, S. L. R. Ellison, and R. Wood, “Harmonized guidelines for single-laboratory validation of methods of analysis (IUPAC Technical Report)," Pure Appl. Chem., vol. 74, pp. 835-855, 2002.

[141] D. R. Shearer and M. Bopaiah, "Dose rate limitations of integrating survey meters for diagnostic x-ray surveys," Health Phys., vol. 79, pp. S20-21, 2000.

[142] I. Clairand, J. M. Bordy, E. Carinou, et al., "Use of active personal dosemeters in interventional radiology and cardiology: tests in laboratory conditions and recommendations - ORAMED project," Radiat. Meas., vol. 46, pp. 1252-1257, 2011.

[143] W. Tress, "Metal halide perovskites as mixed electronic-ionic conductors: challenges and opportunities-from hysteresis to memristivity," J. Phys. Chem. Lett., vol. 8, pp. 3106-3114, 2017.

[144] D. Li, H. Wu, H. C. Cheng, G. Wang, Y. Huang, and X. Duan, "Electronic and ionic transport dynamics in organolead halide perovskites," ACS Nano, vol. 10, pp. 6933-6941, 2016.

[145] B. Yang, W. Pan, H. Wu, et al., "Heteroepitaxial passivation of $\mathrm{Cs}_{2} \mathrm{AgBiBr}_{6}$ wafers with suppressed ionic migration for $\mathrm{X}$-ray imaging," Nat. Commun., vol. 10, p. 1989, 2019.

[146] W. Yuan, G. Niu, Y. Xian, et al., "In situ regulating the orderdisorder phase transition in $\mathrm{CS}_{2} \mathrm{AgBiBr}_{6}$ single crystal toward the application in an X-ray detector," Adv. Funct. Mater., vol. 29, p. 1900234, 2019.

[147] L. Yin, H. Wu, W. Pan, et al., "Controlled cooling for synthesis of $\mathrm{Cs}_{2} \mathrm{AgBiBr}_{6}$ single crystals and its application for X-ray detection," Adv. Opt. Mater., vol. 7, p. 1900491, 2019. 
[148] D. Yu, P. Wang, F. Cao, et al., "Two-dimensional halide perovskite as beta-ray scintillator for nuclear radiation monitoring," Nat. Commun., vol. 11, p. 3395, 2020.

[149] Y. Liu, Z. Xu, Z. Yang, et al., “Inch-size OD-structured lead-free perovskite single crystals for highly sensitive stable X-ray imaging," Matter, vol. 3, pp. 180-196, 2020.

[150] H. Zhang, Z. Gao, R. Liang, et al., "X-ray detector based on allinorganic lead-free $\mathrm{Cs}_{2} \mathrm{AgBiBr}_{6}$ perovskite single crystal," IEEE Trans. Electron. Dev., vol. 66, pp. 2224-2229, 2019.

[151] Z. Jin, Z. Zhang, J. Xiu, H. Song, T. Gatti, and Z. He, “A critical review on bismuth and antimony halide based perovskites and their derivatives for photovoltaic applications: recent advances and challenges," J. Mater. Chem., vol. 8, pp. 16166-16188, 2020.

[152] B. Ghosh, B. Wu, H. K. Mulmudi, et al., "Limitations of $\mathrm{Cs}_{3} \mathrm{Bi}_{2} \mathrm{I}_{9}$ as lead-free photovoltaic absorber materials," ACS Appl. Mater. Interfaces, vol. 10, pp. 35000-35007, 2018.

[153] M. Xia, J. H. Yuan, G. Niu, et al., "Unveiling the structural descriptor of $A_{3} B_{2} X_{9}$ perovskite derivatives toward X-ray detectors with low detection limit and high stability," Adv. Funct. Mater., vol. 30, p. 1910648, 2020.

[154] K. Kim, S. Kim, J. Hong, et al., "Purification of CdZnTe by electromigration,” J. Appl. Phys., vol. 117, p. 145702, 2015.

[155] M. H. Futscher, J. M. Lee, L. McGovern, et al., "Quantification of ion migration in $\mathrm{CH}_{3} \mathrm{NH}_{3} \mathrm{Pbl}_{3}$ perovskite solar cells by transient capacitance measurements," Mater. Horiz., vol. 6, pp. 1497-1503, 2019.

[156] Y. Fang and J. Huang, "Resolving weak light of sub-picowatt per square centimeter by hybrid perovskite photodetectors enabled by noise reduction," Adv. Mater., vol. 27, pp. 2804-2810, 2015.

[157] K. Tao, Y. Li, C. Ji, et al., "A lead-free hybrid iodide with quantitative response to $\mathrm{X}$-ray radiation," Chem. Mater., vol. 31, pp. 5927-5932, 2019.
[158] L. Yao, G. Niu, L. Yin, et al., "Bismuth halide perovskite derivatives for direct X-ray detection,” J. Mater. Chem. C, vol. 8, pp. 1239-1243, 2020.

[159] L. Protesescu, S. Yakunin, M. I. Bodnarchuk, et al., "Nanocrystals of cesium lead halide perovskites ( $\mathrm{CsPbX}(3), \mathrm{X}=\mathrm{Cl}, \mathrm{Br}$, and I): novel optoelectronic materials showing bright emission with wide color gamut," Nano Lett., vol. 15, pp. 3692-3696, 2015.

[160] C. Huo, X. Liu, X. Song, Z. Wang, and H. Zeng, "Field-effect transistors based on van-der-Waals-Grown and dry-transferred all-inorganic perovskite ultrathin platelets," J. Phys. Chem. Lett., vol. 8, pp. 4785-4792, 2017.

[161] Q. Han, S.-H. Bae, P. Sun, et al., "Single crystal formamidinium lead iodide $\left(\mathrm{FAPb}_{3}\right)$ : insight into the structural, optical, and electrical properties," Adv. Mater., vol. 28, pp. 2253-2258, 2016.

[162] M. Choquette, H. Rougeot, J.-P. Martin, L. Laperriere, Z. Shukri, and B. Polischuk, "Direct selenium X-ray detector for fluoroscopy, R\&F, and radiography," Medical Imaging, vol. $3977,2000$.

[163] C. Jiang and J. Song, "An ultrahigh-resolution digital image sensor with pixel size of $50 \mathrm{~nm}$ by vertical nanorod arrays," Adv. Mater., vol. 27, pp. 4454-4460, 2015.

[164] S. Tie, W. Zhao, D. Xin, et al., "Robust fabrication of hybrid leadfree perovskite pellets for stable X-ray detectors with low detection limit," Adv. Mater., vol. 32, p. e2001981, 2020.

[165] S. Tie, W. Zhao, W. Huang, et al., "Efficient X-ray attenuation lead-free $\mathrm{AgBi}_{2} \mathrm{I}_{7}$ halide rudorffite alternative for sensitive and stable X-ray detection," J. Phys. Chem. Lett., vol. 11, pp. 7939-7945, 2020.

[166] F. Giustino and H. J. Snaith, "Toward lead-free perovskite solar cells,” ACS Energy Lett., vol. 1, pp. 1233-1240, 2016.

Supplementary Material: The online version of this article offers supplementary material (https://doi.org/10.1515/nanoph-2020-0632). 